\title{
From the Matrix to the Nucleus and Back: Mechanobiology in the Light of Health, Pathologies, and Regeneration of Oral Periodontal Tissues
}

\author{
Martin Philipp Dieterle ${ }^{1}$, Ayman Husari ${ }^{2,3}$, Thorsten Steinberg ${ }^{1, *}$, Xiaoling Wang ${ }^{1}$, Imke Ramminger ${ }^{1}$ \\ and Pascal Tomakidi ${ }^{1}$ \\ 1 Center for Dental Medicine, Division of Oral Biotechnology, Medical Center-University of Freiburg, \\ Faculty of Medicine, University of Freiburg, Hugstetterstr. 55, 79106 Freiburg, Germany; \\ martin.dieterle@uniklinik-freiburg.de (M.P.D.); xiaoling.wang@uniklinik-freiburg.de (X.W.); \\ imke.ramminger@uniklinik-freiburg.de (I.R.); pascal.tomakidi@uniklinik-freiburg.de (P.T.) \\ 2 Center for Dental Medicine, Department of Orthodontics, Medical Center-University of Freiburg, \\ Faculty of Medicine, University of Freiburg, Hugstetterstr. 55, 79106 Freiburg, Germany; \\ ayman.husari@uniklinik-freiburg.de \\ 3 Faculty of Engineering, University of Freiburg, Georges-Köhler-Allee 101, 79110 Freiburg, Germany \\ * Correspondence: thorsten.steinberg@uniklinik-freiburg.de; Tel.: +49-761-270-47460
}

Citation: Dieterle, M.P.; Husari, A.; Steinberg, T.; Wang, X.; Ramminger, I.; Tomakidi, P. From the Matrix to the Nucleus and Back: Mechanobiology in the Light of Health, Pathologies, and Regeneration of Oral Periodontal Tissues. Biomolecules 2021, 11, 824. https: / / doi.org/10.3390/ biom11060824

Academic Editors:

Taneaki Nakagawa and Takehito Ouchi

Received: 30 March 2021

Accepted: 27 May 2021

Published: 31 May 2021

Publisher's Note: MDPI stays neutral with regard to jurisdictional claims in published maps and institutional affiliations.

Copyright: (c) 2021 by the authors. Licensee MDPI, Basel, Switzerland. This article is an open access article distributed under the terms and conditions of the Creative Commons Attribution (CC BY) license (https:/ / creativecommons.org/licenses/by/ $4.0 /)$.

\begin{abstract}
Among oral tissues, the periodontium is permanently subjected to mechanical forces resulting from chewing, mastication, or orthodontic appliances. Molecularly, these movements induce a series of subsequent signaling processes, which are embedded in the biological concept of cellular mechanotransduction (MT). Cell and tissue structures, ranging from the extracellular matrix (ECM) to the plasma membrane, the cytosol and the nucleus, are involved in MT. Dysregulation of the diverse, fine-tuned interaction of molecular players responsible for transmitting biophysical environmental information into the cell's inner milieu can lead to and promote serious diseases, such as periodontitis or oral squamous cell carcinoma (OSCC). Therefore, periodontal integrity and regeneration is highly dependent on the proper integration and regulation of mechanobiological signals in the context of cell behavior. Recent experimental findings have increased the understanding of classical cellular mechanosensing mechanisms by both integrating exogenic factors such as bacterial gingipain proteases and newly discovered cell-inherent functions of mechanoresponsive co-transcriptional regulators such as the Yes-associated protein 1 (YAP1) or the nuclear cytoskeleton. Regarding periodontal MT research, this review offers insights into the current trends and open aspects. Concerning oral regenerative medicine or weakening of periodontal tissue diseases, perspectives on future applications of mechanobiological principles are discussed.
\end{abstract}

Keywords: mechanotransduction (MT); nuclear mechanotransduction (NMT); YAP/TAZ; extracellular matrix (ECM); gingipain proteases; periodontitis; oral squamous cell carcinoma (OSCC); regeneration

\section{Introduction}

Within tissues, cells are embedded in an extracellular matrix (ECM), consisting of both fibrous proteins similar to collagen and the ground substance, which is mainly made up of proteoglycans and glycoproteins [1]. Tissue homeostasis and regeneration is governed by a plethora of different signals, involving differentiation and growth factors, endocrine signals, and neuronal stimuli, which have been extensively studied in vitro and in vivo [2-6]. Above, the cells are in close contact with neighboring cells for the purpose of metabolic coupling and, in the case of epithelia, to enclose a defined physiological milieu [7,8]. Thus, a complex, three-dimensional environment is not only responsible for histogenesis during development, but also for tissue homeostasis and regeneration $[9,10]$.

This intimate relationship between cells and their ECM makes it necessary that signals are exchanged between both compartments. Beneath biochemical factors and ion currents, 
mechanical cues are transmitted from the ECM to the cell and vice versa within a process called mechanotransduction (MT). The same principles apply to cell-to-cell contact sites, where cellular traction forces are transmitted between adjacent cells [11-15].

On the molecular level, MT relies on membrane-embedded cellular receptor proteins that sense and bind to extracellular ligands, which are either ECM proteins in the case of cell-to-matrix adhesion or cell-bound ligands in the case of cell-to-cell contacts [11-16].

Focal adhesions (FAs) are microscopically detectable contact sites between cells and the ECM and consist of membrane-bound receptor proteins, called integrins, which can bind to collagens, fibronectins, and various other ECM components [15]. Movements of the ECM, such as shear stress or compression forces, induce the formation and consecutive strengthening of FAs, which corresponds with mechanobiological cellular adaptation processes [17]. Intracellularly, integrins are connected to diverse adaptor proteins, which constitute a versatile signaling scaffold to address many different signaling pathways in response to mechanical loading [15]. Finally, these cascades converge on actin-regulating proteins (ARPs) as well as mechanosensitive co-transcriptional activators, such as the Yesassociated protein 1 (YAP1, henceforth designated as YAP) [18,19]. Conversely, actin- and myosin-dependent cellular traction forces are fed back to the ECM via integrins, rendering FAs an outside-in and inside-out signaling hub [20,21].

Cell-to-cell contacts are mostly established by homophilic and $\mathrm{Ca}^{2+}$-dependent cellular adhesion proteins, namely members of the cadherin (Cad) families. The histological equivalents of these connections are called adherens junctions (AJs) and are indispensable for epithelial integrity and barrier functions. Similar to FAs, AJs are intracellularly coupled to further signal-transducing proteins comprising members of the catenin family and the actin cytoskeleton [22-24].

Aside from the cytoplasmic cytoskeleton, more and more experimental evidence proves the enormous contribution of nuclear mechanics and the nuclear cytoskeleton to cellular MT, genomic integrity, and tissue regeneration $[25,26]$. In particular, nuclear lamins, and their role in epigenetic regulation and chromatin structure, are tightly interrelated to mechanobiological processes $[27,28]$. Thus, the concept of nuclear mechanotransduction (NMT) widens the above-described ECM-cytosolic network to an integrative ECM-cytosolnucleus network, involved in cellular key functions as diverse as proliferation, migration, differentiation, and apoptosis. Therefore, understanding the key concepts which govern cellular MT is undoubtedly a prerequisite for a deeper understanding of periodontal tissue homeostasis, regeneration, and disease.

Within the oral cavity, the periodontal structures consisting of the gingiva, the periodontal ligament (PDL), cementum and the alveolar bone are permanently subjected to cyclic and static mechanical loading, which is a direct consequence of chewing, occlusion, mastication or orthodontic treatment [29]. Although the ECMs of the periodontium harbor different biochemical and biophysical properties, their mechanical integrity and continuous remodeling and regeneration is a basic requirement for oral health [30-32]. Imbalances in matrix metalloproteinase (MMP) and the tissue-inhibitor of metalloproteinases (TIMPs) regulation or the presence of pathogen-derived proteases such as the Porphyromonas gingivalis (P. gingivalis) gingipains can severely damage the periodontium and lead to inflammatory processes with consecutive catabolic degradation of the ECM [33-36]. This, of course, changes the mechanosignaling pathways and thus influences cell behavior. In conjunction with the host's inflammatory response, their susceptibility to pathogen-induced damage, and further microbe-derived virulence factors can contribute to or result in the onset or the progression of diseases such as periodontitis or, at worst, even oral squamous cell carcinoma (OSCC) [37,38].

Regarding the various functions of MT in tissue homeostasis, regeneration and health, this review summarizes the molecular principles of core mechanosignaling pathways in the periodontium, including FAs, AJs, YAP1 and NMT. Moreover, potential applications of MT-related processes for periodontal regeneration and disease weakening are described. 


\section{The ECM, Focal Adhesions and Adherens Junctions in Periodontal Health and Disease}

The periodontium is a complex composite tissue consisting of the gingiva, the periodontal ligament (PDL), cementum, and the alveolar bone. Beneath harboring various cell types, amongst others, gingival keratinocytes (GKs), gingival fibroblasts (GFs), periodontal ligament fibroblasts (PDLFs), cementoblasts and osteoblasts, the ECMs of the different periodontal cell and tissue entities are considerably different [39].

The cementum and the alveolar bone consist of an inorganic hydroxyapatite matrix and collagen type I as the major organic compound [40]. Additionally, the glycosaminoglycans (GAGs) decorin and biglycan as well as the glycoproteins (GPs) osteonectin, osteopontin, fibronectin, and osteocalcin can be found in the ECM of both tissues [41,42]. The PDL harbors the fibrous collagen types I and III, and small amounts of collagen V and VI [43]. Above, the basement membrane collagen types IV and VII and collagen type XII, which is important for fibrillar organization, are expressed in the PDL [44]. Elastin, fibronectin (FN) and chondroitin-/dermatan-/keratin-sulfate, containing GAGs, also support PDL function [45].

The gingiva contributes to periodontal integrity via epithelium and connective tissue. While the GKs form a stratified squamous epithelial layer, GFs are embedded in a lamina propria with collagen type I, III, elastin and many other macromolecules [46].

Physical ECM properties are key determinants of cell behavior in vitro and in vivo. The stiffness of the ECM, quantified by the Young's modulus, as well as viscoelastic properties, spatial arrangement of adhesion points, and other geometric constraints, influence cellular responses through MT and other signaling hubs [14,47,48]. This means that ECM composition, homeostasis and MT are tightly coupled and are, therefore, highly interdependent [49]. Cell morphology, migration, proliferation, differentiation, and apoptosis are consequently not only influenced by biochemical signals, but also by the direct mechanical properties of the respective ECM environment [50]. Interestingly, cellular responses, namely the actomyosin-derived cell-inherent contraction forces, as discussed below, seem to directly reflect ECM stiffness, meaning that the Young's modulus of the ECM is encoded within the cell's response to that specific microenvironment [51].

Mechanistically, the above-mentioned ECM constituents directly or indirectly, i.e., mediated through adaptor proteins, interact with neighboring cells via surface receptors. Regarding MT, the family of integrin proteins is especially important as they are the core linking hub between the ECM and the cytosol. Within the plasma membrane, integrins form heterodimers, which are composed of an $\alpha$ - and a $\beta$-subunit. Various combinations of heterodimers have been described in different experimental systems and they proved to have different ligand specificity. Table 1 summarizes the most important integrin heterodimers and their corresponding ligands relevant to periodontal MT [52-58]. As can be seen, one heterodimer can sometimes bind more than one ligand (e.g., $\alpha 1 \beta 1$-integrin) and one ligand, such as fibronectin, is recognized by multiple heterodimers. Therefore, the tissue- or cell-specific expression pattern of integrins determines its interaction with the ECM. Periodontal cell populations foremostly harbor $\alpha 2 \beta 1, \alpha 3 \beta 1$ and $\alpha 5 \beta 1$ integrins. Of interest, the expression pattern of periodontal integrins changes in response to damage or during wound healing or carcinogenesis [59].

Table 1. Selected integrin heterodimers and their corresponding ligands.

\begin{tabular}{|c|c|c|c|c|c|c|c|}
\hline $\begin{array}{c}\text { Integrin } \\
\text { Heterodimers }\end{array}$ & $\alpha 1 \beta 1$ & $\alpha 2 \beta 1$ & $\alpha 3 \beta 1$ & $\alpha 5 \beta 1$ & $\alpha \mathrm{V} \beta 1$ & $\alpha \mathrm{V} \beta 3$ & $\alpha \mathrm{V} \beta 5$ \\
\hline Ligand(s) & $\begin{array}{l}\text { Different collagens } \\
\text { (e.g. type I) }\end{array}$ & $\begin{array}{l}\text { Different collagens } \\
\text { (e.g. type I) }\end{array}$ & laminins & fibronectin & fibronectin & fibronectin & vitronectin \\
\hline
\end{tabular}

Upon mechanical loading, such as during mastication, occlusion or orthodontic treatment, the ECM of the periodontal tissues is deformed. Exemplarily, occlusion forces that 
exert compressive load onto a tooth are transmitted to the PDL, which serves as a push-pull transducer [60]. This means that the ECM components within the PDL, such as the collagen fibers, are stretched. As they are either directly or indirectly connected to the integrin receptors and these proteins undergo a conformational change, which is herewith the consequence of the initial mechanical stimulus. Therefore, these surface receptors are considered mechanoreceptors, as they transmit the ECM's physical state into the cell's interior.

Intracellularly, integrins are linked to various signaling proteins, which function as a molecular clutch that couples integrin-ECM interaction to intracellular biochemical signaling, the centerpiece of MT. Histologically, these integrin-dependent cell-to-matrix connection structures are called FAs [15].

Next to the plasma membrane, a plethora of proteins form the "integrin signaling layer", where focal adhesion kinase (FAK), the head domain of talin and paxillin interact with the cytoplasmic integrin domain. Vinculin and the tail of talin are designated as the "force transduction layer" [61]. Finally, these proteins are linked to the actin cytoskeleton through an "actin binding layer", which consists of $\alpha$-actinin, vasodilator-simulated phosphoprotein (VASP), and zyxin [62]. Beneath the listed proteins, many other cellular key players, such as sarcoma ( $\mathrm{Src}$ )-family kinases or the extracellular signal-regulated kinases 1/2 (ERK1/2) have been shown to directly interact with FAs and regulate the activity and assembly status of its components (Figure 1A) [15,63,64].

The actin cytoskeleton is the common downstream target of all MT pathways $[65,66]$. It not only consists of filamentous (F) actin, but also of actin-regulating proteins (ARPs), which regulate the dynamic building and destruction of the filaments from globular $(\mathrm{G})$ actin monomers. G-actin binds adenosine-triphosphate (ATP) and hydrolyses ATP to adenosinediphosphate (ADP) within F-actin. This reaction goes along with conformational changes of actin monomers and contributes to the dynamic turnover of actin-related cytoskeletal structures [67-69]. Actin polymerization is regulated by a class of guanosine-triphosphate (GTP) binding proteins, known as Ras homologue A (RhoA), cell division control protein homolog 42 (Cdc42), Ras-related C3 botulinum toxin substrate 1 (Rac1), as well as the Rho-associated, coiled-coil-containing protein kinase 1 (ROCK1) (Figure 1A) [70-73]. These small GTPases are addressed by the mechanotransducing proteins of FAs and their activity state determines the polymerization of G-actin as well as the formation of lamellipodia or filopodia. ROCK1 is even more directly involved in periodontal differentiation, homeostasis, and regeneration, as the inhibition of ROCK1 prevents proper the differentiation of PDL cells into osteoblasts and reduces ECM regeneration via the downregulation of collagen I and fibronectin [74,75]. These findings underscore the essential role of actin cytoskeleton regulation in the MT of the periodontium.

Actin filaments are additionally stabilized by ARPs, such as Arp2/3, tropomyosin or profilin. Contrarily, severing proteins, such as gelsolin, support F-actin depolymerization or destruction [76,77]. Altogether, the complex interplay of actin regulatory proteins governs actin's dynamic de- and repolymerization and enables complex cellular processes, such as cell division or migration [78]. Further details of these complex cytoskeletal regulatory principles are beyond the scope of this review and interested readers are referred to other comprehensive discussions on this subject $[79,80]$.

Thus far, the description of the actin cytoskeleton and its dynamics does not explain how cells maintain their shape during mechanical stimulation and how cellular integrity can be achieved by mechanisms of FAs-related signaling. To this end, cells need the ability to actively generate forces to withstand external deformation or to exert mechanical stimuli on their environment. This is possible through the action of cytoplasmic motor proteins, known as myosins, which are coupled to the actin cytoskeleton. Via the hydrolysis of ATP, these motor proteins can actively move along actin filaments [81-83]. Besides functions in cargo transport, myosins can, therefore, generate tension and traction forces through the relative displacement of actin filaments [84-87]. This mechanism immediately explains that FAs are not only outside-in signaling platforms that transmit mechanical ECM signals into the cell, but that actomyosin-generated cytoskeletal forces can also be transmitted to 
the ECM with the help of integrins and their neighboring adaptor proteins. Therefore, FAs are bidirectional mechanosensitive signaling hubs.
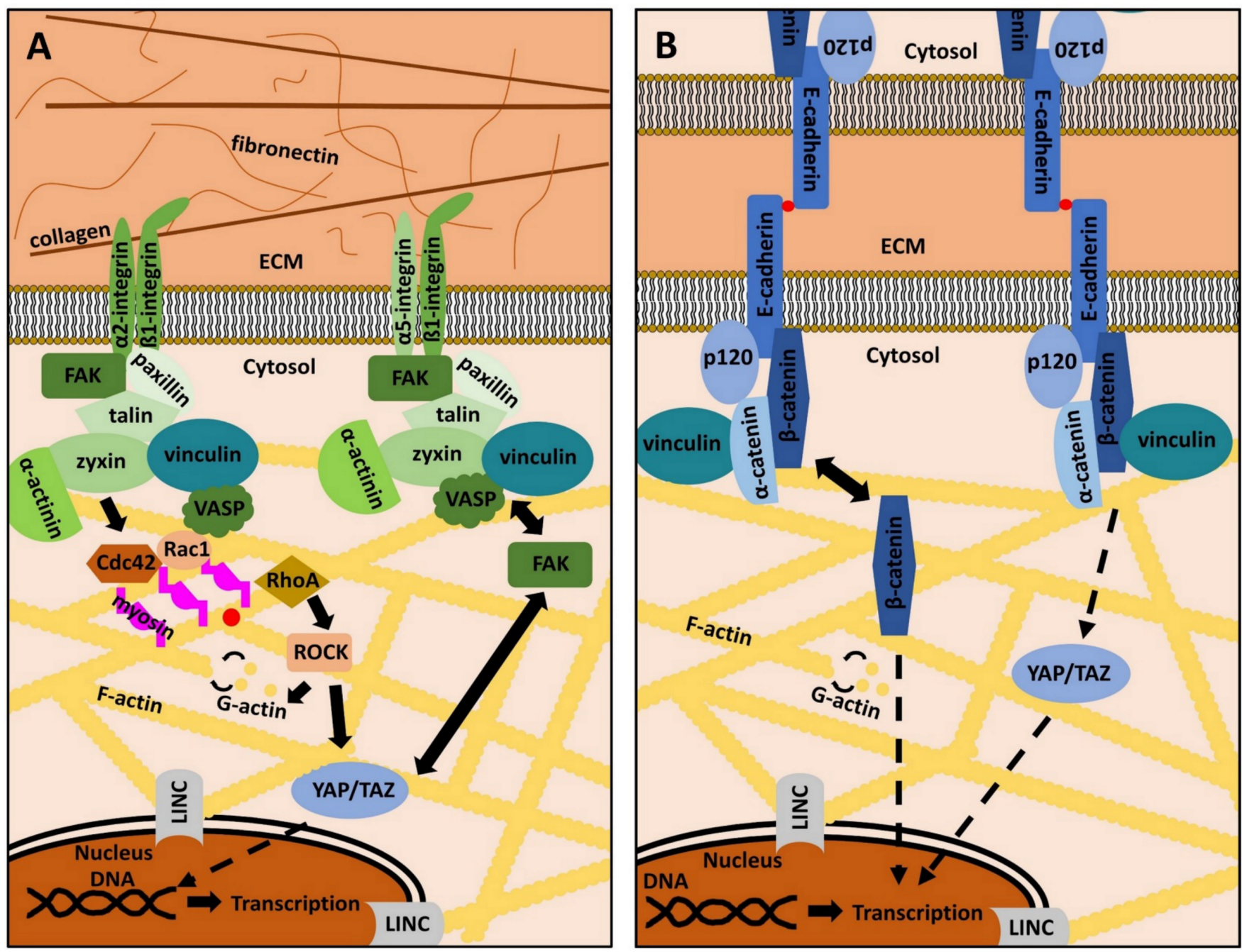

Figure 1. The role of focal adhesions and adherens junctions in mechanotransduction. (A): Focal adhesions (FAs) are adhesion structures that bind extracellular matrix (ECM) ligands via integrin receptors. The latter are composed of varying combinations of an $\alpha$ - and a $\beta$-subunit. Each heterodimer has specific ECM ligands (see Table 1). Intracellularly, integrins are linked to various signaling molecules that constitute a molecular clutch, which transmits mechanical information from the ECM into the cell's interior and vice versa. Focal adhesion kinase (FAK), paxillin, talin, zyxin, vinculin, vasodilator-simulated phosphoprotein (VASP) and $\alpha$-actinin are examples of important FAs proteins, connecting integrin receptors to the actin cytoskeleton (yellow). The small GTP-binding proteins Ras-related C3 botulinum toxin substrate 1 (Rac1), cell division control protein homologue 42 (Cdc42), and Ras homologue A (RhoA), together with Rho-associated, coiled-coil-containing protein kinase (ROCK) modulate the dynamic de- and repolymerization of globular (G)-actin (yellow dots) and filamentous (F)-actin. FAK activity and subcellular localization of yes-associated protein (YAP) and its cellular homologue transcriptional co-activator with PDZ motif (TAZ) are strongly interconnected. The linker of nucleoskeleton and cytoskeleton (LINC) complex couples the cytoplasmic cytoskeleton to the nucleus. Both mechanisms are important to regulate gene expression in response to mechanical signals. Details are described in the main text. (B): Cell-to-cell adhesion depends on adherens junctions (AJs). Cadherins, as exemplified by E-Cadherin, are transmembrane proteins that bind other cadherins on neighboring cells in a $\mathrm{Ca}^{2+}$-dependent manner (red dots). Intracellularly, cadherins are linked to various proteins, such as p120, $\alpha$-catenin, $\beta$-catenin, and vinculin, which indirectly connect cadherins to the actin cytoskeleton (yellow). YAP/TAZ regulation is also dependent on AJs integrity. $\beta$-catenin can also serve as a transcription factor in the nucleus and its subcellular localization contributes to determining cell behavior. Further details are described in the main text. 
Of interest, this is of enormous importance for ECM homeostasis and regeneration in the PDL, as FN and collagen fibrillogenesis depends on intracellularly derived contractile forces. Actin stress fibers serve as a guide trail for the centripetal movement of $\alpha 5 \beta 1$ bound FN, which supports FN-FN interactions [88,89]. Collagen molecules can then be deposited on the pre-existing FN fibrils. As this process is force-dependent, characteristic ECM structures, such as the parallel arrays of collagen fibers within the PDL, can be explained via this mechanism and are, therefore, a result of bidirectional MT related to FAs. Interestingly, a recent study gave new insights into the actual nonuniformity of the PDL and revealed the mechanical properties of different subregions within the gomphosis. The so-called collar region is characterized by a high proportion of collagen type I, making it resistant to tensile forces due to high mechanical stiffness. Contrary to that, the furcation region is less stiff and contains less type I collagen, which seems to be associated with a dual function in resisting compressive loads [30].

In periodontitis, collagen and other ECM components are degraded by proteases, such as MMPs or bacteria-derived gingipains (see Section 4) [90]. This changes integrindependent MT, leading to a decrease in intracellular actomyosin contractility (outside-insignaling). Consequently, inside-out signaling is also impaired, which leads to incorrect collagen fibril deposition, worsening the catabolic destruction of the periodontium [36,59].

FAs related signaling also comprise an important step in (alveolar) osteocyte differentiation and the cell's response to fluid shear stress. The reduction in the protein sclerostin by mechanical loading is mediated by FAK-dependent phosphorylation of the histone deacetylase 5 (HDAC5), which is translocated into the nucleus in response to this post-translational modification. Sclerostin suppression leads to an increase in bone formation and thus mediates an adaptation process by which shear stress leads to mechanical strengthening of the exposed tissue [91,92].

Besides cell-to-matrix adhesion, cell-to-cell adhesion is of great importance, especially in epithelial tissues, such as parts of the gingiva. The main constituents of the so-called adherens junctions (AJs) are cadherin (Cad)-family members (Cads), which are $\mathrm{Ca}^{2+}$-dependent, membrane-embedded proteins that connect cells via homophilic interaction [93]. In the cytoplasm, Cads are connected to various proteins, amongst others $\alpha$-catenin, p120, vinculin or $\beta$-catenin [22,94-96]. These adaptor proteins are comparable to the integrin-linked intracellular mechanotransducers, as they connect Cads to the actin cytoskeleton. The same mechanisms and principles as discussed above also apply for AJs and qualify the actin cytoskeleton not only as the common final pathway of AJs and FAs signaling, but also as a crosstalk platform that integrates mechanical cues transmitted through various MT pathways [97,98]. ERK1/2, YAP, and its cellular homologue transcriptional co-activator with PDZ motif (TAZ), vinculin and FAK, are both addressed by AJs and FAs, underscoring the complex mutuality of cell-to-cell and cell-to-matrix adhesion (Figure 1B) [17,99-101]. This is the reason why current systemic approaches try to elucidate the tissue- and cell-type specific interplay and fine-regulation of signaling crosstalk related to MT [13]. It is of great interest, to shed light into these principles in periodontal tissues.

In the periodontal context, Cads fulfill different functions, ranging from maintenance of cellular differentiation to epithelial barrier function, tumor suppression, and MT-related tissue homeostasis. Specifically, $\beta$-catenin, in its function as a transcriptional regulator, is important in PDLF differentiation and simultaneously inhibits the cementoblastic phenotype [102].

The epithelial E-Cad, which is expressed in GKs, plays a significant role both in periodontitis and oral carcinogenesis. Patients suffering from periodontitis show decreased protein levels of E-Cad, which is indirect evidence for a dysfunctional epithelial barrier function. This further promotes the inflammatory process [103]. Downregulation of E-Cad has also been reported in many carcinomas, where it represents a key step during epithelialto-mesenchymal transition (EMT). Thereby, epithelial cells detach from their surrounding cells and develop a migratory, fibroblastoid phenotype, which is a prerequisite for tissue invasion and metastasis. Regarding oral carcinogenesis, reduced expression levels of E-Cad 
and $\beta$-catenin are indicators of the progression from dysplasia to cancer and an aggressive OSCC phenotype [104]. As chronic inflammation is a risk factor for cancer development, the loss of E-Cad-related barrier function and MT offers valuable insights into the link between periodontitis and OSCC $[105,106]$.

Beneath E-Cad, Cadherin 11 (Cad11) is another member of the cadherin family expressed in periodontal tissues $[107,108]$. Upon mechanical loading, expression of Cad11 and $\beta$-catenin decreases in PDLFs, which consequently leads to a reduction in collagen 1 synthesis and changes in cellular morphology [109]. These findings clearly show that not only FAs but also AJs are involved in ECM homeostasis and regeneration and that cell-to-cell adhesion is not limited to intercellular information exchange. This hypothesis is supported by other experimental results, where knock-down of Cad11 impairs elastin and collagen synthesis [110]. In mice, Cad11 deficiency reduces cell contractility, which again represents the involvement of AJs in both ECM structure and MT [111].

Taken together, the findings presented in this chapter show that the ECM and its molecular composition are important determinants of periodontal cell behavior in the context of MT. As the periodontal tissues are affected by diseases, such as periodontitis or OSCC development, the relevance of MT in these pathophysiological processes is of clinical relevance. So far, the convergence of FAs and AJs-mediated signal transduction on the cytoskeleton has been discussed. However, the mechanisms by which the information encoded within the contractility and tension of the actin-cytoskeleton is translated into cellular adaptation, which depend on further cellular key players, such as the mechanoresponsive co-transcriptional activators YAP/TAZ and the nuclear cytoskeleton, will be discussed in the subsequent sections.

\section{Mechanotransduction to the Core: YAP/TAZ in the Periodontium}

The Yes-associated protein YAP and its cellular homologue TAZ were originally described as transcriptional co-activators in the context of the so-called Hippo signaling pathway. The latter was identified in the fruit fly Drosophila melanogaster by mutagenesis screening and the recognition that loss-of-function mutations of certain genes lead to an increase in organ size (overgrowth phenotype) [112]. The core Hippo pathway is evolutionary conserved and its homologues in mammals are involved in many cellular functions, such as proliferation and differentiation, as well as carcinogenesis. The main components are the serine-threonine kinases Ste-20-like kinases 1/2 (Mst1/2) and large tumor suppressor kinase 1/2 (Lats1/2) as well as the above-mentioned co-transcriptional activators, YAP and TAZ [13,113-116].

Unlike many other phosphorylation cascades, the activity of the Hippo kinases (Hippo signaling turned "on") leads to the inactivation of the effector proteins YAP/TAZ. This is achieved by the phosphorylation of YAP on Serine127 or TAZ on Serine89, which promotes the association of the proteins with their cytosolic sequestration protein 14-3-3 $\sigma$ [117]. Conversely, the inactivity of the Hippo kinases (Hippo signaling turned "off") results in a shift of the phosphorylation-dephosphorylation equilibrium towards dephosphorylation, which enables YAP/TAZ to shuttle into the nucleus, where the proteins can exert their function as co-transcriptional activators. Subsequently, depending on the cellular context, YAP/TAZ promote proliferation, differentiation, or many other core physiological functions $[114,117]$. The slightly non-intuitive mechanism is easily understood by having a look at regulatory upstream signals that govern the activity of the Mst1/2 and Lats $1 / 2$ kinases. For example, in the apical junctional region of the epithelia, proteins such as Merlin/neurofibromatosis 2 (NF2), KIBRA, and Salvador-homologue 1 (Sav1) form a protein complex that responds to cell-to-cell adhesion. Therefore, MT-relevant signals, such as a high cell density, activate the Mst1/2 and Lats1/2 kinases via this junctional complex, and thereby inhibit $\mathrm{YAP} / \mathrm{TAZ}$ translocation into the nucleus, which in turn inhibits proliferation and organ overgrowth [118,119].

Apart from canonical Hippo signaling, YAP/TAZ are also regulated by various other upstream signals, which are at least in part independent of the above-discussed kinase 
mechanisms. Signals from G-protein coupled receptors (GPCRs) as well as receptor tyrosine kinases (RTKs) and receptor serine/threonine kinases also converge on YAP/TAZ, as exemplified by their regulation through platelet-derived growth factor (PDGF) or transforming growth factor beta (TGF- $\beta$ ) [120-122].

Angiomotin (AMOT) is a family member of the angiostatin-binding proteins and was described to bind to F-actin in the cytoplasm [123,124]. Upon the depolymerization of the cytoskeleton, which can be the result of changes in MT, AMOT dissociates from its binding partner and traps YAP/TAZ in the cytoplasm [125]. It is also a matter of debate if some unknown serine kinases may additionally be able to change the phosphorylation status of YAP/TAZ [126]. In the direct MT context, ROCK, FAK and Src have been described as important upstream regulators of YAP activity (Figure 2) [127,128]. The exact mechanism of how these proteins can interfere with the cytoplasmic-nuclear shuttling of YAP/TAZ remains to be elucidated, but indirect dephosphorylation through phosphatases such as PPM1A appears likely $[129,130]$. Similar to the bidirectional signaling of FAs, recent experimental evidence in human mesenchymal stem cells (hMSCs) also shows that YAP is not only regulated by FAK, but that FAK activity, as well as the protein abundancy of FAK and other FA components, is influenced by the cellular sublocalization and activity of YAP [61]. This leads to the conclusion that not only nuclear YAP exerts mechanobiological gene-regulatory functions, but that cytoplasmic YAP is also involved in MT by feeding back on FA activity and integrity. Additionally, the destruction of AJs by inhibiting the interaction of E-Cad with $\alpha$-actinin also favors nuclear translocation of YAP. The latter mechanism was for example described in the context of enamel knot formation during tooth development [131]. Therefore, FAs as well as AJs are input signals for YAP/TAZ activity, which underscores their role as mechanoresponsive co-transcriptional activators.

Of interest, the transcription factor megakaryoblastic acute leukemia factor- 1 and 3 (MKL1/3) is also translocated into the nucleus in a MT-related, force-responsive manner. Mechanistically, MKL1/3 binds go G-actin in the cytoplasm and dissociates from its binding partner as soon as G-actin is incorporated into growing actin filaments during polymerization. Apart from the AMOT-regulated YAP/TAZ transition, a similar mechanism might also apply to YAP/TAZ [132]. This elegant interdependency of YAP/TAZ and the actin cytoskeleton would effortlessly explain the mechanoresponsive features of these co-transcriptional regulators.

Within the nucleus, YAP/TAZ have to interact with transcription factors to regulate gene expression. The TEA domain family (TEAD) of transcription factors are the most important nuclear binding partners of YAP/TAZ. DNA binding of the YAP/TAZ-TEAD complex leads to the expression of core proliferation factors such as cellular myelocytomatosis (c-myc) or Cyclin D1 $[133,134]$. However, regulatory mechanisms to inhibit YAP/TAZ function also exist in the nucleus. The tight junction component zona occludens 2 (ZO-2), a protein also involved in cell-to-cell adhesion, can enter the nucleus and bind dephosphorylated YAP there. This shows, again, the tight interrelationship between "junctional" information and YAP/TAZ activity as well as the diverse signals that converge on these proteins [135-137].

Regarding the periodontium, YAP/TAZ is a central regulator in tooth and craniofacial development. Amongst others, the patterning genes of the Hox cluster are addressed by YAP/TAZ activity and the former's function determines oral epithelial proliferation and the patterning of the enamel knot [138]. The formation of the cranial neural crest also depends on YAP/TAZ function and the induction of Fox transcription factors. The latter point is especially interesting in the context of periodontal regeneration as, e.g., stem cells in the PDL are neural crest derivates $[139,140]$. 


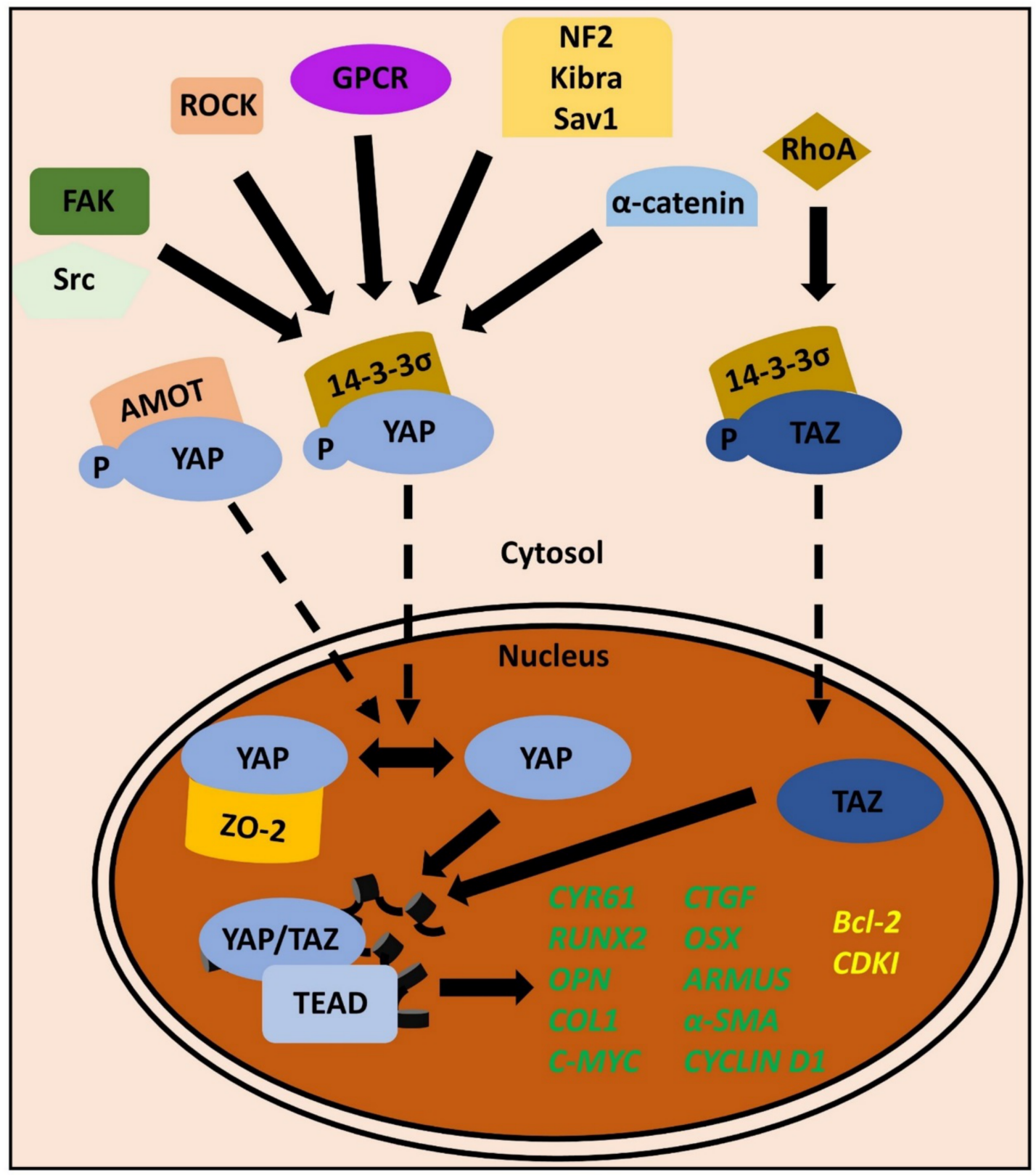

Figure 2. The transcriptional co-activators YAP and TAZ are regulated by many cellular key players. Yes-associated protein (YAP) and its cellular homologue transcriptional co-activator with PDZ motif (TAZ) are master-regulators of cellular mechanotransduction. A plethora of upstream signals converge on these proteins. Nonetheless, there seems to be slight differences in the exact cellular functions of YAP and TAZ (details given in the main text). In the cytosol, YAP/TAZ are phosphorylated $(\mathrm{P})$ and are bound by proteins from the 14-3-3 family, which prevent their translocation into the nucleus. YAP can additionally be bound by angiomotin (AMOT). Dephosphorylation of YAP/TAZ is mediated through regulators as diverse as focal adhesion kinase (FAK), cellular sarcoma (Src), coiled-coil-containing protein kinase 1 (ROCK), G-protein coupled receptors (GPCR), $\alpha$-actinin, or the junctional proteins neurofibromatosis 2 (NF), KIBRA, and Salvador-homologue 1 (Sav1). RhoA also interacts with TAZ. In the nucleus, YAP may be trapped by zona occludens 2 (ZO-2) protein. Otherwise, YAP/TAZ interact with TEA domain family (TEAD) transcription factors to regulate gene expression. Genes written in green, such as cysteine-rich angiogenic inducer 61 (CYR61), connective tissue growth factor (CTGF), runt-related transcription factor 2 (RUNX2), osterix (OSX), osteopontin (OPN), ARMUS, collagen 1 (COL1), $\alpha$-smooth muscle actin $(\alpha-S M A)$, cellular myelocytomatosis $(c-m y c)$, and cyclin D1 are upregulated by YAP/TAZ. Contrary to that, the pro-apoptotic B-cell lymphoma $2(B c l-2)$ as well as cyclin-dependent kinase inhibitor (CDKI) transcripts are downregulated by these transcriptional co-activators (yellow). Details are given in the main text. 
Specific findings in PDL stem cells (PDLCs) proved that cyclic mechanical stimulation results in an increase in nuclear YAP abundancy. Consequently, transcriptional YAP targets, such as cysteine-rich angiogenic inducer $61(C Y R 61)$ and connective tissue growth factor (CTGF), are transcriptionally upregulated. By additionally inducing key differentiation markers of osteoblasts-amongst others, runt-related transcription factor 2 (RUNX2), osterix (OSX), osteopontin (OPN), and alkaline phosphatase-YAP is also involved in supporting the differentiation of PDLCs into osteoblasts (Figure 2) [141-143]. An orthodontic tooth movement (OTM) rat model as well as PDLCs in vitro experiments specifically proved that not only YAP but also TAZ supports osteogenic differentiation. The protein collagen triple helix repeat containing 1 (CTHRC1) was identified as a potent inductor of TAZ activity, which lead to an increase in collagen type 1, alkaline phosphatase, RUNX2, and osteocalcin [144]. However, YAP and TAZ seem to have slightly different biological functions during OTM. The immunochemical staining of histological sections from another rat OTM model pointed to the direction that TAZ activity might be more tightly coupled with RUNX2 expression and thus osteogenesis, whereas YAP activity is more strongly connected to differentiation and proliferation $[145,146]$. This example demonstrates a common problem in YAP/TAZ research, namely that the cellular homologues are often regarded as equal, concerning their function. This assumption is, however, not justified. Another proof of a distinct regulatory mechanism of TAZ activity was described by Cui and colleagues. They reported that the micro-RNA miR-140 is involved in the regulation of osteogenesis of human PDLFs by interacting with a RhoA-TAZ signaling axis. In detail, the expression of this micro-RNA inhibits the transcription of RhoA, which leads to a reduction in TAZ protein activity in the nucleus and thus reduced osteogenesis during OTM. This is especially interesting as (i) this mechanism combines principles of transcriptional regulation on the RNA level with protein activity of important mechanotransducers, and (ii) was so far solely described for TAZ but not for YAP [147]. These slight differences might be decisive when it comes to dental implants and regenerative approaches with periodontal stem cells, as TAZ regulation and therefore cellular differentiation is sensitive to the environmental nano topography [148].

Apart from genuine periodontal tissues, YAP/TAZ were shown to be translocated into the nucleus in response to a static external magnetic field in human dental pulp stem cells and, thereby, induced mineralization beneath the cells. A concomitant rearrangement of the actin cytoskeleton was additionally reported [149]. This raises the general question of to which extent cells can respond to forces generated from static magnetic fields [150-152]. In the context of dentistry, it needs to be considered that ferromagnetic compounds can sometimes be found as part of a prosthetic material $[153,154]$ within overdentures in the oral cavity of patients. As this material may potentially interfere with cell biology and MT, due to magnetism, and the exact molecular consequences are still a matter of scientific debate, it will be of great clinical interest to further study YAP's involvement in these processes.

Concerning ECM homeostasis and regeneration, YAP promotes type I collagen synthesis. This finding together with the promotion of the osteoblast phenotype might explain the PDL-adjacent osteogenesis on the pull side during orthodontic treatment [142]. Alphasmooth muscle actin ( $\alpha$-SMA) is supposedly also an indirect regulatory target of YAP/TAZ, as their nuclear presence was also shown to induce myo-fibroblast differentiation from PDLCs [155]. All these processes in PDLCs are, as already described, connected with actin-related cellular tension and thus MT. It is conceivable that a collagen 1- $\beta 1$-integrinRhoA-ROCK-F-actin-YAP/TAZ-collagen 1 signaling loop facilitates both the sensing and maintenance of the ECM and promotes PDLC lineage decision in a context-dependent manner [142].

Not surprisingly, YAP can maintain the stem cell properties of PDLCs in vivo and in vitro. When artificially overexpressed, YAP nuclear accumulation leads to an increase in proliferation, reduces cellular senescence and promotes apoptosis resistance [156]. On the molecular level, this is achieved via the upregulation of cyclin-dependent kinases 
(CDKs) and a downregulation of the latter's inhibitors, the CDK inhibitors (CDKIs). Above, expression of B cell lymphoma 2 (Bcl-2) family members, as pro-apoptotic cellular regulators, is reduced (Figure 2). Moreover, mitogenic signaling, represented by ERK1/2 and MAPK/ERK kinase (MEK) activity, increases [156]. The proliferative capacity of an immortalized PDLCs-derived cell line, which was established via lentiviral transfection of human telomerase reverse transcriptase (hTERT), also depended on YAP nuclear activity. This can be shown by experimentally inhibiting YAP nuclear translocation via the photosensitizer Verteporfin $[157,158]$. Of interest, the cell line is not tumorigenic in nude mice, proving that hTERT expression in combination with high YAP nuclear activity alone is not sufficient for carcinogenesis $[159,160]$. Such experimental systems will be of great value for further periodontal research regarding appropriate approaches in regenerative medicine.

In the context of oral carcinogenesis, these stem-cell-like properties mediated by YAP bear the potential risk to support cellular transformation. Indeed, YAP overexpression was reported in many cancers, including OSCC [114,134,161]. Apart from the anti-apoptotic and proliferative activities, metabolic supply via the induction of autophagy as well as the regulation of EMT, are functions, which are at least partially attributed to YAP activity.

Recently, a novel mechanism of YAP-dependent OSCC proliferation was proposed. Piezo-type mechanosensitive ion channel component 1 (PIEZO1) is a mechanosensitive calcium channel and transcriptional target of YAP [162]. PIEZO1 signaling consequently leads to an increase in intracellular calcium concentrations, which promotes proliferation. This interesting insight into two mechanoresponsive proteins in the context of OSCC progression offers new perspectives in the pharmaceutical targeting of cancer cell-associated proliferative activity, by addressing the activity of PIEZO1 $[163,164]$. An up-to-date discussion of the Piezo channel family members and their role in mechanobiology was recently presented by Jiang and colleagues [165].

The increase in autophagic flux is mediated via the YAP/TAZ-dependent transcription of Armus, a Ras-related in brain (RAB)-GTPase activating protein (GAP)-family member, which is involved in maturation of autolysosomes from autophagosomes [166,167]. It is a matter of ongoing research to further clarify the interdependency of MT, autophagy, and metabolic integration, also with respect to periodontal tissues.

Regarding EMT, matrix stiffness is a key determinant of YAP activity. As also holding true for OSCC, tumor stroma is often regarded as desmoplastic, which goes along with an increase in the Young's modulus and promotes nuclear YAP translocation [168]. $\beta 1$-integrinFAK-RhoA activity is also elevated under such conditions, as shown in a hepatocellular carcinoma (HCC) mouse model [169]. Nuclear YAP is then able to promote the switch from an epitheloid to a fibroblastoid cellular phenotype, as it controls both the activity and localization of Twist1. The latter, together with Slug and Snail, is a key transcription factor responsible for the molecular changes that occur during EMT, such as the downregulation of E-Cad and concomitant upregulation of fibroblastic marker proteins such as neural cadherin (N-Cad) or vimentin [170-172]. Taken together, it is conceivable that YAP is an important link between ageing, which is accompanied by an increase in ECM stiffness, and carcinogenesis related EMT. Regarding dental research, the clinical or diagnostic implications in the specific OSCC context remain to be elucidated.

Inflammatory periodontal diseases such as periodontitis are also linked to YAP and its role in mechanobiology. Especially the combination of occlusal trauma and periodontal inflammation seems to support periodontal destruction. As recently shown, the inhibition of YAP dephosphorylation and thus its nuclear translocation, could decrease inflammatory signaling in a mouse model of occlusal trauma and periodontitis. This shows the interrelationship of mechanobiological and inflammatory cellular pathways [173]. Alveolar bone loss was also linked to YAP activity and its interaction with Jun N-terminal kinase (JNK) and activator protein 1 (AP-1) [174].

Taken together, the described mechanisms of the action of YAP and TAZ in the periodontal context show both the complexity of the mechanobiological signaling integration 
and the decisive role of these processes in disease conditions such as periodontitis or OSCC (Figure 2) [175].

\section{The Gist of the Matter: Nuclear Mechanotransduction}

Section 3 discussed the mechanisms of YAP/TAZ dependent MT and its implications for periodontal tissues. As YAP/TAZ are soluble proteins, which shuttle between the cytosol and the nucleus, their mode of action can be described as a biochemical way of transmitting biophysical information. However, what about a higher physical intimacy between the cytoplasm and the nucleus?

In recent years, it has become more and more evident that nuclear shape and genomic integrity as well as gene regulation is directly linked to nuclear architecture and nuclear mechanotransduction (NMT) $[26,176,177]$. It is important to note that the molecular findings concerning NMT have been worked out in many different in vitro and in vivo model systems. Direct studies in cells from periodontal tissues are barely reported in the literature. As the proteins involved in NMT are highly conserved, it is, however, conceivable that the general mechanisms discussed below also apply to cells of periodontal tissues [178-180]. It is, therefore, a further research challenge to elucidate the cell-specific properties of NMT and their role for tissue homeostasis in the periodontium.

Various proteins that are localized in the outer nuclear membrane (ONM), the perinuclear space (PNS), the inner nuclear membrane (INM), or the nucleoplasm are directly or indirectly linked to mechanobiological functions and can, in many ways, be regarded as the nuclear equivalent of FAs [26]. From this perspective, the cytosol, similar to the ECM, represents the extranuclear environment in which cytoskeletal structures depict adhesion points for nuclear receptors. The most important structure that mechanically connects the cytoplasm with the nucleus is the linker of the nucleoskeleton and cytoskeleton (LINC) complex. LINC consists of members of the Klarsicht, ANC-1, and Syne-homology (KASH) domain protein family and members of the Sad1p and UNC-84 homology (SUN) protein family [181,182]. The former consists of Nesprin 1-4 in humans, which are embedded in the ONM. Of interests, Nesprins can physically interact with (i) plectin, a binding partner of intermediate filaments (IFs), (ii) kinesin and dynein, which are the motor proteins of microtubules, and (iii) directly with F-actin [183-187]. This means, that Nesprins can get in contact with all kinds of cytosolic cytoskeletal filament systems, rendering them the perfect adhesion proteins for transmitting cytoskeletal tension, including actomyosin contractility, into the nucleus. Nesprins further bind SUN proteins, namely Sun1 and Sun2, which span the PNS and the INM. Within the nucleoplasm, SUN proteins are in direct physical contact with a network of Lamins, nuclear pore complexes (NPC), and chromatin (Figure 3) [26,188].

Lamins are IFs in the nucleus and are encoded by three genes in men: LMNA, LMNB1 and LMNB2. LMNA encodes for the two protein isoforms, Lamin A and Lamin C. Lamin $\mathrm{B} 1$ and Lamin B2 are the corresponding gene products of $L M N B 1$ and $L M N B 2$, respectively $[189,190]$. All Lamin types form a tight meshwork of filaments of approximately 10-30 nm thickness along the INM [191]. Above, Lamins directly interact with chromatin, transcription factors, and proteins, such as Emerin [192]. The functions of the respective Lamin isoforms are interdependent and only partially redundant, as the deletion of one isoform leads to a loosening of the whole meshwork [26,193]. NPC localization is also associated with Lamin function. As the NPC is the central gate for the nuclear-cytoplasmic shuttling of proteins and vice versa, Lamins indirectly influence the exchange of soluble factors between both compartments [191,194]. Forces that lead to nucleus deformation, such as during cellular spreading on 2D culture substrates, result in a mechanical opening of NPCs and facilitate the nuclear entry of YAP [195]. However, sole osmotic nuclear swelling does not lead to the same result [195]. This elegant mechanism shows the stringent regulation of NPC opening and its relation to mechanobiology. 


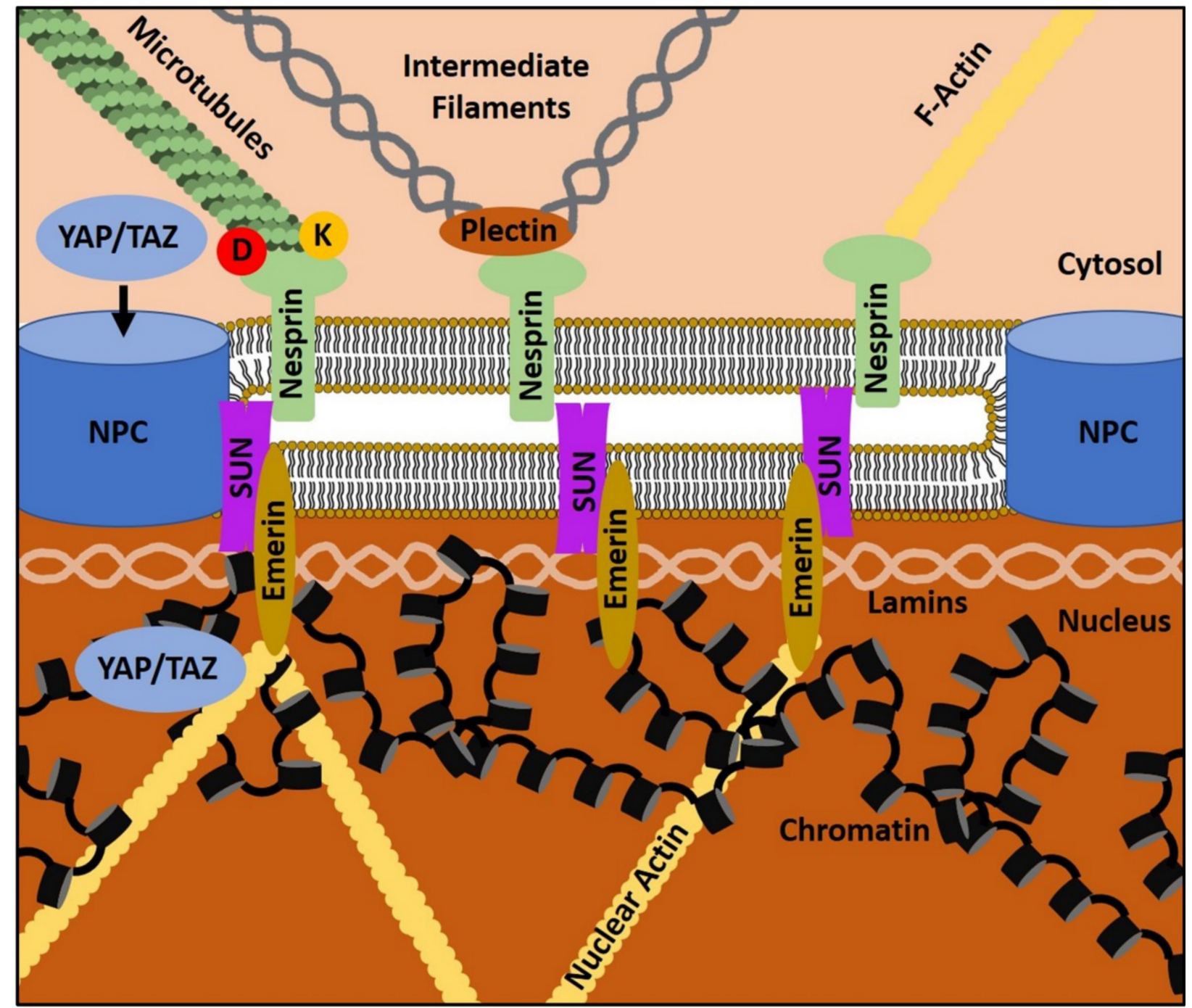

Figure 3. LINC complex-dependent mechanotransduction at the cytosol-nucleus interface. Nuclear mechanotransduction is a process at the cytosol-nucleus interface, where mechanobiological information is exchanged between the cyctosol and the nucleus and vice versa. The linker of nucleoskeleton and cytoskeleton (LINC) complex consists of Nesprins, which are embedded in the outer nuclear membrane, and Sad1p and UNC-84 homology (SUN) proteins in the inner nuclear membrane. At the nuclear periphery and within the nucleus, LINC is connected to nuclear pore complexes (NPC), Emerin, and the nuclear intermediate filament system, which consists of Lamins. This is the reason why LINC is directly and/or indirectly connected to the chromatin and the nuclear actin filament system. In the cytoplasm, Nesprin interacts with all cytoskeletal systems. Microtubules interact with Nesprins through the motor proteins Kinesin (K) and Dynein (D); intermediate filaments are connected to Nesprins via Plectin. Filamentous actin (F-actin) can directly bind Nesprins. Mechanoresponsive translocation of YAP/TAZ through NPCs into the nucleus is also connected to nuclear mechanotransduction (NMT). Details are described in the main text.

Besides IFs, the nucleus also harbors actin and actin-binding proteins. G-actin has been shown to act as a co-transcription factor for RNA-Polymerases 1-3, and to modulate the activity of other transcription factors and epigenetic regulators, such as histone deacetylases [196-200]. Upon polymerization, nuclear G-actin can form nuclear actin filaments. This process is triggered by cell spreading or adhesion and seems to correlate with the activity of integrins, cytosolic actin and the LINC complex [201]. Emerin, as well as Lamin A and B, have also been shown to bind nuclear actin [202-204]. Similar to its cytosolic analogue, nuclear F-actin is involved in the maintenance of nuclear integrity and shape and even participates in the cell's stress response during replication [205]. Consequently, coordinated gene expression and genomic integrity is not only a result of biochemical factors 
and their related signal transduction, but is also based on nucleo-cytoskeletal dynamics and NMT.

The molecular architecture of the LINC complex in conjunction with its associated molecules in the cytoplasm and the nucleus reveals how biophysical cues can be mechanically transmitted from the cytosol to the nucleus and back. Exemplarily, integrintransmitted forces can lead to changes in cytosolic actomyosin contractility, which is further transduced into the nucleus via LINC. LINC addresses lamins, nuclear actin and chromatin regulating proteins, and thereby regulates the condensation of chromatin, i.e., the transition between eu- or heterochromatin, which changes the cell's expression profile and promotes cellular adaptation to the initial extracellular cue [26]. The reverse process; namely, the transduction of nuclear mechanical properties, such as stiffness, to the cytoplasm and consequently to the ECM via integrins is less well studied. Nonetheless, there is unambiguous evidence that LINC-dependent NMT is no one-way road. A stiffer nucleus facilitates FA formation and the newly built FAs are larger [206]. As above, the deletion of Nesprin-1 impairs the cell's ability to adequately adapt to cyclic strain. This means that the nucleus is directly involved in the regulation of cytoplasmic actomyosin contractility, which consequently feeds back on FAs and the ECM through integrins [207]. Additionally, the nuclear position within the cell changes during these NMT processes. To prevent nuclear damage, the whole nucleus is oriented perpendicular to the stretch vector and parallels actin stress fibers [208]. This extends the above-discussed ECM-cytosolic mechanosignaling network to a bidirectional ECM-cytosol-nucleus network that is relevant to MT. Similar to cells as a whole, the nucleus can, therefore, also be characterized by physical properties, such as compressibility and elasticity $[25,209]$.

Aside from the cytoskeletal coupling, described above, mechanosignaling-inherent post-translational modifications, together with conformational changes in involved molecules, also influence NMT. Lamin A and C, as well as Emerin, are subjected to phosphorylation in response to mechanical cues, such as changes in culture substrate stiffness. Emerin phosphorylation is mediated by Src, which is an FAs component and other kinases such as Abelson murine leukamie viral oncogene homolog 1 (Abl1) [210-212]. Lamin was reported to undergo conformational changes in response to mechanical loading, which might uncover the actual phosphorylation site [213]. This switch- or spring-like behavior has also been shown for $\alpha$-catenin, where mechanical stretching exposes the vinculin binding site of $\alpha$-catenin [214]. The phosphorylation is also a mean to mediate nuclear stiffness and cytosolic-nuclear coupling as well as regulation of YAP/TAZ nuclear abundancy. This indirect regulation of YAP nuclear import might explain why certain Lamin mutations lead to unphysiologically high levels of nuclear YAP [215].

Chromatin structure and dynamics change in response to mechanical stimulation, which is a result of the integration of the above-described signaling processes. Depending on the intensity and duration of the stimulus, the exact type of chromatin change varies [216]. On the short time scale, a reduction in histone methylation and thus heterochromatin leads to a nuclear softening. This means that the genome is protected from damage by decoupling the chromatin from the lamina until adaptation processes, such as cellular reorientation, have been accomplished [217]. Long-term effects include adaptations in methylation patterns and thus epigenetic changes. For example, an increase in H3K27me3 (tri-methylation on Lysine residue 27 of Histone H3) can be detected, which is a marker of heterochromatin and therefore gene downregulation [218]. Conversely, it is unclear how specific genuine mechanosensitive genes are switched on in response to mechanical loading, as so far experimental results are only available from artificial gene constructs [219]. It will thus be of great interest to analyze chromatin structure and dynamics in mechanically stimulated periodontal tissues and to see, which cell-type specific changes in cell behavior and gene expression can be attributed to NMT and related mechanisms.

As stated at the beginning, NMT concepts have, so far, been barely worked out in a periodontal context. However, morphological findings give indirect evidence that cells such as PDLFs also strictly depend on NMT and mechanical nuclear integrity. In one 
such study, an interesting link between ATP levels, ATP receptors and cell shape has been made. According to these findings, extracellular ATP levels are upregulated upon mechanical loading and nuclear deformation. The ATP-associated signaling cascades result in an increase in the receptor activator of nuclear factor kappa-B ligand (RANK-L) expression in PDLFs, which contributes to alveolar bone resorption. The latter process, which is important for periodontal regeneration disease, might, therefore, be in part the macroscopic correlate of periodontal NMT [220].

During tooth eruption, the PDL undergoes dramatic morphological and mechanical changes. The Notch pathway is involved in this process and responds to cell-to-cell and cellto-matrix mechanical cues. Of interest, a transcriptional downstream target of mechanically activated Notch signaling in the PDL is Lamin A, whose Notch signaling-derived increase in expression supports the notion of the involvement of NMT in the periodontium [221].

In a broader medical context, it has been recognized for decades that mutations or changes in nuclear Lamins can have dramatic consequences for the individual. There exists a disease group called laminopathies, which are all related to aberrant functions of Lamins [222]. Envelopathies additionally include the disease of Lamin-associated proteins, such as Emerin or Nesprin [223]. The most relevant medical syndromes are CharcotMarie-Tooth neuropathies, Emery-Dreifuss muscular dystrophies, and Hutchinson-Gilford syndrome, which is also known as Progeria [224-226]. Mechanically exposed tissues, such as the skeletal muscle, cardiomyocytes and tendons, are often affected by these diseases [26].

Two different hypotheses in the current literature discuss the reasons of the deleterious effects of the laminopathies. The gene regulation hypothesis claims that the mutations or defects in LINC components or Lamin/Emerin lead to a severe dysregulation of gene expression [227]. Consequently, cellular physiology is dysregulated, impairing, e.g., stem cell differentiation, and thus resulting in the clinical disease manifestations such as premature aging or muscle weakness [228]. Contrary to this, the structural hypothesis states that nuclear deformation and fragility caused by the mutations is the most important step in the disease process. However, a more holistic "MT-hypothesis" of the pathophysiology should actually incorporate both the gene dysregulation and the mechanobiological consequences, as both are highly interdependent [229]. This can be explained by the above-discussed functions of LINC and Lamins. The mutations associated with envelopathies are, therefore, valuable models for elucidating both general and tissue-specific mechanisms of NMT and its integration into the cellular context. One interesting molecular insight is the fact that certain Lamin mutations increase the abundance of phosphorylated Lamin. This subsequently increases the solubility of the protein and promotes its dissociation from the Lamin meshwork and thus creates nuclear fragility [230,231]. Additionally, direct DNA damage and cell-cycle arrest are associated with these mutations [232]. Reduction in the function of the ATPase associated with diverse cellular activities (AAA+ ATPase) TorsinA or rather its Caenorhabditis elegans ortholog OOC-5 have been shown to rescue the Lamin mutation phenotype [233]. This is interesting, as TorsinA normally enhances NMT through LINC regulation, and mutations in the gene are associated with dystonia and joint contracture $[234,235]$. Thus, in the presence of a mutated and, therefore, dysfunctional Lamin, an additional decrease in TorsinA activity with concomitant reduction in NMT prevents nuclear damage. This means that, under certain circumstances, the decoupling of cytoskeletal and nuclear mechanics is favorable for cell survival [236].

In the context of dentistry, delayed tooth eruption and impairments in dental root integrity as well as micrognathia are also related to Lamin mutations [237]. Patients suffering from Hutchinson-Gilford-Syndrome sometimes show developmental abnormalities in the craniofacial region and suffer from early onset periodontitis [238]. Based on the discussion of NMT, we hypothesize that mechanobiological ECM-cytosol-nucleus networks are in such a manner defective that both embryological processes as well as host-oral microbiome interactions are fundamentally misguided. Testing this hypothesis experimentally will shed light into both the pathophysiological mechanisms of envelopathies and their direct consequences for periodontal tissues. 
Taken together, LINC-dependent NMT, Lamins and nuclear actin are fascinating aspects of an integrated ECM-cytosol-nucleus signaling hub, which orchestrates mechanobiological signaling pathways. Mechanically exposed tissues are particularly dependent on functional coupling of mechanical processes in the cytosol and the nucleus and dysfunctions in this system lead to severe diseases, such as laminopathies.

\section{Porphyromonas gingivalis-Derived Proteases: A “Heavy Load” for the Periodontium}

Having discussed the intrinsic properties and functions of cellular MT and NMT, it is important to have a look at exogenic factors interfering with core mechanobiological processes, which thereby affect periodontal tissue homeostasis. Approximately $20-50 \%$ of the worldwide population is affected by periodontal disease. In particular, periodontitis, an inflammatory condition thought to also support systemic cardiovascular and neurodegenerative diseases, as well as diabetes, leads to deleterious consequences such as loss of teeth [239-241].

The exact pathogenesis of periodontitis, as well as the onset of gingivitis and its shift towards periodontitis, are still incompletely understood. Many different models have been proposed in the last few years that try to incorporate the host's individual susceptibility to periodontal disease, the immune system's response to bacterial invasion, as well as bacterial colonization and virulence factors [242-244]. Above, it is still a matter of debate if bacterial infection is causal for periodontitis and if it really precedes the host's inflammatory response. Apart from that, it is, however, clear that changes in the composition of the bacterial population, the oral bacterial load, and the oral milieu can promote oral dysbiosis. The interindividual presence and variance of different bacterial taxa in the subgingival region under healthy and pathological conditions has, therefore, been intensively studied during the last few years with the help of, e.g., next-generation sequencing (NGS) techniques $[245,246]$.

The subgingival microbiome harbors around 500 different bacterial species, while a few dominate under healthy conditions. Among them, the Gram-positive bacteria Actinomyces naeslundi, Actinomyces meyeri, Rothia aeria, Rothia dentocariosa, Streptococcus sanguinis, Streptococcus oralis, and Streptococcus intermediuas are commonly found in great quantities. The Gram-negative bacterium Fusobacterium nucleatum also contributes to the composition of the normal subgingival plaque $[247,248]$. The above-described aetiologic factors can, however, induce qualitative and quantitative shifts in the oral microbiome, which contribute to periodontal inflammation and subsequently periodontitis. This process mostly functions with an increase in Gram-negative species, especially the bacteria from the so-called "red complex" (originally described by Sigmund Socransky), namely P. gingivalis, Treponema denticola, and Tannerella forsythia, emerge and play a pivotal role in periodontitis. Moreover, a strong association of oral dysbiosis and periodontitis with Aggregatibacter actinomycetemcomitans, Bacteroides spp., Fretibacterium spp., Desulfobulus spp., and Parvimonas micra is reported in the literature $[249,250]$. All of those periodontopathogens lead to a mixed infection of the periodontium and directly contribute to periodontitis via virulence factors or indirectly through immunopathology.

Host factors contributing to periodontitis include various chemokines, pro-inflammatory cytokines, and MMPs, as well as arachidonic acid derivates such as Leukotriene B4 and Prostaglandin E2 [242,251]. Apart from that, the serum-like composition of the crevicular fluid specifically promotes the growth of protease-rich taxa, which stimulate the progression of destructive processes during periodontitis $[252,253]$. These proteases are able to destroy the host's protease inhibitors, such as secretory leukocyte protease inhibitor (SLPI), which further contributes to disease progression [254]. The actual inflammation consequently arises from the complex spatio-temporal interplay of these host factors with the subgingival microbiome and its virulence factors.

Among the many bacteria found in the subgingival region of periodontitis patients, the anaerobe, Gram-negative bacterium, $P$. gingivalis, has been extensively studied and is seen as one major etiologic factor in severe periodontitis [255]. This is the reason 
why its virulence factors and their interaction with MT are currently best understood compared to the above-mentioned pathogens. Therefore, this section focuses on the intricate interrelationship between periodontal MT and P. gingivalis.

Aside from lipopolysaccharides (LPS), the bacterial capsule and fimbriae, $P$. gingivalis, expresses another group of virulence factors, named gingipains [256]. The latter are cysteine proteases with a specificity for arginine (HRgpA and RgpB) or lysine (Kgp) and are either secreted or non-covalently attached to the bacteria. Molecular studies over the past few years have shed light into the exact functions of gingipains during the initiation and promotion of periodontitis. Of interest, these proteases not only induce and modulate pro-inflammatory cytokines but also digest host antibodies and are involved in hemagglutination [257].

From a mechanobiological point of view, gingipain proteases serve as an important example of how external pathogen-derived virulence factors can interfere with MT pathways by either interacting with or destroying its signaling components. Therefore, without generating genuine mechanical signals, $P$. gingivalis metaphorically imposes "heavy loads" on the periodontium via different mechanisms.

Concerning the ECM, gingipains have been shown to degrade various collagen isoforms, including collagen type I, III, IV and V, as well as fibronectin (FN). Interestingly, HRgpA and Kgp possess hemagglutinin domains, which directly guide the proteases to FN [258]. FN degradation generates FN fragments, which can be used as a periodontitis biomarker in the crevicular fluid of patients [258]. These fragments also change the cell's perception of their environment, as integrin-related signaling changes upon the recognition of such fragments [259]. Moreover, the proteases induce the expression of MMPs in tissue-resident fibroblasts, which further promotes catabolic ECM processes [260].

Gingipain-related ECM degradation is, however, not limited to fibrous components, as these proteases, in conjunction with the receptor activator of nuclear factor kappa-B ligand (RANK-L), promote osteoclastogenesis, which is a prerequisite for the destruction of the mineral matrix during alveolar bone resorption in periodontitis [261]. In detail, gingipains induce osteoclast-specific genes, such as cathepsin K, MMP-9, and alkaline phosphatase type 5, in a dose-dependent manner [262]. This happens only in the presence of RANK$\mathrm{L}$, the ligand of the receptor activator of nuclear factor kappa-B (RANK) expressed in osteoclastic progenitor cells. RANK-dependent signaling is a strong inducer of osteoclastic phenotype and osteoclast function. In vivo, RANK-L is secreted by osteoblasts and its action can be perturbed via osteoprotegerin (OPG). The latter functions as a decoy receptor of RANK and is digested by gingipains, who thereby further support osteoclast activation by shifting the RANK-L to OPG ratio towards RANK-L $[263,264]$. Periodontal disease also leads to round PDLF nuclear morphology in vivo, which is accompanied by a reduction in actomyosin contractility and a decrease in OPG synthesis from PDLFs. This additional mechanism might, therefore, contribute to this shift in biochemical signaling and is a direct consequence of disturbed MT (Figure 4) [265].

Intracellularly, RANK downstream signaling activates inflammatory pathways such as nuclear factor kappa B (NF-kB) and nuclear factor of activated T cell c1 (NFATc1) signaling. Subsequently, the expression of $\beta 3$ integrin is upregulated, whereas $\beta 5$ integrin is suppressed [266]. The former is necessary for the building of $\alpha \mathrm{V} \beta 3$, which mediates the adhesion of osteoclasts to the bony matrix and enables the formation of resorption pits for matrix degradation. During this adhesion process, FAK and paxillin phosphorylation and activity increases, indicating active mechanotransduction between focal adhesion structures and the cytoskeleton. Taken together, gingipains promote MT cascades in the context of alveolar bone resorption by both facilitating osteoclast differentiation and integrin-dependent resorption pit formation [261]. It remains to be elucidated how the presence of gingipains exactly augments the function of RANK-L. 


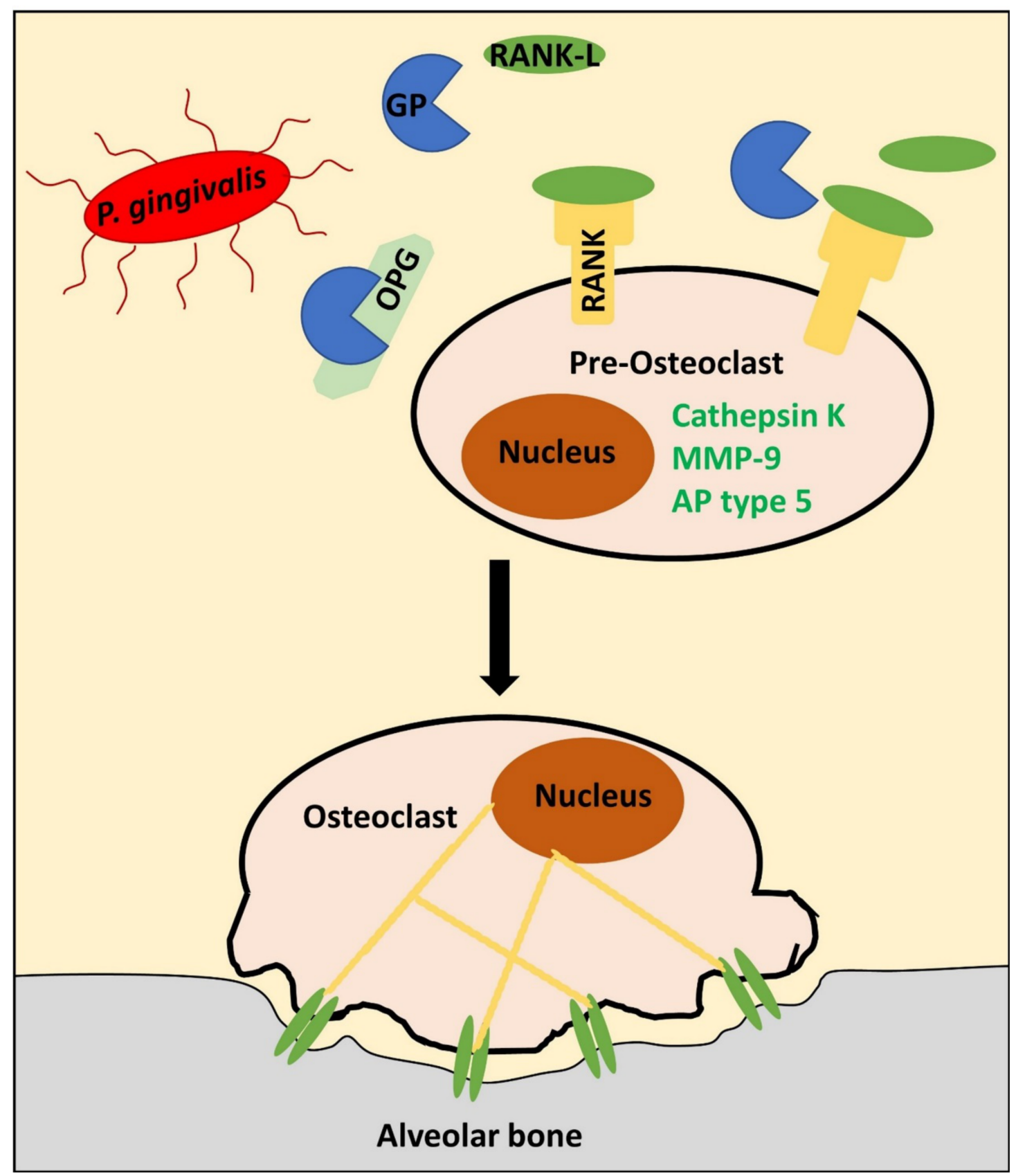

Figure 4. P. gingivalis induces alveolar bone resorption through gingipain proteases. Secreted proteases, so-called gingipains (GPs), from the microbe Porphyromonas gingivalis (P. gingivalis) interact with the receptor activator of nuclear factor kappa-B ligand (RANK-L), osteoprotegerin (OPG), and receptor activator of nuclear factor kappa-B (RANK) system of osteocytes and osteoclasts. In the presence of GPs, OPG is degraded, which favors RANK-L binding to RANK. Consequently, osteoclasts differentiate out of pre-osteoclasts through upregulation of Cathepsin K, matrix metalloproteinase 9 (MMP-9), and alkaline phosphatase type 5 (AP). Subsequently, osteoclasts can bind to the alveolar bone via $\alpha \mathrm{V} \beta 3$ integrins (green, dimeric sticks), which regulate actin cytoskeletal tension (yellow lines). Altogether, these processes favor alveolar bone resorption within resorption pits. Details are given in the main text.

Findings from other studies suggest that certain integrins are not only indirectly targeted by gingipains through transcriptional regulation, but directly cleaved by the proteases. Hydrolysis of $\beta 1, \alpha 2$ and $\alpha 5$ integrin is repeatedly reported in the literature. This leads to a loss of cell adhesions, as described for GKs, GFs, and osteoblasts. When a cell loses its contacts with neighboring cells or the ECM, cytoskeletal changes induce a rounding of the cell culminating in a specific form of apoptosis known as anoikis $[267,268]$. $\beta 1$ integrin 
degradation was also shown to result in a remarkable decrease in cytoplasmic RhoA activity but not RhoA abundancy in an osteoblast cell culture system. As RhoA is an important regulator of actin cytoskeletal tension, the gingipain-induced events consequently led to F-actin disruption and, therefore, cell shrinkage or apoptosis. Overexpression of $\beta 1$ integrin or gingipain inhibition could rescue this phenotype, sustaining the conclusion of a direct relationship between $\beta 1$ degradation, cellular MT, and cell death. Apart from the above-discussed activation of osteoclast activity, P. gingivalis can further contribute to apoptotic bone loss in periodontitis [269].

Beneath extracellular catabolic processes, $P$. gingivalis is known to directly invade cells such as GKs. Therefore, gingipains can also trigger intracellular processes related to MT [270]. Kinane and colleagues reported that cytosolically released gingipains, especially the lysine-specific form, hydrolyze actin and provoke the collapse of the cytoskeleton and, consequently, apoptosis. This proves that the actin cytoskeleton, as the signaling hub of both outside-in and inside-out MT, is vital for cells. Moreover, the bacterial proteases downregulate caspase 3 activity, making it plausible that cell death occurs independently of caspases [271]. A similar observation has been made for endothelial cells [272].

AJ-dependent cell-to-cell adhesion is also affected by $P$. gingivalis proteases. Generally, E-Cad-mediated cell contacts, as well as tight junctions and desmosomes, are involved in epithelial barrier function by physically defining different physiological milieus and polarized cellular structures, such as apical-basal polarity. In GKs, this function is particularly important to protect other periodontal structures from invasion of the oral microbiome. GK and GF microtissue 3D models have clearly demonstrated that $P$. gingivalis invades the connective tissue of the gingiva by bypassing the epithelial barrier. This occurs alongide cytoskeletal changes and disruption of adhesion structures, thereby feeding back on MT processes [273]. E-Cad is also directly cleaved by Kgp. Loss of the extracellular cadherin domain disrupts the epithelial integrity of the oral mucosa [257]. Porphyromonas LPS additionally promotes transcriptional downregulation of E-Cad and thereby enhances gingival epithelial permeability [274]. Unsurprisingly, these processes go along with inflammatory responses, as can be seen from increases in reactive oxygen species (ROS) and tumor necrosis factor $\alpha$ (TNF- $\alpha$ ) levels. Together with the recruitment of immune cells, this substantially contributes to periodontal destruction in periodontitis [105]. This subject is also relevant regarding dental implants. As was shown for titanium-zirconium alloys, gingipain-mediated E-Cad degradation prevents GK adhesion to the implants, which hinders proper material incorporation into the dental alveolus [275].

In the context of oral carcinogenesis, the interplay of E-Cad and P. gingivalis, as well as other periodontal pathogens, is also relevant, although the direct involvement of the gingipain proteases has not, so far, been shown. However, GK cell culture models clearly show that the pathogens promote epithelial to mesenchymal transition (EMT), a core step in carcinogenesis, by the downregulation of E-Cad. This accounts for the concomitant increase in neural (N)-Cad, vimentin, the transcription factor snail, as well as MMP-2, which are markers of a fibroblastoid phenotype and accordingly characterize the process of a phenotypic switch seen in malignant transformation. These observations are paralleled by an increase in the migratory ability of the GKs and hint at a potential invasive phenotype [276-278]. It is tempting to speculate that these phenomena at least in part depend on gingipain-mediated proteolytic processes of surface adhesion receptors. OSCC invasion is also promoted by an increase in MMP-9 in response to gingipain expression in the host. MMP-9 related ECM degradation inevitably feeds back to MT pathways and, hence, cell behavior.

From a regenerative perspective, microbial colonization of the oral cavity can also be protective. The germ Akkermansia muciniphilia was recently described to counteract proteaserelated damage of $P$. gingivalis by both sustaining an anti-inflammatory milieu through interleukin 10 (IL-10) and by enhancing the transcription of E-Cad and $\beta 1$-integrin. Probiotics are, therefore, a tempting option in the treatment of bacteria-induced periodontitis [279]. 
Taken together, the discussion of $P$. gingivalis- and gingipain-related changes in mechanobiologically relevant signaling axes underscores the complex interplay of cells and their ECM and the diverse mechanisms of action occurring during periodontitis.

\section{May the Force Be with You: MT and Its Implications for Periodontal Regeneration}

In the context of MT, the previous four sections discussed the molecular principles of cellular mechanoperception and mechanotransmission, which are perspectively mandatory for any kind of force/MT-related periodontal regeneration approach. As can be seen by the enormous number of proteins involved and the extensive signaling crosstalk, it is evident that artificially modulating MT pathways can lead to unexpected results $[13,280]$. It is therefore of great importance to note that broader basic research is needed to elucidate cell-type specific and spatiotemporal aspects of MT, its exact regulation during the lifespan of an individual, and the dysregulation in pathological processes [281].

So far, there exists no therapeutic application in the context of oral regeneration and health that directly addresses MT pathways in order to enhance treatment efficiency. Nonetheless, it is worth discussing selected experimental strategies and rather theoretical concepts, which could in the future be used to support regeneration or to mitigate periodontal disease processes in patients by means of mechanobiological principles.

Regarding regenerative medicine, the development of innovative, mechano-active biomaterials plays an increasingly important role in the field of bioengineering with the ultimate goal to replace or imitate natural periodontal tissue environments $[282,283]$. Thus, ECM-mimetic, biocompatible substrates, such as hydrogels, are designed to initiate or maintain cell differentiation, proliferation or migration and should ideally lead to a restitutio ad integrum [284]. The increasing notion of the intricate role of periodontal ECM, adhesion structures, as well as the cyto- and nucleoskeleton as biochemical and biomechanical signaling platforms that govern cell behavior, makes it tempting to speculate that the proper integration of inductive and, therefore, cell-instructive stimulatory signals will allow researchers and clinicians to offer personalized therapeutic options to their patients in the future.

However, mechanobiological studies are often conducted as in vitro experiments with only a single cell type or with isolated tissue samples $[146,285,286]$. This leads to various difficulties in interpreting the results and in transferring them to the in vivo situation. It was shown by different groups that cell behavior is directly connected to their environment, meaning that culturing cells in 2D or 3D substrates makes an enormous difference [287]. Two-dimensional substrates, such as the classical polystyrene culture dishes, are, from a mechanobiological point of view, relatively simple, as they are easily characterized by stiffness (Young's modulus), the material's physiochemical properties (composition), and ligand density in the case of biofunctionalized materials [288,289]. Contrary to that, 3D materials offer adhesion points in all three dimensions and further show differences in porosity, microarchitecture, and local rigidity. This is the reason that processes, such as cell migration, differ between 2D and 3D substrates [290]. A higher substrate porosity also favors the migratory phenotype, which is especially important in studying pathologies like OSCC [291,292]. Above, interactions of different cell types and the role of the immune system and vasculature are seldomly addressed in mechanobiological studies [293-295]. These obstacles must be considered when discussing the application of MT principles regarding the design of, e.g., innovative dental implants for periodontal regeneration [296].

Considering integrin-dependent FAs, their roles in fibrillogenesis of ECM molecules, e.g., collagen or FN, wound healing, and osteocyte differentiation are particularly interesting for regenerative approaches. Consequently, an optimal intervention strategy should enable (i) tissue-specific ECM synthesis in response to integrin signaling, (ii) support and sustain the proliferation, differentiation, and migration of embedded and neighboring periodontal cells by also taking into account their developmental stage, (iii) inhibit matrix degradation, and (iv) sustain an overall anti-inflammatory oral milieu. Exemplarily, in the case of a periodontal defect or alveolar bone loss, a regenerative approach could either 
stimulate tissue-inherent stem cells in situ or make use of biomaterial-based strategies. The latter are specifically interesting, as such generally polymer-based materials can stimulate cells and guide their behavior by making use of biochemical and biomechanical signals. As above, (stem) cells can be directly incorporated into scaffold matrixes via bioprinting and transferred to the patient [297]. Besides, bioprinting offers the opportunity for tailored periodontal defect coverage in case of trauma or surgery. By considering all of these properties, such materials are sometimes designated to be "cell-instructive", meaning that they harbor all necessary biochemical and biophysical information to properly integrate cells into the site of defect $[298,299]$.

Guo and colleagues recently presented a modular platform of biodegradable crosslinkers for hydrogel engineering that can be adapted to tissue-specific needs. This crosslinker can be modified with small peptides or naturally occurring ECM components to specifically stimulate receptors on target cells. The amino acid motif arginine-glycine-aspartate (RGD) is important to bind integrins and can easily be incorporated into such synthetic hydrogels to stimulate integrin receptors and, thereby, FAs-linked MT pathways [300].

In order to selectively induce osteocyte differentiation from mesenchymal stem cells in the periodontium, such a stimulus alone is, however, not sufficient [301,302]. Additional spatiotemporal factors as well as biochemical factors need to be included [303]. Of note, biocompatible materials can be used as vehicles for drug delivery, which can for example be antibiotics or differentiation factors. In this context, spatiotemporal control of drug release is of enormous importance in order to induce and sustain the intended tissue phenotype by simultaneously avoiding unwanted off-target effects, such as systemic adverse effects, cellular toxicity, inflammation or the induction of malignant processes. Therefore, the cautious selection of drug delivering biomaterials under the consideration of tissue-specific conditions is obligatory [304]. In the periodontal context, this means that such systems should promote, e.g., bone or PDL regeneration from stem cells in the case of periodontitis-associated bone loss or mitigate inflammation in periodontitis through antimicrobial agents.

Generally, implantable drug delivery devices, such as exemplified by the belowmentioned injectable hydrogel, can be divided into passive polymeric implants or dynamic/active polymeric implants. The latter are mostly electronically regulated devices, such as pump type implants (e.g., for diabetes therapy) and are not discussed further here. The former can additionally be subdivided into non-biodegradable and biodegradable implants [304,305].

Non-Biodegradable implants are composed of synthetic polymers that are biocompatible but cannot be degraded within the body. Generally, these kinds of implants need to be removed after they have served their purpose. Silicones, poly(urethanes), and poly(acrylates) are commonly used for such implants. In the case of monolithic implants, the drug is homogeneously dispersed within the polymer, whereas reservoir-type implants contain a compact drug core with some sort of polymer membrane around it that controls diffusion and the release of the pharmacological compound [306-309].

Biodegradable polymers, such as poly(caprolactone), poly(lactic acid), or poly(lacticco-glycolic acid) or naturally occurring poylmers, such as collagen or fibrin, can be degraded within the body. The latter process can be achieved via simple hydrolysis, enzyme degradation, redox reactions, or simply physical deterioration. The great advantage of biodegradable polymers is the fact that they can remain within the body, i.e., there is no need for removal [310-313].

Mechanistically, drug release in all these systems is either possible through controlled swelling (e.g., in hydrogels), osmotic pumping, or passive diffusion. Moreover, chemical triggers of drug release include $\mathrm{pH}$-responsive sidechains or redox switches. Mechanically induced drug release through ultrasound, magnetic or electric fields, and temperature changes is also under investigation and these stimuli could work synergistically with tissueinherent MT pathways. Matrix degradation is also possible in the case of biodegradable 
polymers, where either the polymer itself or biodegradable crosslinkers are digested and the drug is released thereby [304,314].

When considering drug delivery into a site of disease, it needs to be considered that the local micromilieu is different from physiological conditions. This means that different parameters, such as hypoxia, reactive oxygen species (ROS), blood vessel expansion, temperature, and acidity, need to be considered [314]. As discussed above for periodontitis in Section 5, the infection with a pathogen such as P. gingivalis can lead to the presence of proteases, which are normally not found within the human body.

For example, minimally invasive alveolar bone regeneration with injectable hydrogels offers a high degree of spatial and temporal control and are suitable for additional drug delivery. A recently presented thermosensitive hydrogel, which gelatinizes upon heating to $37^{\circ} \mathrm{C}$, made from $\beta$-glycerol phosphate, chitosan and collagen has been shown to support PDLCs growth. By adding osteo-inductive drug compounds, such an approach combines several stimulatory principles, thereby enhancing the bone regenerative capacity of the material [315]. Another recently published article presents a cellulose/ $\mathrm{k}$-carrageenan oligosaccharid-based hydrogel with incorporated antimicrobial agents, which showed strong antibacterial activities in a periodontitis model [316]. As there is a vastly growing amount of such applications, the interested reader is referred to some recent, innovate research work, which cannot be discussed in detail here [317-321].

Synthetic integrin ligands, among them some that contain mutated RGD motifs, have also been shown to change MT in a mouse model [322,323]. It is, therefore, an interesting perspective to search for integrin-subtype specific ligands, which can selectively stimulate or inhibit integrins on different periodontal cell types and under different conditions, such as during periodontal wound healing or periodontitis. By exemplarily stimulating $\alpha 5 \beta 1$ integrin on PDLFs in the right context, collagen or FN fibrillogenesis could be enhanced to strengthen dentoalveolar integrity via MT pathways [324]. Khorolsuren, as well as Matsugami and colleagues, presented a study with PDLCs and such synthetic integrin ligands. Cell adhesion, as well as migration and osteogenic differentiation of the PDLCs, was promoted by different cyclic integrin-ligand mimics, thus proving the suitability of the concept $[325,326]$.

Low-intensity pulsed ultrasound (LIPUS) is a method to mechanically stimulate tissues via ultrasound in the range of $1-4 \mathrm{MHz}$ and $0.01-90 \mathrm{~mW} / \mathrm{cm}^{2}$. LIPUS was shown to enhance ECM synthesis and regeneration and to be a potent stimulator of osteogenic differentiation and is used, e.g., in the context of fracture healing [327-329]. Bone mass and maturation is also increased upon LIPUS treatment in different animal models, and it was shown that osteocytes in particular respond to LIPUS treatment [330,331]. Transcriptional analysis in a mouse cell line revealed that approximately 180 genes from clusters related to transcription, cellular secretion and immunity are responsive to the mechanical stimulation [331].

Several studies have investigated the role of LIPUS in the periodontal context and it is a tempting mean to enhance oral regenerative approaches. Upon stimulation of PDLCs via LIPUS, osteogenesis in the alveolar region and ECM regeneration was observed [332]. Although not directly shown, it is conceivable that these adaptation processes are mediated through MT signaling pathways [333]. The endoplasmic reticulum unfolded protein response (ER-UPR) as well as autophagic pathways, as detected by an increase in LC3 and Beclin-1 expression, are molecularly involved in the regulation of PDLCs behavior under inflammatory conditions [328,334]. LIPUS also reduces oxidative stress [335] and downregulates the expression of pro-inflammatory cytokines such as IL-8 and inhibits the NF- $\mathrm{KB}$ signaling axis [336]. This is of clinical interest, since inflammation, as observed during periodontitis, normally inhibits osteogenesis. It is, however, not clear how the mechanical ultrasound waves are transmitted to induce these cellular signaling responses. A recent study on dento-alveolar integrity during orthodontic force application in normal and diabetic rats could show that LIPUS leads to a significant increase in predentin and cementum thickness in all study groups. As above, the number of odontoblasts, as well as 
periodontal ligament cells, increased. On the tension side, bone remodeling was enhanced, whereas the number of resorption pits increased on the compression side [337]. LIPUS also augments bone formation in the context of osseointegration of dental implants in mice [338]. As the molecular mode of action of LIPUS is still insufficiently understood, it is a further research challenge to determine if and to what extent the herein discussed MT pathways are involved in the above-described cellular responses to the treatment. It is conceivable to assume that different periodontal regenerative approaches could benefit from additional LIPUS application in order to increase therapeutic effects.

Receding gums are, likewise, a relatively common problem and, therefore, gingival regeneration is of high clinical interest [339]. Stratified epithelia, such as the gingival epithelium, show a complex pattern of differentiation markers in an apical-basal direction, such as different keratin isoforms or involucrin in the gingival epithelium [340,341]. In vitro experiments with electrospun, gelatin-based matrices with a specific elasticity of $3.2 \mathrm{kPa}$ proved to promote proper gingival morphogenesis, which was independent of a co-culture with mesenchymal cells. Molecularly, this process depends on the ERK1/2- $\beta 1$-integrin signaling axis, underlining the role of MT-triggering basal integrins for gingival epithelial tissue morphogenesis [342-344]. These promising results show that addressing MT through integrins by choosing a biocompatible material with the right stiffness is a cornerstone for tissue engineering and prospective regeneration of periodontal tissues, such as the gingiva.

The modulation of AJs-related signaling is important in the context of mucosal barrier function and OSCC suppression. As discussed in Section 1, Cads also sustain periodontal ECM and induce collagen 1 and elastin synthesis [345]. Cad-dependent signaling can be addressed and mimicked by the same principles as discussed above for integrins. Additionally, we hypothesize that the cleavage sites of gingipains within the E-Cad amino acid sequence could be an interesting target to be addressed by mutational studies. It is tempting to mutate the sequence of E-Cad, rendering it insensitive to gingipain digestion. Cell culture experiments and animal studies would need to support the idea of reducing destructive and inflammatory consequences of gingipains and the normalization of AJsdependent MT by this approach. If successful, patients suffering from severe periodontitis could then be treated with autologous epithelial stem cells, expressing the protease-resistant E-Cad under the control of a constitutively active promotor in the long run [346,347]. Thus, in combination with pro-epitheliogenic biomaterials, gingival integrity could potentially be increased while simultaneously decreasing the chance of periodontitis associated OSCC development. This hypothesis is, of course, highly speculative, but should be considered by addressing it experimentally.

The indirect modulation of E-Cad expression and the activity of inflammatory cellular pathways in the periodontium is possible via vitamin D administration. Oh and colleagues showed that GKs respond to the vitamin by upregulating E-Cad and downregulation of NF-KB and MMPs. This offers the possibility to change the expression pattern of mechanobiologically relevant proteins by the simple administration of a widely available, single biochemical molecule [348]. Similarly, junctional epithelial function in a model of peri-implantitis was enhanced by application of a low molecular weight JNK inhibitor. Mechanistically, this promoted E-Cad upregulation and F-actin regulation [349]. Both examples show that biochemical modulation, apart from actual mechanical stimulation, is a promising alternative to influence MT through changing the expression patterns of its molecular constituents.

The actin cytoskeleton as the central hub of AJs, FAs, and NMT signaling is another interesting target to be addressed by intervention strategies for periodontal tissue regeneration $[350,351]$. The difference in addressing AJs or FAs on the cellular surface is that RhoA, Rac1, Cdc42 or ROCK cannot be modulated via direct interaction with a biomaterial. As these are all cytoplasmic proteins, low molecular weight pharmacological compounds or RNA-based strategies are promising candidates. A recently published proofof-principle study addressed RhoA transcription via a drug-releasing polymer containing a RhoA-siRNA embedded in a nanocarrier [352]. Efficient drug delivery and subsequent 
downregulation of RhoA was shown, and this principle could also be used in periodontal tissues to modulate cytoskeletal stiffness during different phases of regeneration.

The well-known RhoA activator Calpeptin is another candidate to influence cytoskeletal MT processes. Contrary to siRNA, Calpeptin enhances the activity of RhoA and is able to increase actomyosin contractility and thus cell stiffness [353,354]. This is especially important in the context of alveolar bone osteogenesis, where increased ECM and cytoskeletal stiffness favors osteogenic differentiation patterns [355].

Furthermore, cell penetrating peptides (CPPs) offer the possibility to deliver cargos to the cell's interior [356]. CPPs are covalently or non-covalently linked to small drugs, peptides, proteins, or nucleic acids, which are thereby delivered to the cell [357]. Thus, the small GTPases or modulators of their activity could be directly transported to the cell via CPPs. This regenerative strategy would be suitable for local and targeted therapy of periodontal defects without implanting a foreign material into the patient. First clinical trials with the application of CPPs in humans have been reported and have shown no severe toxic effects so far $[358,359]$. Therefore, this technology may be broadly available in the future. The applicability and effectiveness in oral tissues, however, remains to be determined.

YAP and TAZ have been implicated in many in the periodontium, including myofibroblast differentiation, osteogenesis, and oral mechanobiological carcinogenesis processes. Addressing these Hippo components pharmacologically is not a new concept, as their role in many different human cancers makes them a promising target to slow down disease progression or hopefully to suppresses features of malignant transformed tumor cells $[164,360,361]$. There exist different mechanisms of how to prevent YAP nuclear entry and thus induction of proliferation and EMT.

Verteporfin is a photosensitizing pharmakon, which is already in clinical use in ophthalmology [362]. Verteporfin enhances cytoplasmic 14-3-3 $\sigma$, which in turn binds YAP and prevents its translocation into the nucleus [363]. Regarding the stiff, desmoplastic stroma in OSCC, Verteporfin-enhanced treatment strategies could help to reduce the stiffness-susceptible and thus MT-sensitive proliferative capacity and migratory potential of malignant cells.

Nuciferin is an alkaloid compound from lotus plants and was recently shown to sensitize cancer cells to chemotherapeutic agents [364]. Mechanistically, Nuciferin promotes adenosine monophosphate-activated protein kinase (AMPK)-related YAP phosphorylation on Ser127 and consequently cytoplasmic trapping of the co-transcriptional activator. It will, therefore, be interesting to see if similar principles apply to OSCC.

Sophisticated, innovative biomaterials have also been evaluated in the context of mechanobiology and YAP. As regenerative stem cell therapies have great therapeutic potential, it is still an active field of research, if such approaches in mechanically exposed tissues such as joints or the periodontium benefit from concomitant mechanical stimulation of the transplanted cells. The so-called "loading history" of the cells might, therefore, play an important role in regenerative stem cell therapies and underscore the pivotal role of MT [365-367]. To study these potential influences, Kojima and co-workers presented a micropatterned, polymer-based micropillar research platform that enables the study of FAK and YAP activity in response to mechanical loading. As a special feature, the skillful combination of two biocompatible polymers guarantees highly specific cell adhesion on the top surfaces of the micro-posts. The simultaneous integration of magnetic nanoparticles into the polymer additionally offers the possibility to magnetically actuate the pillars to exert shear forces on the cells [368]. The first biological data from human mesenchymal stem cells show that early adaptation of cells to cyclic mechanical loading includes the recruitment of phosphorylated and, thus, active FAK to the cellular periphery and the translocation of YAP into the nucleus [369], thereby potentially supporting regeneration-relevant cell proliferation or differentiation. It will be interesting to apply such mechanobiological test platforms to periodontal cells and even to try to develop the principle further to actual mechano-active, implantable biomaterials. 
Concerning innovative biomaterials that have the potential to regulate YAP/TAZ activity, the technique of guided bone regeneration (GBR) offers great regenerative potentials. In the GBR of periodontal tissues, biocompatible materials are used as spacers between connective tissue and the alveolar bone in order to prevent overgrowth of gingival soft tissues by simultaneously allowing the regeneration of bone. This is especially important in periodontitis, where alveolar bone loss and hence the ensuing loss of teeth is a major problem [370,371].

Different materials and strategies for periodontal GBR have been proposed in recent years. Porrelli and colleagues presented an electrospun polycaprolactone-based biomaterial, which was functionalized with lactose-modified chitosan and antimicrobial silver nanoparticles. They could show that osteoblast adhesion and proliferation was significantly enhanced with this regenerative approach. As above, the incorporation of the antibacterial nanoparticles prevented biofilm formation of bacteria such as Staphylococcus aureus and Pseudomonas aeruginosa. Cytotoxic effects were not reported [372]. Another study by Balbinot and co-workers used a polybutylene adipate terephthalate biodegradable membrane, which was enhanced with niobium-containing bioactive glasses. Again, the material was permissive for osteogenesis [373]. GBR can also be enhanced via incorporation of pharmacologically active compounds. Recently, a thermosensitive Pluronic F127/poly(lactic acid) formulation with zoledronic acid nanoparticles was reported, which lead to lamellar bone formation in a rabbit model, while tissue fibrosis was inhibited [374]. A similar study with a silicon dioxide nanoparticle-loaded, non-resorbable membrane that was either functionalized with zinc or doxycycline revealed induction of osteogenic marker genes in cell culture experiments, while simultaneously suppressing RANK-L expression $[375,376]$. Clinical data from a 5-year period of patients treated with GBR materials also revealed promising outcomes [377].

New generations of GBR materials even offer in situ mineralization and thus stiffening of membranes, which is important in the context of cellular mechanosensing. According to $\mathrm{Li}$ et al., the modification of a Bio-Guide ${ }^{\circledR}$ membrane with polyacrylic acid led to self-mineralization of the material after transplantation in a murine bone defect model. Additionally, osteogenesis from mesenchymal stem cells was induced. Molecularly, a clear nuclear accumulation of both YAP and TAZ was registered, which shows both the decisive role of both proteins for osteogenesis and the applicability of such dynamic materials for regenerative purposes [378]. The complex histological composition of the periodontium will, therefore, be an optimal candidate to apply such self-regulating biomaterials, which is especially important regarding tissue-tissue interfaces [148,379].

One major challenge in the application of GBR remains the fact that cells behave differently on 2D or 3D substrates, as already mentioned in the beginning of this section. As above, the actual "cell-guidance", i.e., the induction of the desired cell behavior, is strongly connected to the material's properties and topography. Therefore, biophysical and biochemical cues of biomaterials need to be carefully selected in order to enable the clinical success of periodontal regeneration via GBR and other methods. Matrix stiffness, pore size and porosity, the nanotopography, and the stress-relaxation behavior need to be considered from a biomechanical point of view. From the biochemical perspective, the incorporation of growth factors, cytokines, small bioactive molecules, ions, genetic information or other compounds relevant to cellular physiology is noteworthy [380-383].

In 2D systems, different materials have been tested for their capacity to guide cell behavior. Generally, guided adhesion, migration, spreading, proliferation, differentiation, and stemness maintenance can be distinguished. Adhesion is established via material composition and stiffness. Migration results from compositional gradients, which induce chemotaxis, or mechanical stimuli, which induce mechanotaxis. Cell spreading is the consequence of positive charges or a moderate material hydrophobicity. Compositional motifs are able to stimulate proliferation, while a tissue-like stiffness induces differentiation. In general, soft substrates support stemness maintenance [384]. For instance, graphene-based materials induce osteogenic differentiation of hMSCs [385]. As above, they sustain cell 
adhesion, spreading, and proliferation. Boron nitride, Tungsten disulfide or molybdenum disulfide materials are other examples for such cell-instructive 2D materials [386]. The exact molecular interplay with the herein presented MT pathways, however, remains to be elucidated.

Studies on 3D-directed cell migration on biocompatible polymers offer great potential to further study cell-guidance. Compared to 2D materials, the third dimensions offer the possibility to construct a certain nanotopography, which feeds back on cellular physiology. For instance, photopolymers are used in fabrication techniques known as laser ablation or direct laser writing (multiphoton lithography). This enables researchers to generate a broad variety of biomaterials with complex $3 \mathrm{D}$ nanotopographies. Other possibilities for scaffold preparation include freeze-drying, electrospinning, or 3D printing [387]. Consequently, cell behavior changes upon contact with the material in response to the geometry and physical properties. Exemplarily, Cheng and colleagues observed cell migration parallel to ridges, also known as contact guidance, on a material fabricated with direct laser writing. Therefore, this technique offers the possibility for 3D spatial control of cell behavior [388]. Controlled cell-alignment, which is important for tissue organization, especially in complex composite organs such as the periodontium, is also achievable on such substrates [387]. By using materials with varying matrix stiffnesses, an effect called durotaxis can be observed, meaning that cells migrate from softer to stiffer regions. The incorporation of such a "strain field" in combination with the material's nanotopography enables even more control on cell behavior and guidance [389]. The exact molecular signaling events that occur during these processes are so far only incompletely understood. Of interest, laser-guided direct writing is not limited to the fabrication process of the biomaterial, but optical forces can be directly used to deposit cells. Thus, cell-to-cell distances and the spatial control of cell-to-cell interaction as well as the interplay of different cell types can be experimentally manipulated [390]. Thus, GBR in combination with the above-discussed properties of 2D and $3 \mathrm{D}$ materials in the context of cell guidance in the periodontium harbor great potential to improve oral regenerative therapy approaches.

NMT is less well understood in the context of periodontal health, pathology, and regeneration. Further molecular studies on the regulation of nuclear mechanics and its interplay with other mechanobiological players will shed light into its mechanisms of regulation. In turn, the elucidation of such interplay-governing mechanisms and their underlying molecules opens the road for the discovery of potential targets for therapeutic approaches. As Lamins and Emerin are subjected to phosphorylation, it is tempting to speculate that pharmacologic inhibition of kinases, for instance with currently available tyrosine kinase inhibitors (TKI), will influence NMT and related signaling processes [391]. Screening for mechanobiological consequences of TKI application could clarify regulatory principles of NMT. This is also interesting regarding the many TKIs that are currently applied in cancer therapy [392,393].

To summarize, the discussed principles of therapeutically addressing MT in the context of periodontal homeostasis and regeneration have again demonstrated the importance and complexity of the interconnectedness of MT and NMT, thereby rendering it a fascinating issue of basic and translational research to achieve and/or improve oral tissue regeneration. Apart from growth factors, endocrine stimuli, and the general extracellular milieu, it is of great importance to consider the various mechanisms of actions of MTinherent mechanobiological signaling and its related processes. In the future, MT will be an indispensable cornerstone of research with respect to oral regenerative medicine.

\section{Conclusions}

MT-immanent mechanobiological signals are key determinants of cell behavior and tissue adaptation to the external cell and tissue environment. The interplay of molecular mechanosensors and mechanotransducers is complex and represents the tight interrelationship between different cellular compartments and signaling hubs. FAs, AJs, YAP/TAZ, the cytoskeleton, LINC, and the nucleoskeleton only represent a small subset of cellular players 
involved in MT and NMT but reveal important principles of how the cell percepts and integrates biophysical mechanical information. Periodontal tissues are of special interest to MT research and are a paradigm of how the above-discussed signaling networks, cascades, and molecules govern tissue development, homeostasis and regeneration, cell proliferation, differentiation, and pathologic processes, such as periodontitis or OSCC. By further elucidating the cell-type specific and spatiotemporal fine-tuning of mechanobiological processes, the future translation of these principles into clinical applications will prove to be a strong tool in the field of oral regenerative medicine.

Author Contributions: M.P.D. contributed to conception, design, acquisition, drafted and critically revised the manuscript; A.H., X.W. and I.R. contributed to acquisition and critically revised the manuscript; T.S. contributed to design and critically revised the manuscript; P.T. contributed to conception, design, acquisition, drafted and critically revised the manuscript. All authors gave their final approval and agreed to be accountable for all aspects of the work. All authors have read and agreed to the published version of the manuscript.

Funding: Parts of the mechanobiological studies integrated in this review were funded by the Deutsche Forschungsgemeinschaft (DFG) grant references TO 198/15-1, RU 489/29-1 and TO 198/23-1, RO 2511/11-1, project number: 437439888.

Conflicts of Interest: The authors declare no conflict of interest.

\section{References}

1. Vogel, V. Unraveling the mechanobiology of extracellular matrix. Annu. Rev. Physiol. 2018, 80, 353-387. [CrossRef] [PubMed]

2. Shi, A.; Hillege, M.M.; Wüst, R.C.; Wu, G.; Jaspers, R.T. Synergistic short-term and long-term effects of TGF- $\beta 1$ and 3 on collagen production in differentiating myoblasts. Biochem. Biophys. Res. Commun. 2021, 547, 176-182. [CrossRef] [PubMed]

3. Petrescu, N.B.; Jurj, A.; Sorițău, O.; Lucaciu, O.P.; Dirzu, N.; Raduly, L.; Berindan-Neagoe, I.; Cenariu, M.; Boșca, B.A.; Campian, R.S. Cannabidiol and Vitamin D3 Impact on Osteogenic Differentiation of Human Dental Mesenchymal Stem Cells. Medicina 2020, 56, 607. [CrossRef] [PubMed]

4. Guo, S.; Debbi, L.; Zohar, B.; Samuel, R.; Arzi, R.S.; Fried, A.I.; Carmon, T.; Shevach, D.; Redenski, I.; Schlachet, I. Stimulating Extracellular Vesicles Production from Engineered Tissues by Mechanical Forces. Nano Lett. 2021, 21, 2497-2504. [CrossRef]

5. Cicciù, M.; Fiorillo, L.; Cervino, G.; Habal, M.B. BMP Application as Grafting Materials for Bone Regeneration in the Craniofacial Surgery: Current Application and Future Directions by an RCT Analysis. J. Craniofac. Surg. 2020, 32, 787-793. [CrossRef] [PubMed]

6. Chang, H.-T.; Heuer, R.A.; Oleksijew, A.M.; Coots, K.S.; Roque, C.B.; Nella, K.T.; McGuire, T.L.; Matsuoka, A.J. An engineered three-dimensional stem cell niche in the inner ear by applying a nanofibrillar cellulose hydrogel with a sustained-release neurotrophic factor delivery system. Acta Biomater. 2020, 108, 111-127. [CrossRef] [PubMed]

7. Danish, A.; Gedschold, R.; Hinz, S.; Schiedel, A.C.; Thimm, D.; Bedner, P.; Steinhäuser, C.; Müller, C.E. A Cellular Assay for the Identification and Characterization of Connexin Gap Junction Modulators. Int. J. Mol. Sci. 2021, 22, 1417. [CrossRef]

8. Imafuku, K.; Kamaguchi, M.; Natsuga, K.; Nakamura, H.; Shimizu, H.; Iwata, H. Zonula occludens-1 demonstrates a unique appearance in buccal mucosa over several layers. Cell Tissue Res. 2021, 1-12. [CrossRef]

9. Patil, R.; Kale, A.D.; Mane, D.R.; Patil, D. Isolation, culture and characterization of primary cell lines of human buccal mucosal fibroblasts: A combination of explant enzamytic technique. J. Oral Maxillofac. Pathol. JOMFP 2020, 24, 68. [CrossRef]

10. Fagalde, P.; Reininger, D. Oral tissues regeneration using intraoral mesenchymal stem cells. J. Clin. Exp. Dent. 2021, 13, e268. [CrossRef]

11. Chukkapalli, S.S.; Lele, T.P. Periodontal cell mechanotransduction. Open Biol. 2018, 8, 180053. [CrossRef]

12. Kechagia, J.Z.; Ivaska, J.; Roca-Cusachs, P. Integrins as biomechanical sensors of the microenvironment. Nat. Rev. Mol. Cell Biol. 2019, 20, 457-473. [CrossRef]

13. Zuidema, A.; Wang, W.; Sonnenberg, A. Crosstalk between Cell Adhesion Complexes in Regulation of Mechanotransduction. BioEssays 2020, 42, 2000119. [CrossRef]

14. Naqvi, S.M.; McNamara, L.M. Stem Cell Mechanobiology and the Role of Biomaterials in Governing Mechanotransduction and Matrix Production for Tissue Regeneration. Front. Bioeng. Biotechnol. 2020, 8, 1375. [CrossRef]

15. Case, L.B.; Waterman, C.M. Integration of actin dynamics and cell adhesion by a three-dimensional, mechanosensitive molecular clutch. Nat. Cell Biol. 2015, 17, 955-963. [CrossRef]

16. Hatte, G.; Prigent, C.; Tassan, J.-P. Adherens junctions are involved in polarized contractile ring formation in dividing epithelial cells of Xenopus laevis embryos. Exp. Cell Res. 2021, 402, 112525. [CrossRef]

17. Jasuja, H.; Kar, S.; Katti, D.R.; Katti, K. Perfusion bioreactor enabled fluid-derived shear stress conditions for novel bone metastatic prostate cancer testbed. Biofabrication 2021, 13, 035004. [CrossRef] 
18. Jaumouillé, V.; Cartagena-Rivera, A.X.; Waterman, C.M. Coupling of $\beta 2$ integrins to actin by a mechanosensitive molecular clutch drives complement receptor-mediated phagocytosis. Nat. Cell Biol. 2019, 21, 1357-1369. [CrossRef]

19. Yu, D.; Wang, J.; Qian, K.-j.; Yu, J.; Zhu, H.-y. Effects of nanofibers on mesenchymal stem cells: Environmental factors affecting cell adhesion and osteogenic differentiation and their mechanisms. J. Zhejiang Univ. Sci. B 2020, 21, 871-884. [CrossRef]

20. Liu, M.; Banerjee, R.; Rossa Jr, C.; D'Silva, N. RAP1-RAC1 signaling has an important role in adhesion and migration in HNSCC. J. Dent. Res. 2020, 99, 959-968. [CrossRef]

21. Jacob, A.E.; Amack, J.D.; Turner, C.E. Paxillin genes and actomyosin contractility regulate myotome morphogenesis in zebrafish. Dev. Biol. 2017, 425, 70-84. [CrossRef] [PubMed]

22. Pence, L.J.; Kourtidis, A.; Feathers, R.W.; Haddad, M.T.; Sotiriou, S.; Decker, P.A.; Nassar, A.; Ocal, I.T ; Shah, S.S.; Anastasiadis, P.Z. PLEKHA7, an Apical Adherens Junction Protein, Suppresses Inflammatory Breast Cancer in the Context of High E-Cadherin and p120-Catenin Expression. Int. J. Mol. Sci. 2021, 22, 1275. [CrossRef] [PubMed]

23. Gray, M.E.; Sotomayor, M. Crystal structure of the nonclassical cadherin-17 N-terminus and implications for its adhesive binding mechanism. Acta Crystallogr. Sect. F Struct. Biol. Commun. 2021, 77, 85-94. [CrossRef] [PubMed]

24. Ilina, O.; Gritsenko, P.G.; Syga, S.; Lippoldt, J.; La Porta, C.A.; Chepizhko, O.; Grosser, S.; Vullings, M.; Bakker, G.-J.; Starruß, J. Cell-cell adhesion and 3D matrix confinement determine jamming transitions in breast cancer invasion. Nat. Cell Biol. 2020, 22, 1103-1115. [CrossRef]

25. Dahl, K.N.; Kahn, S.M.; Wilson, K.L.; Discher, D.E. The nuclear envelope lamina network has elasticity and a compressibility limit suggestive of a molecular shock absorber. J. Cell Sci. 2004, 117, 4779-4786. [CrossRef]

26. Maurer, M.; Lammerding, J. The driving force: Nuclear mechanotransduction in cellular function, fate, and disease. Annu. Rev. Biomed. Eng. 2019, 21, 443-468. [CrossRef]

27. Reynolds, N.; McEvoy, E.; Ghosh, S.; Pérez, J.A.P.; Neu, C.P.; McGarry, P. Image-derived modeling of nucleus strain amplification associated with chromatin heterogeneity. Biophys. J. 2021, 120, 1323-1332. [CrossRef]

28. Owens, D.J.; Messéant, J.; Moog, S.; Viggars, M.; Ferry, A.; Mamchaoui, K.; Lacène, E.; Roméro, N.; Brull, A.; Bonne, G. Lamin-related congenital muscular dystrophy alters mechanical signaling and skeletal muscle growth. Int. J. Mol. Sci. 2021, $22,306$.

29. Lin, J.D.; Ryder, M.; Kang, M.; Ho, S.P. Biomechanical pathways of dentoalveolar fibrous joints in health and disease. Periodontology 2000 2020, 82, 238-256. [CrossRef]

30. Connizzo, B.; Sun, L.; Lacin, N.; Gendelman, A.; Solomonov, I.; Sagi, I.; Grodzinsky, A.; Naveh, G. Nonuniformity in Periodontal Ligament: Mechanics and Matrix Composition. J. Dent. Res. 2020, 100, 179-186. [CrossRef]

31. Li, Z.; Yu, M.; Jin, S.; Wang, Y.; Luo, R.; Huo, B.; Liu, D.; He, D.; Zhou, Y.; Liu, Y. Stress distribution and collagen remodeling of periodontal ligament during orthodontic tooth movement. Front. Pharmacol. 2019, 10, 1263. [CrossRef]

32. Takewaki, M.; Kajiya, M.; Takeda, K.; Sasaki, S.; Motoike, S.; Komatsu, N.; Matsuda, S.; Ouhara, K.; Mizuno, N.; Fujita, T. MSC/ECM cellular complexes induce periodontal tissue regeneration. J. Dent. Res. 2017, 96, 984-991. [CrossRef]

33. Lundmark, A.; Johannsen, G.; Eriksson, K.; Kats, A.; Jansson, L.; Tervahartiala, T.; Rathnayake, N.; Åkerman, S.; Klinge, B.; Sorsa, T. Mucin 4 and matrix metalloproteinase 7 as novel salivary biomarkers for periodontitis. J. Clin. Periodontol. 2017, 44, 247-254. [CrossRef]

34. Nakagawa, M.; Shirasugi, M.; Yamamoto, T.; Nakaya, T.; Kanamura, N. Long-term exposure to butyric acid induces excessive production of matrix metalloproteases in human gingival fibroblasts. Arch. Oral Biol. 2021, 123, 105035. [CrossRef]

35. Park, H.-J.; Kim, Y.; Kim, M.-K.; Park, H.-R.; Kim, H.-J.; Bae, S.-K.; Bae, M.-K. Infection of Porphyromonas gingivalis Increases Phosphate-Induced Calcification of Vascular Smooth Muscle Cells. Cells 2020, 9, 2694. [CrossRef]

36. Behm, C.; Nemec, M.; Blufstein, A.; Schubert, M.; Rausch-Fan, X.; Andrukhov, O.; Jonke, E. Interleukin-1ß Induced Matrix Metalloproteinase Expression in Human Periodontal Ligament-Derived Mesenchymal Stromal Cells under In Vitro Simulated Static Orthodontic Forces. Int. J. Mol. Sci. 2021, 22, 1027. [CrossRef]

37. Kamarajan, P.; Ateia, I.; Shin, J.M.; Fenno, J.C.; Le, C.; Zhan, L.; Chang, A.; Darveau, R.; Kapila, Y.L. Periodontal pathogens promote cancer aggressivity via TLR/MyD88 triggered activation of Integrin/FAK signaling that is therapeutically reversible by a probiotic bacteriocin. PLoS Pathog. 2020, 16, e1008881. [CrossRef]

38. Li, Y.; Tan, X.; Zhao, X.; Xu, Z.; Dai, W.; Duan, W.; Huang, S.; Zhang, E.; Liu, J.; Zhang, S. Composition and function of oral microbiota between gingival squamous cell carcinoma and periodontitis. Oral Oncol. 2020, 107, 104710. [CrossRef]

39. Batool, H.; Nadeem, A.; Kashif, M.; Shahzad, F.; Tahir, R.; Afzal, N. Salivary levels of IL-6 and IL-17 could be an indicator of disease severity in patients with calculus associated chronic periodontitis. BioMed Res. Int. 2018, 2018, 8531961. [CrossRef]

40. Arroyo, R.; López, S.; Romo, E.; Montoya, G.; Hoz, L.; Pedraza, C.; Garfias, Y.; Arzate, H. Carboxy-Terminal Cementum Protein 1-Derived Peptide 4 (cemp1-p4) Promotes Mineralization through wnt/ $\beta$-catenin Signaling in Human Oral Mucosa Stem Cells. Int. J. Mol. Sci. 2020, 21, 1307. [CrossRef]

41. Martins, L.; Amorim, B.R.; Salmon, C.R.; Leme, A.F.P.; Kantovitz, K.R.; Nociti Jr, F.H. Novel LRAP-binding partner revealing the plasminogen activation system as a regulator of cementoblast differentiation and mineral nodule formation in vitro. J. Cell. Physiol. 2020, 235, 4545-4558. [CrossRef] [PubMed]

42. Zhang, Y.; Yang, Y.; Xu, M.; Zheng, J.; Xu, Y.; Chen, G.; Guo, Q.; Tian, W.; Guo, W. The Dual Effects of Reactive Oxygen Species on the Mandibular Alveolar Bone Formation in SOD1 Knockout Mice: Promotion or Inhibition. Oxidative Med. Cell. Longev. 2021, 2021, 8847140. [CrossRef] [PubMed] 
43. Denes, B.J.; Ait-Lounis, A.; Wehrle-Haller, B.; Kiliaridis, S. Core matrisome protein signature during periodontal ligament maturation from pre-occlusal eruption to occlusal function. Front. Physiol. 2020, 11, 174. [CrossRef] [PubMed]

44. Zvackova, I.; Matalova, E.; Lesot, H. Regulators of collagen fibrillogenesis during molar development in the mouse. Front. Physiol. 2017, 8, 554. [CrossRef]

45. Kurylo, M.P.; Grandfield, K.; Marshall, G.W.; Altoe, V.; Aloni, S.; Ho, S.P. Effect of proteoglycans at interfaces as related to location, architecture, and mechanical cues. Arch. Oral Biol. 2016, 63, 82-92. [CrossRef]

46. Wei, L.; Chen, Q.; Zheng, Y.; Nan, L.; Liao, N.; Mo, S. Potential Role of Integrin $\alpha 5 \beta 1 /$ Focal Adhesion Kinase (FAK) and Actin Cytoskeleton in the Mechanotransduction and Response of Human Gingival Fibroblasts Cultured on a 3-Dimension Lactide-Co-Glycolide (3D PLGA) Scaffold. Med Sci. Monit. Int. Med J. Exp. Clin. Res. 2020, 26, e921621-e921626.

47. Hetmanski, J.H.; Jones, M.C.; Chunara, F.; Schwartz, J.-M.; Caswell, P.T. Combinatorial mathematical modelling approaches to interrogate rear retraction dynamics in 3D cell migration. PLoS Comput. Biol. 2021, 17, e1008213. [CrossRef]

48. Kao, T.-W.; Chiou, A.; Lin, K.-H.; Liu, Y.-S.; Lee, O.K.-S. Alteration of 3D Matrix Stiffness Regulates Viscoelasticity of Human Mesenchymal Stem Cells. Int. J. Mol. Sci. 2021, 22, 2441. [CrossRef]

49. Humphrey, J.D.; Dufresne, E.R.; Schwartz, M.A. Mechanotransduction and extracellular matrix homeostasis. Nat. Rev. Mol. Cell Biol. 2014, 15, 802-812. [CrossRef]

50. Hegedû́s, O.; Juriga, D.; Sipos, E.; Voniatis, C.; Juhász, Á.; Idrissi, A.; Zrínyi, M.; Varga, G.; Jedlovszky-Hajdú, A.; Nagy, K.S. Free thiol groups on poly (aspartamide) based hydrogels facilitate tooth-derived progenitor cell proliferation and differentiation. PLoS ONE 2019, 14, e0226363. [CrossRef]

51. Feld, L.; Kellerman, L.; Mukherjee, A.; Livne, A.; Bouchbinder, E.; Wolfenson, H. Cellular contractile forces are nonmechanosensitive. Sci. Adv. 2020, 6, eaaz6997. [CrossRef]

52. Reyes-Ramos, A.M.; Álvarez-García, Y.R.; Solodin, N.; Almodovar, J.; Alarid, E.T.; Torres-Garcia, W.; Domenech, M. Collagen I Fibrous Substrates Modulate the Proliferation and Secretome of Estrogen Receptor-Positive Breast Tumor Cells in a HormoneRestricted Microenvironment. ACS Biomater. Sci. Eng. 2021. [CrossRef]

53. Wei, D.; Li, C.; Ye, J.; Xiang, F.; Liu, J. Extracellular Collagen Mediates Osteosarcoma Progression Through an Integrin $\alpha 2 \beta 1 /$ JAK/STAT3 Signaling Pathway. Cancer Manag. Res. 2020, 12, 12067. [CrossRef]

54. Xing, Q.; Parvizi, M.; Higuita, M.L.; Griffiths, L.G. Basement membrane proteins modulate cell migration on bovine pericardium extracellular matrix scaffold. Sci. Rep. 2021, 11, 4607. [CrossRef]

55. Al-Yafeai, Z.; Orr, A.W. Quantification of integrin activation and ligation in adherent cells. In The Integrin Interactome; Springer: New York, NY, USA, 2021; pp. 17-25.

56. Ye, Y.; Zhang, R.; Feng, H. Fibronectin promotes tumor cells growth and drugs resistance through a CDC42-YAP-dependent signaling pathway in colorectal cancer. Cell Biol. Int. 2020, 44, 1840-1849. [CrossRef]

57. Roy, S.; Spinali, K.; Schmuck, E.G.; Kink, J.A.; Hematti, P.; Raval, A.N. Cardiac fibroblast derived matrix-educated macrophages express VEGF and IL-6, and recruit mesenchymal stromal cells. J. Immunol. Regen. Med. 2020, 10, 100033.

58. Sugahara, M.; Nakaoki, Y.; Yamaguchi, A.; Hashimoto, K.; Miyamoto, Y. Vitronectin is involved in the morphological transition of neurites in retinoic acid-induced neurogenesis of neuroblastoma cell line neuro2a. Neurochem. Res. 2019, 44, 1621-1635. [CrossRef]

59. Jakhu, H.; Gill, G.; Singh, A. Role of integrins in wound repair and its periodontal implications. J. Oral Biol. Craniofac. Res. 2018, 8, 122-125. [CrossRef]

60. Jang, A.; Wang, B.; Ustriyana, P.; Gansky, S.A.; Maslenikov, I.; Useinov, A.; Prevost, R.; Ho, S.P. Functional adaptation of interradicular alveolar bone to reduced chewing loads on dentoalveolar joints in rats. Dent. Mater. 2021, 37, 486-495. [CrossRef]

61. Husari, A.; Steinberg, T.; Dieterle, M.P.; Prucker, O.; Rühe, J.; Jung, B.; Tomakidi, P. On the relationship of YAP and FAK in hMSCs and osteosarcoma cells: Discrimination of FAK modulation by nuclear YAP depletion or YAP silencing. Cell. Signal. 2019, 63, 109382. [CrossRef]

62. Belgardt, E.; Steinberg, T.; Husari, A.; Dieterle, M.P.; Hülter-Hassler, D.; Jung, B.; Tomakidi, P. Force-responsive Zyxin modulation in periodontal ligament cells is regulated by YAP rather than TAZ. Cell. Signal. 2020, 72, 109662. [CrossRef]

63. Gao, W.-J.; Liu, J.-X.; Xie, Y.; Luo, P.; Liu, Z.-Q.; Liu, L.; Zhou, H. Suppression of macrophage migration by downregulating Src/FAK/P130Cas activation contributed to the anti-inflammatory activity of sinomenine. Pharmacol. Res. 2021, 167, 105513. [CrossRef]

64. Zhang, L.; Yan, H.; Tai, Y.; Xue, Y.; Wei, Y.; Wang, K.; Zhao, Q.; Wang, S.; Kong, D.; Midgley, A.C. Design and Evaluation of a Polypeptide that Mimics the Integrin Binding Site for EDA Fibronectin to Block Profibrotic Cell Activity. Int. J. Mol. Sci. 2021, 22, 1575. [CrossRef]

65. Boujemaa-Paterski, R.; Martins, B.; Eibauer, M.; Beales, C.T.; Geiger, B.; Medalia, O. Talin-activated vinculin interacts with branched actin networks to initiate bundles. eLife 2020, 9, e53990. [CrossRef]

66. Damiano-Guercio, J.; Kurzawa, L.; Mueller, J.; Dimchev, G.; Schaks, M.; Nemethova, M.; Pokrant, T.; Brühmann, S.; Linkner, J.; Blanchoin, L. Loss of Ena/VASP interferes with lamellipodium architecture, motility and integrin-dependent adhesion. eLife 2020, 9, e55351. [CrossRef]

67. Hsiao, B.-Y.; Chen, C.-H.; Chi, H.-Y.; Yen, P.-R.; Yu, Y.-Z.; Lin, C.-H.; Pang, T.-L.; Lin, W.-C.; Li, M.-L.; Yeh, Y.-C. Human Costars Family Protein ABRACL Modulates Actin Dynamics and Cell Migration and Associates with Tumorigenic Growth. Int. J. Mol. Sci. 2021, 22, 2037. [CrossRef] 
68. Roopnarine, O.; Thomas, D.D. Mechanistic analysis of actin-binding compounds that affect the kinetics of cardiac myosin-actin interaction. J. Biol. Chem. 2021, 196, 100471. [CrossRef]

69. Mani, S.; Katkar, H.H.; Voth, G.A. Compressive and Tensile Deformations Alter ATP Hydrolysis and Phosphate Release Rates in Actin Filaments. J. Chem. Theory Comput. 2021, 17, 1900-1913. [CrossRef]

70. Zeng, Y.; Cao, Y.; Liu, L.; Zhao, J.; Zhang, T.; Xiao, L.; Jia, M.; Tian, Q.; Yu, H.; Chen, S. SEPT9_i1 regulates human breast cancer cell motility through cytoskeletal and RhoA/FAK signaling pathway regulation. Cell Death Dis. 2019, 10, 720. [CrossRef]

71. Kurotsu, S.; Sadahiro, T.; Fujita, R.; Tani, H.; Yamakawa, H.; Tamura, F.; Isomi, M.; Kojima, H.; Yamada, Y.; Abe, Y. Soft Matrix Promotes Cardiac Reprogramming via Inhibition of YAP/TAZ and Suppression of Fibroblast Signatures. Stem Cell Rep. 2020, 15, 612-628. [CrossRef]

72. Nikoloudaki, G.; Snider, P.; Simmons, O.; Conway, S.J.; Hamilton, D.W. Periostin and matrix stiffness combine to regulate myofibroblast differentiation and fibronectin synthesis during palatal healing. Matrix Biol. 2020, 94, 31-56. [CrossRef] [PubMed]

73. Liu, Y.; Rens, E.G.; Edelstein-Keshet, L. Spots, stripes, and spiral waves in models for static and motile cells. J. Math. Biol. 2021, 82, 1-38. [CrossRef] [PubMed]

74. Ugawa, Y.; Yamamoto, T.; Kawamura, M.; Yamashiro, K.; Shimoe, M.; Tomikawa, K.; Hongo, S.; Maeda, H.; Takashiba, S. Rho-kinase regulates extracellular matrix-mediated osteogenic differentiation of periodontal ligament cells. Cell Biol. Int. 2017, 41, 651-658. [CrossRef] [PubMed]

75. Yamamoto, T.; Ugawa, Y.; Yamashiro, K.; Shimoe, M.; Tomikawa, K.; Hongo, S.; Kochi, S.; Ideguchi, H.; Maeda, H.; Takashiba, S. Osteogenic differentiation regulated by Rho-kinase in periodontal ligament cells. Differentiation 2014, 88, 33-41. [CrossRef]

76. Liu, C.; Zhang, Y.; Ren, H. Profilin promotes formin-mediated actin filament assembly and vesicle transport during polarity formation in pollen. Plant Cell 2021. [CrossRef]

77. Matarrese, P.; Vona, R.; Ascione, B.; Paggi, M.G.; Mileo, A.M. Physical Interaction between HPV16E7 and the Actin-Binding Protein Gelsolin Regulates Epithelial-Mesenchymal Transition via HIPPO-YAP Axis. Cancers 2021, 13, 353. [CrossRef]

78. Choi, C.K.; Vicente-Manzanares, M.; Zareno, J.; Whitmore, L.A.; Mogilner, A.; Horwitz, A.R. Actin and $\alpha$-actinin orchestrate the assembly and maturation of nascent adhesions in a myosin II motor-independent manner. Nat. Cell Biol. 2008, 10, 1039-1050. [CrossRef]

79. Yamamoto, T.; Ugawa, Y.; Kawamura, M.; Yamashiro, K.; Kochi, S.; Ideguchi, H.; Takashiba, S. Modulation of microenvironment for controlling the fate of periodontal ligament cells: The role of Rho/ROCK signaling and cytoskeletal dynamics. J. Cell Commun. Signal. 2018, 12, 369-378. [CrossRef]

80. Romero, S.; Le Clainche, C.; Gautreau, A.M. Actin polymerization downstream of integrins: Signaling pathways and mechanotransduction. Biochem. J. 2020, 477, 1-21. [CrossRef]

81. Ramirez, I.; Gholkar, A.A.; Velasquez, E.F.; Guo, X.; Tofig, B.; Damoiseaux, R.; Torres, J.Z. The myosin regulatory light chain Myl5 localizes to mitotic spindle poles and is required for proper cell division. Cytoskeleton 2021, 78, 23-35. [CrossRef]

82. Jarvis, K.J.; Bell, K.M.; Loya, A.K.; Swank, D.M.; Walcott, S. Force-velocity and tension transient measurements from Drosophila jump muscle reveal the necessity of both weakly-bound cross-bridges and series elasticity in models of muscle contraction. Arch. Biochem. Biophys. 2021, 701, 108809. [CrossRef]

83. Salomon, J.; Gaston, C.; Magescas, J.; Duvauchelle, B.; Canioni, D.; Sengmanivong, L.; Mayeux, A.; Michaux, G.; Campeotto, F.; Lemale, J. Contractile forces at tricellular contacts modulate epithelial organization and monolayer integrity. Nat. Commun. 2017, 8, 13998. [CrossRef]

84. Schreiber, C.; Amiri, B.; Heyn, J.C.; Rädler, J.O.; Falcke, M. On the adhesion-velocity relation and length adaptation of motile cells on stepped fibronectin lanes. Proc. Natl. Acad. Sci. USA 2021, 118. [CrossRef]

85. Santa-Cruz Mateos, C.; Valencia-Expósito, A.; Palacios, I.M.; Martín-Bermudo, M.D. Integrins regulate epithelial cell shape by controlling the architecture and mechanical properties of basal actomyosin networks. PLoS Genet. 2020, 16, e1008717. [CrossRef]

86. Uçar, M.C.; Lipowsky, R. Collective force generation by molecular motors is determined by strain-induced unbinding. Nano Lett. 2019, 20, 669-676. [CrossRef]

87. Cong, J.; Fang, B.; Wang, Q.; Su, Y.; Gu, T.; Luo, T. The mechanobiology of actin cytoskeletal proteins during cell-cell fusion. J. R. Soc. Interface 2019, 16, 20190022. [CrossRef]

88. Van Helvert, S.; Friedl, P. Strain stiffening of fibrillar collagen during individual and collective cell migration identified by AFM nanoindentation. ACS Appl. Mater. Interfaces 2016, 8, 21946-21955. [CrossRef]

89. Wu, C.; Bauer, J.; Juliano, R.; McDonald, J. The alpha 5 beta 1 integrin fibronectin receptor, but not the alpha 5 cytoplasmic domain, functions in an early and essential step in fibronectin matrix assembly. J. Biol. Chem. 1993, 268, 21883-21888. [CrossRef]

90. Attia, M.S.; Alblowi, J.A. Effect of Subantimicrobial Dose Doxycycline Treatment on Gingival Crevicular Fluid Levels of MMP-9 and MMP-13 in Periodontitis Stage 2, Grade B in Subjects with Type 2 Diabetes Mellitus. J. Immunol. Res. 2020, 2020, 2807259. [CrossRef]

91. Sato, T.; Verma, S.; Andrade, C.D.C.; Omeara, M.; Campbell, N.; Wang, J.S.; Cetinbas, M.; Lang, A.; Ausk, B.J.; Brooks, D.J. A FAK/HDAC5 signaling axis controls osteocyte mechanotransduction. Nat. Commun. 2020, 11, 3282. [CrossRef]

92. Li, X.; Ominsky, M.S.; Niu, Q.T.; Sun, N.; Daugherty, B.; D’Agostin, D.; Kurahara, C.; Gao, Y.; Cao, J.; Gong, J. Targeted deletion of the sclerostin gene in mice results in increased bone formation and bone strength. J. Bone Miner. Res. 2008, 23, 860-869. [CrossRef]

93. Muhamed, I.; Wu, J.; Sehgal, P.; Kong, X.; Tajik, A.; Wang, N.; Leckband, D.E. E-cadherin-mediated force transduction signals regulate global cell mechanics. J. Cell Sci. 2016, 129, 1843-1854. [CrossRef] 
94. Krischak, A.; Kowaliuk, J.; Sarsarshahi, S.; Dörr, W.; Kleiter, M. Effect of irradiation on the expression of E-cadherin and $\beta$-catenin in early and late radiation sequelae of the urinary bladder and its modulation by NF-kB inhibitor thalidomide. Strahlenther. Onkol. 2021, 197, 537-546. [CrossRef]

95. Kluger, C.; Braun, L.; Sedlak, S.M.; Pippig, D.A.; Bauer, M.S.; Miller, K.; Milles, L.F.; Gaub, H.E.; Vogel, V. Different vinculin binding sites use the same mechanism to regulate directional force transduction. Biophys. J. 2020, 118, 1344-1356. [CrossRef]

96. Chandran, R.; Kale, G.; Philippe, J.-M.; Lecuit, T.; Mayor, S. Distinct actin-dependent nanoscale assemblies underlie the dynamic and hierarchical organization of E-cadherin. Curr. Biol. 2021, 31, 1726-1736.e4. [CrossRef]

97. Huang, S.-C.; Liang, J.Y.; Vu, L.V.; Faye, H.Y.; Ou, A.C.; Ou, J.P.; Zhang, H.S.; Burnett, K.M.; Benz, E.J., Jr. Epithelial-specific isoforms of protein $4.1 \mathrm{R}$ promote adherens junction assembly in maturing epithelia. J. Biol. Chem. 2020, 295, 191-211. [CrossRef]

98. Ishiyama, N.; Sarpal, R.; Wood, M.N.; Barrick, S.K.; Nishikawa, T.; Hayashi, H.; Kobb, A.B.; Flozak, A.S.; Yemelyanov, A.; Fernandez-Gonzalez, R. Force-dependent allostery of the $\alpha$-catenin actin-binding domain controls adherens junction dynamics and functions. Nat. Commun. 2018, 9, 5121. [CrossRef]

99. Liu, Y.-H.; Chen, C.-C.; Hsueh, Y.-J.; Hung, L.-M.; Ma, D.H.-K.; Chen, H.-C.; Len, W.-B.; Meir, Y.-J.J. Extraneous E-Cadherin Engages the Deterministic Process of Somatic Reprogramming through Modulating STAT3 and Erk1/2 Activity. Cells 2021, 10, 284. [CrossRef]

100. Ma, Y.-C.; Yang, Z.-S.; Ma, L.-Q.; Shu, R.; Zou, C.-G.; Zhang, K.-Q. YAP in epithelium senses gut barrier loss to deploy defenses against pathogens. PLoS Pathog. 2020, 16, e1008766. [CrossRef]

101. Monster, J.L.; Donker, L.; Vliem, M.J.; Win, Z.; Matthews, H.K.; Cheah, J.S.; Yamada, S.; de Rooij, J.; Baum, B.; Gloerich, M. An asymmetric junctional mechanoresponse coordinates mitotic rounding with epithelial integrity. J. Cell Biol. 2021, 220. [CrossRef]

102. Lim, J.C.; Bae, S.H.; Lee, G.; Ryu, C.J.; Jang, Y.J. Activation of $\beta$-catenin by TGF- $\beta 1$ promotes ligament-fibroblastic differentiation and inhibits cementoblastic differentiation of human periodontal ligament cells. STEM CELLS 2020, 38, 1612-1623. [CrossRef] [PubMed]

103. Arun, R.; Hemalatha, R.; Arun, K.; Kumar, T. E-cadherin and CD1a expression in gingival epithelium in periodontal health, disease and post-treatment. Indian J. Dent. Res. 2010, 21, 396. [CrossRef] [PubMed]

104. Gupta, A.; Sharma, S.; Batra, M.; Abidullah, M.; Bhuvinder, S.; Katragadda, P. Role of E-cadherin in Progression of Oral Squamous Cell Carcinoma: A Retrospective Immunohistochemical Study. J. Contemp. Dent. Pract. 2018, 19, 1105-1110. [PubMed]

105. Abe-Yutori, M.; Chikazawa, T.; Shibasaki, K.; Murakami, S. Decreased expression of E-cadherin by Porphyromonas gingivalislipopolysaccharide attenuates epithelial barrier function. J. Periodontal Res. 2017, 52, 42-50. [CrossRef]

106. Sowmya, S.; Rao, R.S.; Prasad, K. Development of clinico-histopathological predictive model for the assessment of metastatic risk of oral squamous cell carcinoma. J. Carcinog. 2020, 19, 2. [CrossRef]

107. Johnson, C.L.; Merryman, W.D. Side-specific valvular endothelial-interstitial cell mechano-communication via cadherin-11. J. Biomech. 2021, 119, 110253. [CrossRef]

108. Piao, S.; Inglehart, R.C.; Scanlon, C.S.; Russo, N.; Banerjee, R.; D'Silva, N.J. CDH 11 inhibits proliferation and invasion in head and neck cancer. J. Oral Pathol. Med. 2017, 46, 89-97. [CrossRef]

109. Feng, L.; Zhang, Y.; Kou, X.; Yang, R.; Liu, D.; Wang, X.; Song, Y.; Cao, H.; He, D.; Gan, Y. Cadherin-11 modulates cell morphology and collagen synthesis in periodontal ligament cells under mechanical stress. Angle Orthod. 2017, 87, 193-199. [CrossRef]

110. Row, S.; Liu, Y.; Alimperti, S.; Agarwal, S.K.; Andreadis, S.T. Cadherin-11 is a novel regulator of extracellular matrix synthesis and tissue mechanics. J. Cell Sci. 2016, 129, 2950-2961. [CrossRef]

111. Alimperti, S.; You, H.; George, T.; Agarwal, S.K.; Andreadis, S.T. Cadherin-11 regulates both mesenchymal stem cell differentiation into smooth muscle cells and the development of contractile function in vivo. J. Cell Sci. 2014, 127, 2627-2638.

112. Steinmetz, E.L.; Dewald, D.N.; Walldorf, U. Drosophila Homeodomain-Interacting Protein Kinase (Hipk) Phosphorylates the Hippo/Warts Signalling Effector Yorkie. Int. J. Mol. Sci. 2021, 22, 1862. [CrossRef]

113. Piccolo, S.; Dupont, S.; Cordenonsi, M. The biology of YAP/TAZ: Hippo signaling and beyond. Physiol. Rev. 2014, 94, 1287-1312. [CrossRef]

114. Dobrokhotov, O.; Samsonov, M.; Sokabe, M.; Hirata, H. Mechanoregulation and pathology of YAP/TAZ via Hippo and non-Hippo mechanisms. Clin. Transl. Med. 2018, 7, 23. [CrossRef]

115. Wu, S.; Huang, J.; Dong, J.; Pan, D. hippo encodes a Ste-20 family protein kinase that restricts cell proliferation and promotes apoptosis in conjunction with salvador and warts. Cell 2003, 114, 445-456. [CrossRef]

116. Sharma, J.; Antenos, M.; Madan, P. A Comparative Analysis of Hippo Signaling Pathway Components during Murine and Bovine Early Mammalian Embryogenesis. Genes 2021, 12, 281. [CrossRef]

117. Oh, J.-E.; Kim, H.; Kang, H.K.; Chung, C.-P.; Park, W.H.; Min, B.-M. $\alpha 3 \beta 1$ integrin promotes cell survival via multiple interactions between 14-3-3 isoforms and proapoptotic proteins. Exp. Cell Res. 2009, 315, 3187-3200. [CrossRef]

118. Elbediwy, A.; Vincent-Mistiaen, Z.I.; Spencer-Dene, B.; Stone, R.K.; Boeing, S.; Wculek, S.K.; Cordero, J.; Tan, E.H.; Ridgway, R.; Brunton, V.G. Integrin signalling regulates YAP and TAZ to control skin homeostasis. Development 2016, 143, $1674-1687$.

119. Park, J.; Kim, J.S.; Nahm, J.H.; Kim, S.-K.; Lee, D.-H.; Lim, D.-S. WWC1 and NF2 Prevent the Development of Intrahepatic Cholangiocarcinoma by Regulating YAP/TAZ Activity through LATS in Mice. Mol. Cells 2020, 43, 491.

120. Li, T.; Guo, T.; Liu, H.; Jiang, H.; Wang, Y. Platelet-derived growth factor-BB mediates pancreatic cancer malignancy via regulation of the Hippo/Yes-associated protein signaling pathway. Oncol. Rep. 2021, 45, 83-94. [CrossRef] 
121. Maziarz, M.; Federico, A.; Zhao, J.; Dujmusic, L.; Zhao, Z.; Monti, S.; Varelas, X.; Garcia-Marcos, M. Naturally occurring hotspot cancer mutations in G $\alpha 13$ promote oncogenic signaling. J. Biol. Chem. 2020, 295, 16897-16904. [CrossRef]

122. Strippoli, R.; Sandoval, P.; Moreno-Vicente, R.; Rossi, L.; Battistelli, C.; Terri, M.; Pascual-Antón, L.; Loureiro, M.; Matteini, F.; Calvo, E. Caveolin1 and YAP drive mechanically induced mesothelial to mesenchymal transition and fibrosis. Cell Death Dis. 2020, 11, 647. [CrossRef]

123. Kang, P.H.; Schaffer, D.V.; Kumar, S. Angiomotin links ROCK and YAP signaling in mechanosensitive differentiation of neural stem cells. Mol. Biol. Cell 2020, 31, 386-396. [CrossRef]

124. Pagliari, S.; Vinarsky, V.; Martino, F.; Perestrelo, A.R.; De La Cruz, J.O.; Caluori, G.; Vrbsky, J.; Mozetic, P.; Pompeiano, A.; Zancla, A. YAP-TEAD1 control of cytoskeleton dynamics and intracellular tension guides human pluripotent stem cell mesoderm specification. Cell Death Differ. 2021, 28, 1193-1207. [CrossRef]

125. Zhang, C.; Wang, F.; Xie, Z.; Chen, L.; Sinkemani, A.; Yu, H.; Wu, X. AMOT 130 linking F-actin to YAP is involved in intervertebral disc degeneration. Cell Prolif. 2018, 51, e12492. [CrossRef]

126. Low, B.C.; Pan, C.Q.; Shivashankar, G.; Bershadsky, A.; Sudol, M.; Sheetz, M. YAP/TAZ as mechanosensors and mechanotransducers in regulating organ size and tumor growth. FEBS Lett. 2014, 588, 2663-2670. [CrossRef]

127. Hu, J.K.-H.; Du, W.; Shelton, S.J.; Oldham, M.C.; DiPersio, C.M.; Klein, O.D. An FAK-YAP-mTOR signaling axis regulates stem cell-based tissue renewal in mice. Cell Stem Cell 2017, 21, 91-106.e106. [CrossRef]

128. Marikawa, Y.; Alarcon, V.B. RHOA activity in expanding blastocysts is essential to regulate HIPPO-YAP signaling and to maintain the trophectoderm-specific gene expression program in a ROCK/actin filament-independent manner. MHR Basic Sci. Reprod. Med. 2019, 25, 43-60. [CrossRef]

129. Zhou, R.; Wu, Q.; Wang, M.; Irani, S.; Li, X.; Zhang, Q.; Meng, F.; Liu, S.; Zhang, F.; Wu, L. The protein phosphatase PPM1A dephosphorylates and activates YAP to govern mammalian intestinal and liver regeneration. PLoS Biol. 2021, 19, e3001122.

130. Samarakoon, R.; Chitnis, S.S.; Higgins, S.P.; Higgins, C.E.; Krepinsky, J.C.; Higgins, P.J. Redox-induced Src kinase and caveolin-1 signaling in TGF- $\beta 1$-initiated SMAD2/3 activation and PAI-1 expression. PLoS ONE 2011, 6, e22896. [CrossRef]

131. Li, C.-Y.; Hu, J.; Lu, H.; Lan, J.; Du, W.; Galicia, N.; Klein, O.D. $\alpha$ E-catenin inhibits YAP/TAZ activity to regulate signalling centre formation during tooth development. Nat. Commun. 2016, 7, 12133. [CrossRef]

132. Alisafaei, F.; Jokhun, D.S.; Shivashankar, G.; Shenoy, V.B. Regulation of nuclear architecture, mechanics, and nucleocytoplasmic shuttling of epigenetic factors by cell geometric constraints. Proc. Natl. Acad. Sci. USA 2019, 116, 13200-13209. [CrossRef] [PubMed]

133. Wu, Y.; Li, M.; Lin, J.; Hu, C. Hippo/TEAD4 signaling pathway as a potential target for the treatment of breast cancer. Oncol. Lett. 2021, 21, 17. [CrossRef] [PubMed]

134. Chen, X.; Gu, W.; Wang, Q.; Fu, X.; Wang, Y.; Xu, X.; Wen, Y. C-MYC and BCL-2 mediate YAP-regulated tumorigenesis in OSCC. Oncotarget 2018, 9, 668. [CrossRef] [PubMed]

135. Oka, T.; Remue, E.; Meerschaert, K.; Vanloo, B.; Boucherie, C.; Gfeller, D.; Bader, G.D.; Sidhu, S.S.; Vandekerckhove, J.; Gettemans, J. Functional complexes between YAP2 and ZO-2 are PDZ domain-dependent, and regulate YAP2 nuclear localization and signalling. Biochem. J. 2010, 432, 461-478. [CrossRef]

136. Oka, T.; Schmitt, A.; Sudol, M. Opposing roles of angiomotin-like-1 and zona occludens-2 on pro-apoptotic function of YAP. Oncogene 2012, 31, 128-134. [CrossRef]

137. Domínguez-Calderón, A.; Ávila-Flores, A.; Ponce, A.; López-Bayghen, E.; Calderón-Salinas, J.-V.; Luis Reyes, J.; Chávez-Munguía, B.; Segovia, J.; Angulo, C.; Ramírez, L. ZO-2 silencing induces renal hypertrophy through a cell cycle mechanism and the activation of YAP and the mTOR pathway. Mol. Biol. Cell 2016, 27, 1581-1595. [CrossRef]

138. Liu, M.; Zhao, S.; Lin, Q.; Wang, X.-P. YAP regulates the expression of Hoxa1 and Hoxc13 in mouse and human oral and skin epithelial tissues. Mol. Cell. Biol. 2015, 35, 1449-1461. [CrossRef]

139. Wang, J.; Xiao, Y.; Hsu, C.-W.; Martinez-Traverso, I.M.; Zhang, M.; Bai, Y.; Ishii, M.; Maxson, R.E.; Olson, E.N.; Dickinson, M.E. Yap and Taz play a crucial role in neural crest-derived craniofacial development. Development 2016, 143, 504-515. [CrossRef]

140. Kaku, M.; Komatsu, Y.; Mochida, Y.; Yamauchi, M.; Mishina, Y.; Ko, C.-C. Identification and characterization of neural crestderived cells in adult periodontal ligament of mice. Arch. Oral Biol. 2012, 57, 1668-1675. [CrossRef]

141. Dong, T.; Sun, X.; Jin, H. Role of YAP1 gene in proliferation, osteogenic differentiation, and apoptosis of human periodontal ligament stem cells induced by TNF- $\alpha$. J. Periodontol. 2020. [CrossRef]

142. Komatsu, N.; Kajiya, M.; Motoike, S.; Takewaki, M.; Horikoshi, S.; Iwata, T.; Ouhara, K.; Takeda, K.; Matsuda, S.; Fujita, T. Type I collagen deposition via osteoinduction ameliorates YAP/TAZ activity in 3D floating culture clumps of mesenchymal stem cell/extracellular matrix complexes. Stem Cell Res. Ther. 2018, 9, 342. [CrossRef]

143. Yang, Y.; Wang, B.-K.; Chang, M.-L.; Wan, Z.-Q.; Han, G.-L. Cyclic stretch enhances osteogenic differentiation of human periodontal ligament cells via YAP activation. BioMed Res. Int. 2018, 2018, 2174824. [CrossRef]

144. Wang, C.; Gu, W.; Sun, B.; Zhang, Y.; Ji, Y.; Xu, X.; Wen, Y. CTHRC1 promotes osteogenic differentiation of periodontal ligament stem cells by regulating TAZ. J. Mol. Histol. 2017, 48, 311-319. [CrossRef]

145. Sun, B.; Wen, Y.; Wu, X.; Zhang, Y.; Qiao, X.; Xu, X. Expression pattern of YAP and TAZ during orthodontic tooth movement in rats. J. Mol. Histol. 2018, 49, 123-131. [CrossRef]

146. Wang, Y.; Hu, B.; Hu, R.; Tong, X.; Zhang, M.; Xu, C.; He, Z.; Zhao, Y.; Deng, H. TAZ contributes to osteogenic differentiation of periodontal ligament cells under tensile stress. J. Periodontal Res. 2020, 55, 152-160. [CrossRef] 
147. Cui, Z.; Wang, X.N.; Lu, Y.; Wu, P.; Zhao, H.G.; Li, Q.L.; Xu, Y.H. miR-140 inhibits osteogenic differentiation of human periodontal ligament fibroblasts through ras homolog gene family, member A-transcriptional co-activator with PDZ-binding motif pathway. Kaohsiung J. Med Sci. 2021, 37, 38-46. [CrossRef]

148. Hu, P.; Gao, Q.; Zheng, H.; Tian, Y.; Zheng, G.; Yao, X.; Zhang, J.; Wu, X.; Sui, L. The Role and Activation Mechanism of TAZ in Hierarchical Microgroove/Nanopore Topography-Mediated Regulation of Stem Cell Differentiation. Int. J. Nanomed. 2021, 16, 1021. [CrossRef]

149. Zheng, L.; Zhang, L.; Chen, L.; Jiang, J.; Zhou, X.; Wang, M.; Fan, Y. Static magnetic field regulates proliferation, migration, differentiation, and YAP/TAZ activation of human dental pulp stem cells. J. Tissue Eng. Regen. Med. 2018, 12, 2029-2040. [CrossRef]

150. Kim, S.C.; Im, W.; Shim, J.Y.; Kim, S.-K.; Kim, B.J. Static magnetic field controls cell cycle in cultured human glioblastoma cells. Cytotechnology 2016, 68, 2745-2751. [CrossRef]

151. Jouni, F.J.; Abdolmaleki, P.; Behmanesh, M.; Movahedin, M. An in vitro study of the impact of $4 \mathrm{mT}$ static magnetic field to modify the differentiation rate of rat bone marrow stem cells into primordial germ cells. Differentiation 2014, 87, 230-237. [CrossRef]

152. Izzo, L.; Tunesi, M.; Boeri, L.; Laganà, M.; Giordano, C.; Raimondi, M.T. Influence of the static magnetic field on cell response in a miniaturized optically accessible bioreactor for 3D cell culture. Biomed. Microdevices 2019, 21, 531. [CrossRef]

153. Hu, F.; Gong, Y.; Bian, Z.; Zhang, X.; Xu, B.; Zhang, J.; Shi, X.; Yu, Y.; Song, L. Comparison of three different types of twoimplant-supported magnetic attachments on the stress distribution in edentulous mandible. Comput. Math. Methods Med. 2019, 2019, 6839517. [CrossRef]

154. Alfarsi, M.A.; Shaik, S. Oral rehabilitation of a cleft palate patient with tooth-supported, telescopic magnetic overdenture. BMJ Case Rep. CP 2020, 13, e233777. [CrossRef]

155. He, Y.; Xu, H.; Xiang, Z.; Yu, H.; Xu, L.; Guo, Y.; Tian, Y.; Shu, R.; Yang, X.; Xue, C. YAP regulates periodontal ligament cell differentiation into myofibroblast interacted with RhoA/ROCK pathway. J. Cell. Physiol. 2019, 234, 5086-5096. [CrossRef]

156. Jia, L.; Gu, W.; Zhang, Y.; Jiang, B.; Qiao, X.; Wen, Y. Activated Yes-associated protein accelerates cell cycle, inhibits apoptosis, and delays senescence in human periodontal ligament stem cells. Int. J. Med Sci. 2018, 15, 1241. [CrossRef]

157. Liu-Chittenden, Y.; Huang, B.; Shim, J.S.; Chen, Q.; Lee, S.-J.; Anders, R.A.; Liu, J.O.; Pan, D. Genetic and pharmacological disruption of the TEAD-YAP complex suppresses the oncogenic activity of YAP. Genes Dev. 2012, 26, 1300-1305. [CrossRef]

158. Morice, S.; Mullard, M.; Brion, R.; Dupuy, M.; Renault, S.; Tesfaye, R.; Royer, B.-L.; Ory, B.; Redini, F.; Verrecchia, F. The YAP/TEAD Axis as a New Therapeutic Target in Osteosarcoma: Effect of Verteporfin and CA3 on Primary Tumor Growth. Cancers 2020, 12, 3847. [CrossRef]

159. Chen, X.; Wang, Q.; Gu, K.; Li, A.; Fu, X.; Wang, Y.; Gu, W.; Wen, Y. Effect of YAP on an immortalized periodontal ligament stem cell line. Stem Cells Int. 2019, 2019, 6804036. [CrossRef] [PubMed]

160. Lau, H.Y.; Tang, J.; Casey, P.J.; Wang, M. Evaluating the Epithelial-Mesenchymal Program in Human Breast Epithelial Cells Cultured in Soft Agar Using a Novel Macromolecule Extraction Protocol. Cancers 2021, 13, 807. [CrossRef]

161. Omori, H.; Nishio, M.; Masuda, M.; Miyachi, Y.; Ueda, F.; Nakano, T.; Sato, K.; Mimori, K.; Taguchi, K.; Hikasa, H. YAP1 is a potent driver of the onset and progression of oral squamous cell carcinoma. Sci. Adv. 2020, 6, eaay3324. [CrossRef]

162. Shen, Y.; Pan, Y.; Guo, S.; Sun, L.; Zhang, C.; Wang, L. The roles of mechanosensitive ion channels and associated downstream MAPK signaling pathways in PDLC mechanotransduction. Mol. Med. Rep. 2020, 21, 2113-2122. [CrossRef] [PubMed]

163. Velasco-Estevez, M.; Gadalla, K.K.; Liñan-Barba, N.; Cobb, S.; Dev, K.K.; Sheridan, G.K. Inhibition of Piezo1 attenuates demyelination in the central nervous system. Glia 2020, 68, 356-375. [CrossRef] [PubMed]

164. Hasegawa, K.; Fujii, S.; Matsumoto, S.; Tajiri, Y.; Kikuchi, A.; Kiyoshima, T. YAP signaling induces PIEZO1 to promote oral squamous cell carcinoma cell proliferation. J. Pathol. 2021, 253, 80-93. [CrossRef] [PubMed]

165. Jiang, Y.; Yang, X.; Jiang, J.; Xiao, B. Structural Designs and Mechanogating Mechanisms of the Mechanosensitive Piezo Channels. Trends Biochem. Sci. 2021, 46, 472-488. [CrossRef]

166. Totaro, A.; Zhuang, Q.; Panciera, T.; Battilana, G.; Azzolin, L.; Brumana, G.; Gandin, A.; Brusatin, G.; Cordenonsi, M.; Piccolo, S. Cell phenotypic plasticity requires autophagic flux driven by YAP/TAZ mechanotransduction. Proc. Natl. Acad. Sci. USA 2019, 116, 17848-17857. [CrossRef]

167. Pavel, M.; Renna, M.; Park, S.J.; Menzies, F.M.; Ricketts, T.; Füllgrabe, J.; Ashkenazi, A.; Frake, R.A.; Lombarte, A.C.; Bento, C.F. Contact inhibition controls cell survival and proliferation via YAP/TAZ-autophagy axis. Nat. Commun. 2018, 9, 2961. [CrossRef]

168. Zainab, H.; Ameena Sultana, S. Stromal desmoplasia as a possible prognostic indicator in different grades of oral squamous cell carcinoma. J. Oral Maxillofac. Pathol. JOMFP 2019, 23, 338.

169. Matte, B.F.; Kumar, A.; Placone, J.K.; Zanella, V.G.; Martins, M.D.; Engler, A.J.; Lamers, M.L. Matrix stiffness mechanically conditions EMT and migratory behavior of oral squamous cell carcinoma. J. Cell Sci. 2019, 132, jcs224360. [CrossRef]

170. Gjorevski, N.; Sachs, N.; Manfrin, A.; Giger, S.; Bragina, M.E.; Ordóñez-Morán, P.; Clevers, H.; Lutolf, M.P. Designer matrices for intestinal stem cell and organoid culture. Nature 2016, 539, 560-564. [CrossRef]

171. Dou, C.; Liu, Z.; Tu, K.; Zhang, H.; Chen, C.; Yaqoob, U.; Wang, Y.; Wen, J.; Van Deursen, J.; Sicard, D. P300 acetyltransferase mediates stiffness-induced activation of hepatic stellate cells into tumor-promoting myofibroblasts. Gastroenterology 2018, 154, 2209-2221.e2214. [CrossRef]

172. Nilsson, M.B.; Sun, H.; Robichaux, J.; Pfeifer, M.; McDermott, U.; Travers, J.; Diao, L.; Xi, Y.; Tong, P.; Shen, L. A YAP/FOXM1 axis mediates EMT-associated EGFR inhibitor resistance and increased expression of spindle assembly checkpoint components. Sci. Transl. Med. 2020, 12, eaaz4589. [CrossRef] 
173. Wei, W.; Xue, L.; Tan, L.; Liu, J.; Yang, Q.; Wang, J.; Yan, B.; Cai, Q.; Yang, L.; Yue, Y. Inhibition of yes-associated protein dephosphorylation prevents aggravated periodontitis with occlusal trauma. J. Periodontol. 2020. [CrossRef]

174. Pan, W.; Yang, L.; Li, J.; Xue, L.; Wei, W.; Ding, H.; Deng, S.; Tian, Y.; Yue, Y.; Wang, M. Traumatic occlusion aggravates bone loss during periodontitis and activates Hippo-YAP pathway. J. Clin. Periodontol. 2019, 46, 438-447. [CrossRef]

175. Dupont, S. Regulation of YAP/TAZ activity by mechanical cues: An experimental overview. Hippo Pathw. 2019, 183-202. [CrossRef]

176. Bautista, M.; Fernandez, A.; Pinaud, F. A Micropatterning Strategy to Study Nuclear Mechanotransduction in Cells. Micromachines 2019, 10, 810. [CrossRef]

177. Stephens, A.D.; Liu, P.Z.; Banigan, E.J.; Almassalha, L.M.; Backman, V.; Adam, S.A.; Goldman, R.D.; Marko, J.F. Chromatin histone modifications and rigidity affect nuclear morphology independent of lamins. Mol. Biol. Cell 2018, 29, 220-233. [CrossRef]

178. Morel, V.; Lepicard, S.; Rey, A.N.; Parmentier, M.-L.; Schaeffer, L. Drosophila Nesprin-1 controls glutamate receptor density at neuromuscular junctions. Cell. Mol. Life Sci. 2014, 71, 3363-3379. [CrossRef]

179. Kracklauer, M.P.; Banks, S.M.; Xie, X.; Wu, Y.; Fischer, J.A. Drosophila klaroid encodes a SUN domain protein required for Klarsicht localization to the nuclear envelope and nuclear migration in the eye. Fly 2007, 1, 75-85. [CrossRef]

180. Ulianov, S.V.; Doronin, S.A.; Khrameeva, E.E.; Kos, P.I.; Luzhin, A.V.; Starikov, S.S.; Galitsyna, A.A.; Nenasheva, V.V.; Ilyin, A.A.; Flyamer, I.M. Nuclear lamina integrity is required for proper spatial organization of chromatin in Drosophila. Nat. Commun. 2019, 10, 1176. [CrossRef]

181. Jahed, Z.; Hao, H.; Thakkar, V.; Vu, U.T.; Valdez, V.A.; Rathish, A.; Tolentino, C.; Kim, S.C.; Fadavi, D.; Starr, D.A. Role of KASH domain lengths in the regulation of LINC complexes. Mol. Biol. Cell 2019, 30, 2076-2086. [CrossRef]

182. Gurusaran, M.; Davies, O.R. A molecular mechanism for LINC complex branching by structurally diverse SUN-KASH 6: 6 assemblies. eLife 2021, 10, e60175. [CrossRef] [PubMed]

183. Alena, S.K.; Eva, B.; Aleš, K.; Emilie, L. Spatiotemporal Mislocalization of Nuclear Membrane-Associated Proteins in $\gamma$-IrradiationInduced Senescent Cells. Cells 2020, 9, 999.

184. Ketema, M.; Kreft, M.; Secades, P.; Janssen, H.; Sonnenberg, A. A Highlights from MBoC Selection: Nesprin-3 connects plectin and vimentin to the nuclear envelope of Sertoli cells but is not required for Sertoli cell function in spermatogenesis. Mol. Biol. Cell 2013, 24, 2454. [CrossRef] [PubMed]

185. Gonçalves, J.C.; Quintremil, S.; Yi, J.; Vallee, R.B. Nesprin-2 recruitment of BicD2 to the nuclear envelope controls dynein/kinesinmediated neuronal migration in vivo. Curr. Biol. 2020, 30, 3116-3129.e3114. [CrossRef]

186. Holt, I.; Fuller, H.R.; Sewry, C.A.; Shirran, S.L.; Zhang, Q.; Shanahan, C.M.; Morris, G.E. Nesprin-1-alpha2 associates with kinesin at myotube outer nuclear membranes, but is restricted to neuromuscular junction nuclei in adult muscle. Sci. Rep. 2019, 9, 14202. [CrossRef]

187. Porter, L.; Minaisah, R.-M.; Ahmed, S.; Ali, S.; Norton, R.; Zhang, Q.; Ferraro, E.; Molenaar, C.; Holt, M.; Cox, S. SUN1/2 are essential for RhoA/ROCK-regulated actomyosin activity in isolated vascular smooth muscle cells. Cells 2020, 9, 132. [CrossRef]

188. Matsumoto, A.; Sakamoto, C.; Matsumori, H.; Katahira, J.; Yasuda, Y.; Yoshidome, K.; Tsujimoto, M.; Goldberg, I.G.; Matsuura, N.; Nakao, M. Loss of the integral nuclear envelope protein SUN1 induces alteration of nucleoli. Nucleus 2016, 7, 68-83. [CrossRef]

189. Ahn, J.; Lee, J.; Jeong, S.; Kang, S.-m.; Park, B.-J.; Ha, N.-C. Beta-strand-mediated dimeric formation of the Ig-like domains of human lamin A/C and B1. Biochem. Biophys. Res. Commun. 2021, 550, 191-196. [CrossRef]

190. Parry, D.A.; Martin, C.-A.; Greene, P.; Marsh, J.A.; Blyth, M.; Cox, H.; Donnelly, D.; Greenhalgh, L.; Greville-Heygate, S.; Harrison, V. Heterozygous lamin B1 and lamin B2 variants cause primary microcephaly and define a novel laminopathy. Genet. Med. 2021, 23, 408-414. [CrossRef]

191. Xie, W.; Chojnowski, A.; Boudier, T.; Lim, J.S.; Ahmed, S.; Ser, Z.; Stewart, C.; Burke, B. A-type lamins form distinct filamentous networks with differential nuclear pore complex associations. Curr. Biol. 2016, 26, 2651-2658. [CrossRef]

192. Li, H.-P.; Liu, J.-T.; Chen, Y.-X.; Wang, W.-B.; Han, Y.; Yao, Q.-P.; Qi, Y.-X. Suppressed nuclear envelope proteins activate autophagy of vascular smooth muscle cells during cyclic stretch application. Biochim. Biophys. Acta BBA Mol. Cell Res. 2021, 1868, 118855. [CrossRef]

193. Shimi, T.; Kittisopikul, M.; Tran, J.; Goldman, A.E.; Adam, S.A.; Zheng, Y.; Jaqaman, K.; Goldman, R.D. Structural organization of nuclear lamins A, C, B1, and B2 revealed by superresolution microscopy. Mol. Biol. Cell 2015, 26, 4075-4086. [CrossRef]

194. Oldenburg, A.; Briand, N.; Sørensen, A.L.; Cahyani, I.; Shah, A.; Moskaug, J.Ø.; Collas, P. A lipodystrophy-causing lamin A mutant alters conformation and epigenetic regulation of the anti-adipogenic MIR335 locus. J. Cell Biol. 2017, 216, 2731-2743. [CrossRef]

195. Elosegui-Artola, A.; Andreu, I.; Beedle, A.E.M.; Lezamiz, A.; Uroz, M.; Kosmalska, A.J.; Oria, R.; Kechagia, J.Z.; Rico-Lastres, P.; Le Roux, A.-L.; et al. Force Triggers YAP Nuclear Entry by Regulating Transport across Nuclear Pores. Cell 2017, 171, 1397-1410. [CrossRef]

196. Serebryannyy, L.A.; Cruz, C.M.; De Lanerolle, P. A role for nuclear actin in HDAC 1 and 2 regulation. Sci. Rep. 2016, 6, 28460. [CrossRef]

197. Philimonenko, V.V.; Zhao, J.; Iben, S.; Dingová, H.; Kyselá, K.; Kahle, M.; Zentgraf, H.; Hofmann, W.A.; de Lanerolle, P.; Hozák, P. Nuclear actin and myosin I are required for RNA polymerase I transcription. Nat. Cell Biol. 2004, 6, 1165-1172. [CrossRef]

198. Hu, P.; Wu, S.; Hernandez, N. A role for $\beta$-actin in RNA polymerase III transcription. Genes Dev. 2004, 18, 3010-3015. [CrossRef]

199. Sokolova, M.; Moore, H.M.; Prajapati, B.; Dopie, J.; Meriläinen, L.; Honkanen, M.; Matos, R.C.; Poukkula, M.; Hietakangas, V.; Vartiainen, M.K. Nuclear actin is required for transcription during Drosophila oogenesis. iScience 2018, 9, 63-70. [CrossRef] 
200. Wei, M.; Fan, X.; Ding, M.; Li, R.; Shao, S.; Hou, Y.; Meng, S.; Tang, F.; Li, C.; Sun, Y. Nuclear actin regulates inducible transcription by enhancing RNA polymerase II clustering. Sci. Adv. 2020, 6, eaay6515. [CrossRef]

201. Plessner, M.; Melak, M.; Chinchilla, P.; Baarlink, C.; Grosse, R. Nuclear F-actin formation and reorganization upon cell spreading. J. Biol. Chem. 2015, 290, 11209-11216. [CrossRef]

202. Lattanzi, G.; Cenni, V.; Marmiroli, S.; Capanni, C.; Mattioli, E.; Merlini, L.; Squarzoni, S.; Maraldi, N.M. Association of emerin with nuclear and cytoplasmic actin is regulated in differentiating myoblasts. Biochem. Biophys. Res. Commun. 2003, 303, 764-770. [CrossRef]

203. Lombardi, M.L.; Jaalouk, D.E.; Shanahan, C.M.; Burke, B.; Roux, K.J.; Lammerding, J. The interaction between nesprins and sun proteins at the nuclear envelope is critical for force transmission between the nucleus and cytoskeleton. J. Biol. Chem. 2011, 286, 26743-26753. [CrossRef] [PubMed]

204. Kim, J.-K.; Louhghalam, A.; Lee, G.; Schafer, B.W.; Wirtz, D.; Kim, D.-H. Nuclear lamin A/C harnesses the perinuclear apical actin cables to protect nuclear morphology. Nat. Commun. 2017, 8, 2123. [CrossRef] [PubMed]

205. Lamm, N.; Read, M.N.; Nobis, M.; Van Ly, D.; Page, S.G.; Masamsetti, V.P.; Timpson, P.; Biro, M.; Cesare, A.J. Nuclear F-actin counteracts nuclear deformation and promotes fork repair during replication stress. Nat. Cell Biol. 2020, 22, 1460-1470. [CrossRef]

206. Cao, X.; Lin, Y.; Driscoll, T.P.; Franco-Barraza, J.; Cukierman, E.; Mauck, R.L.; Shenoy, V.B. A chemomechanical model of matrix and nuclear rigidity regulation of focal adhesion size. Biophys. J. 2015, 109, 1807-1817. [CrossRef]

207. Chancellor, T.; Lee, J.; Thodeti, C.K.; Lele, T. Actomyosin tension exerted on the nucleus through nesprin-1 connections influences endothelial cell adhesion, migration, and cyclic strain-induced reorientation. Biophys. J. 2010, 99, 115-123. [CrossRef]

208. Hoffman, L.M.; Smith, M.A.; Jensen, C.C.; Yoshigi, M.; Blankman, E.; Ullman, K.S.; Beckerle, M.C. Mechanical stress triggers nuclear remodeling and the formation of transmembrane actin nuclear lines with associated nuclear pore complexes. Mol. Biol. Cell 2020, 31, 1774-1787. [CrossRef]

209. Ren, J.; Li, Y.; Hu, S.; Liu, Y.; Tsao, S.W.; Lau, D.; Luo, G.; Tsang, C.M.; Lam, R.H. Nondestructive quantification of single-cell nuclear and cytoplasmic mechanical properties based on large whole-cell deformation. Lab Chip 2020, 20, 4175-4185. [CrossRef]

210. Guilluy, C.; Osborne, L.D.; Van Landeghem, L.; Sharek, L.; Superfine, R.; Garcia-Mata, R.; Burridge, K. Isolated nuclei adapt to force and reveal a mechanotransduction pathway in the nucleus. Nat. Cell Biol. 2014, 16, 376-381. [CrossRef]

211. Buxboim, A.; Swift, J.; Irianto, J.; Spinler, K.R.; Dingal, P.D.P.; Athirasala, A.; Kao, Y.-R.C.; Cho, S.; Harada, T.; Shin, J.-W. Matrix elasticity regulates lamin-A, C phosphorylation and turnover with feedback to actomyosin. Curr. Biol. 2014, 24, 1909-1917. [CrossRef]

212. Tifft, K.E.; Bradbury, K.A.; Wilson, K.L. Tyrosine phosphorylation of nuclear-membrane protein emerin by Src, Abl and other kinases. J. Cell Sci. 2009, 122, 3780-3790. [CrossRef]

213. Bera, M.; Kotamarthi, H.C.; Dutta, S.; Ray, A.; Ghosh, S.; Bhattacharyya, D.; Ainavarapu, S.R.K.; Sengupta, K. Characterization of Unfolding Mechanism of Human Lamin a Ig Fold by Single-Molecule Force Spectroscopy Implications in EDMD. Biochemistry 2014, 53, 7247-7258. [CrossRef]

214. Yao, M.; Qiu, W.; Liu, R.; Efremov, A.; Cong, P.; Seddiki, R.; Payre, M.; Lim, C.; Ladoux, B.; Mege, R.-M.; et al. Force-dependent conformational switch of $\alpha$-catenin controls vinculin binding. Nat. Commun. 2014, 5, 4525. [CrossRef]

215. Owens, D.J.; Fischer, M.; Jabre, S.; Moog, S.; Mamchaoui, K.; Butler-Browne, G.; Coirault, C. Lamin mutations cause increased YAP nuclear entry in muscle stem cells. Cells 2020, 9, 816. [CrossRef]

216. Stephens, A.D.; Banigan, E.J.; Adam, S.A.; Goldman, R.D.; Marko, J.F. Chromatin and lamin A determine two different mechanical response regimes of the cell nucleus. Mol. Biol. Cell 2017, 28, 1984-1996. [CrossRef]

217. Nava, M.M.; Miroshnikova, Y.A.; Biggs, L.C.; Whitefield, D.B.; Metge, F.; Boucas, J.; Vihinen, H.; Jokitalo, E.; Li, X.; Arcos, J.M.G. Heterochromatin-driven nuclear softening protects the genome against mechanical stress-induced damage. Cell 2020, 181, 800-817.e822. [CrossRef]

218. Quang Le, H.; Ghatak, S.; Chloé Yeung, C.-Y.; Tellkamp, F.; Günschmann, C.; Dieterich, C.; Yeroslaviz, A.; Habermann, B.; Pombo, A.; Niessen, C.M.; et al. Mechanical regulation of transcription controls Polycomb-mediated gene silencing during lineage commitment. Nat. Cell Biol. 2016, 18, 864-875.

219. Tajik, A.; Zhang, Y.; Wei, F.; Sun, J.; Jia, Q.; Zhou, W.; Singh, R.; Khanna, N.; Belmont, A.S.; Wang, N. Transcription upregulation via force-induced direct stretching of chromatin. Nat. Mater. 2016, 15, 1287-1296. [CrossRef]

220. Gadban, N.; Weinberg, E.; Zoabi, A.; Ashkenazi, M.; Yaffe, A.; Binderman, I. Strain reduction of human gingival fibroblasts induces the ATP pathway. J. Interdiscipl. Med. Dent. Sci. 2015, 3. [CrossRef]

221. Denes, B.J.; Bolton, C.; Illsley, C.; Kok, W.; Walker, J.; Poetsch, A.; Tredwin, C.; Kiliaridis, S.; Hu, B. Notch coordinates periodontal ligament maturation through regulating Lamin, A. J. Dent. Res. 2019, 98, 1357-1366. [CrossRef]

222. Shah, P.P.; Lv, W.; Rhoades, J.H.; Poleshko, A.; Abbey, D.; Caporizzo, M.A.; Linares-Saldana, R.; Heffler, J.G.; Sayed, N.; Thomas, D. Pathogenic LMNA variants disrupt cardiac lamina-chromatin interactions and de-repress alternative fate genes. Cell Stem Cell 2021, 28, 938-954.e9. [CrossRef] [PubMed]

223. Ishikawa, T.; Mishima, H.; Barc, J.; Takahashi, M.P.; Hirono, K.; Terada, S.; Kowase, S.; Sato, T.; Mukai, Y.; Yui, Y. Cardiac Emerinopathy: A Nonsyndromic Nuclear Envelopathy With Increased Risk of Thromboembolic Stroke Due to Progressive Atrial Standstill and Left Ventricular Noncompaction. Circ. Arrhythmia Electrophysiol. 2020, 13, e008712. [CrossRef] [PubMed]

224. Liang, J.J.; Goodsell, K.; Grogan, M.; Ackerman, M.J. LMNA-mediated arrhythmogenic right ventricular cardiomyopathy and charcot-marie-tooth type 2B1: A patient-discovered unifying diagnosis. J. Cardiovasc. Electrophysiol. 2016, 27, 868-871. [CrossRef] 
225. Huang, J.; Wan, Q.; Zou, Y.; Wang, L.; Pan, Y. Familial dilated cardiomyopathy caused by a novel variant in the Lamin A/C gene: A case report. BMC Cardiovasc. Disord. 2020, 20, 423. [CrossRef] [PubMed]

226. Erdos, M.R.; Cabral, W.A.; Tavarez, U.L.; Cao, K.; Gvozdenovic-Jeremic, J.; Narisu, N.; Zerfas, P.M.; Crumley, S.; Boku, Y.; Hanson, G. A targeted antisense therapeutic approach for Hutchinson-Gilford progeria syndrome. Nat. Med. 2021, 27, 536-545. [CrossRef] [PubMed]

227. Peric-Hupkes, D.; Meuleman, W.; Pagie, L.; Bruggeman, S.W.; Solovei, I.; Brugman, W.; Gräf, S.; Flicek, P.; Kerkhoven, R.M.; van Lohuizen, M. Molecular maps of the reorganization of genome-nuclear lamina interactions during differentiation. Mol. Cell 2010, 38, 603-613. [CrossRef]

228. Killaars, A.R.; Walker, C.J.; Anseth, K.S. Nuclear mechanosensing controls MSC osteogenic potential through HDAC epigenetic remodeling. Proc. Natl. Acad. Sci. USA 2020, 117, 21258-21266. [CrossRef] [PubMed]

229. Mozzetta, C.; Tedesco, F.S. Challenging the "chromatin hypothesis" of cardiac laminopathies with LMNA mutant iPS cells. J. Cell Biol. 2019, 218, 2826-2828. [CrossRef]

230. Swift, J.; Ivanovska, I.; Buxboim, A.; Harada, T.; Dingal, P.; Pinter, J.; Pajerowski, J.; Spinler, K.; Shin, J.; Manorama, T.; et al Nuclear Lamin-A Scales with Tissue Stiffness and Enhances Matrix-Directed Differentiation. Science 2013, 341, 1240104. [CrossRef]

231. Torvaldson, E.; Kochin, V.; Eriksson, J.E. Phosphorylation of lamins determine their structural properties and signaling functions. Nucleus 2015, 6, 166-171. [CrossRef]

232. Cho, S.; Vashisth, M.; Abbas, A.; Majkut, S.; Vogel, K.; Xia, Y.; Ivanovska, I.L.; Irianto, J.; Tewari, M.; Zhu, K. Mechanosensing by the lamina protects against nuclear rupture, DNA damage, and cell-cycle arrest. Dev. Cell 2019, 49, 920-935.e925. [CrossRef]

233. VanGompel, M.J.; Nguyen, K.C.; Hall, D.H.; Dauer, W.T.; Rose, L.S. A novel function for the Caenorhabditis elegans torsin OOC-5 in nucleoporin localization and nuclear import. Mol. Biol. Cell 2015, 26, 1752-1763. [CrossRef]

234. Li, J.; Levin, D.S.; Kim, A.J.; Pappas, S.S.; Dauer, W.T. TorsinA restoration in a mouse model identifies a critical therapeutic window for DYT1 dystonia. J. Clin. Investig. 2021. [CrossRef] [PubMed]

235. Gill, N.K.; Ly, C.; Kim, P.H.; Saunders, C.A.; Fong, L.G.; Young, S.G.; Luxton, G.; Rowat, A.C. DYT1 dystonia patient-derived fibroblasts have increased deformability and susceptibility to damage by mechanical forces. Front. Cell Dev. Biol. 2019, 7, 103. [CrossRef]

236. Huelgas-Morales, G.; Sanders, M.; Mekonnen, G.; Tsukamoto, T.; Greenstein, D. Decreased mechanotransduction prevents nuclear collapse in a Caenorhabditis elegans laminopathy. Proc. Natl. Acad. Sci. USA 2020, 117, 31301-31308. [CrossRef]

237. Maloney, $\mathrm{W}$. The integral role of the dentist in treating individuals with Hutchinson-Gilford progeria syndrome. DENTISTRY 2010, 1, WMC00446.

238. Reichert, C.; Gölz, L.; Götz, W.; Wolf, M.; Deschner, J.; Jäger, A. Dental and craniofacial characteristics in a patient with Hutchinson-Gilford progeria syndrome. J. Orofac. Orthop. Fortschr. Kieferorthopädie 2014, 75, 251-263. [CrossRef]

239. Bengtsson, V.W.; Persson, G.R.; Berglund, J.S.; Renvert, S. Periodontitis related to cardiovascular events and mortality: A long-time longitudinal study. Clin. Oral Investig. 2021, 25, 4085-4095. [CrossRef]

240. Almeida-Santos, A.; Martins-Mendes, D.; Gayà-Vidal, M.; Pérez-Pardal, L.; Beja-Pereira, A. Characterization of the oral microbiome of medicated type-2 diabetes patients. Front. Microbiol. 2021, 12, 56. [CrossRef]

241. Feng, Y.-K.; Wu, Q.-L.; Peng, Y.-W.; Liang, F.-Y.; You, H.-J.; Feng, Y.-W.; Li, G.; Li, X.-J.; Liu, S.-H.; Li, Y.-C.; et al. gingivalis impairs gut permeability and mediates immune responses associated with neurodegeneration in LRRK2 R1441G mice. J. Neuroinflammation 2020, 17, 347. [CrossRef]

242. Curtis, M.A.; Diaz, P.I.; Van Dyke, T.E. The role of the microbiota in periodontal disease. Periodontology 2000 2020, 83, 14-25. [CrossRef] [PubMed]

243. Groeger, S.E.; Meyle, J. Epithelial barrier and oral bacterial infection. Periodontology 2000 2015, 69, 46-67. [CrossRef] [PubMed]

244. Roberts, H.M.; Ling, M.R.; Insall, R.; Kalna, G.; Spengler, J.; Grant, M.M.; Chapple, I.L. Impaired neutrophil directional chemotactic accuracy in chronic periodontitis patients. J. Clin. Periodontol. 2015, 42,1-11. [CrossRef] [PubMed]

245. Gupta, S.; Mortensen, M.S.; Schjørring, S.; Trivedi, U.; Vestergaard, G.; Stokholm, J.; Bisgaard, H.; Krogfelt, K.A.; Sørensen, S.J. Amplicon sequencing provides more accurate microbiome information in healthy children compared to culturing. Commun. Biol. 2019, 2, 291. [CrossRef]

246. Arweiler, N.B.; Auschill, T.M.; Heumann, C.; Hellwig, E.; Al-Ahmad, A. Influence of Probiotics on the Salivary Microflora Oral Streptococci and Their Integration into Oral Biofilm. Antibiotics 2020, 9, 803. [CrossRef]

247. Moore, W.; Moore, L.V. The bacteria of periodontal diseases. Periodontology 2000 1994, 5, 66-77. [CrossRef]

248. Diaz, P.I.; Chalmers, N.I.; Rickard, A.H.; Kong, C.; Milburn, C.L.; Palmer, R.J.; Kolenbrander, P.E. Molecular characterization of subject-specific oral microflora during initial colonization of enamel. Appl. Environ. Microbiol. 2006, 72, 2837-2848. [CrossRef]

249. Abusleme, L.; Dupuy, A.K.; Dutzan, N.; Silva, N.; Burleson, J.A.; Strausbaugh, L.D.; Gamonal, J.; Diaz, P.I. The subgingival microbiome in health and periodontitis and its relationship with community biomass and inflammation. ISME J. 2013, 7, 1016-1025. [CrossRef]

250. Hong, B.-Y.; Araujo, M.V.F.; Strausbaugh, L.D.; Terzi, E.; Ioannidou, E.; Diaz, P.I. Microbiome profiles in periodontitis in relation to host and disease characteristics. PLoS ONE 2015, 10, e0127077. [CrossRef]

251. Souto, G.R.; Queiroz-Junior, C.M.; de Abreu, M.H.N.G.; Costa, F.O.; Mesquita, R.A. Pro-inflammatory, Th1, Th2, Th17 cytokines and dendritic cells: A cross-sectional study in chronic periodontitis. PLoS ONE 2014, 9, e91636. [CrossRef] 
252. Özkavaf, A.; Aras, H.; Huri, C.B.; Mottaghian-Dini, F.; Tözüm, T.F.; Etikan, I.; Yamalik, N.; Çaglayan, F. Relationship between the quantity of gingival crevicular fluid and clinical periodontal status. J. Oral Sci. 2000, 42, 231-238. [CrossRef]

253. Sandholm, L. Proteases and their inhibitors in chronic inflammatory periodontal disease. J. Clin. Periodontol. 1986, 13, 19-26. [CrossRef]

254. Laugisch, O.; Schacht, M.; Guentsch, A.; Kantyka, T.; Sroka, A.; Stennicke, H.; Pfister, W.; Sculean, A.; Potempa, J.; Eick, S. Periodontal pathogens affect the level of protease inhibitors in gingival crevicular fluid. Mol. Oral Microbiol. 2012, 27, 45-56. [CrossRef]

255. Fiorillo, L.; Cervino, G.; Laino, L.; D’Amico, C.; Mauceri, R.; Tozum, T.F.; Gaeta, M.; Cicciù, M. Porphyromonas gingivalis, periodontal and systemic implications: A systematic review. Dent. J. 2019, 7, 114. [CrossRef]

256. Nunes, J.M.; Fillis, T.; Page, M.J.; Venter, C.; Lancry, O.; Kell, D.B.; Windberger, U.; Pretorius, E. Gingipain R1 and lipopolysaccharide from Porphyromonas gingivalis have major effects on blood clot morphology and mechanics. Front. Immunol. 2020, 11. [CrossRef]

257. Katz, J.; Yang, Q.-B.; Zhang, P.; Potempa, J.; Travis, J.; Michalek, S.M.; Balkovetz, D.F. Hydrolysis of epithelial junctional proteins by Porphyromonas gingivalis gingipains. Infect. Immun. 2002, 70, 2512-2518. [CrossRef]

258. Feghali, K.; Grenier, D. Priming effect of fibronectin fragments on the macrophage inflammatory response: Potential contribution to periodontitis. Inflammation 2012, 35, 1696-1705. [CrossRef]

259. Lindemann, W.R.; Mijalis, A.J.; Alonso, J.L.; Borbat, P.P.; Freed, J.H.; Arnaout, M.A.; Pentelute, B.L.; Ortony, J.H. Conformational dynamics in extended RGD-containing peptides. Biomacromolecules 2020, 21, 2786-2794. [CrossRef]

260. Sela, M.N.; Babitski, E.; Steinberg, D.; Kohavi, D.; Rosen, G. Degradation of collagen-guided tissue regeneration membranes by proteolytic enzymes of Porphyromonas gingivalis and its inhibition by antibacterial agents. Clin. Oral Implant. Res. 2009, 20, 496-502. [CrossRef]

261. Mo, W.; Luo, H.; Wu, J.; Xu, N.; Zhang, F.; Qiu, Q.; Zhu, W.; Liang, M. Gingipains promote RANKL-induced osteoclastogenesis through the enhancement of integrin $\beta 3$ in RAW264. 7 cells. J. Mol. Histol. 2020, 51, 147-159. [CrossRef] [PubMed]

262. Chang, Y.; Hu, C.-C.; Wu, Y.-Y.; Ueng, S.W.; Chang, C.-H.; Chen, M.-F. Ibudilast Mitigates Delayed Bone Healing Caused by Lipopolysaccharide by Altering Osteoblast and Osteoclast Activity. Int. J. Mol. Sci. 2021, 22, 1169. [CrossRef] [PubMed]

263. Okahashi, N.; Inaba, H.; Nakagawa, I.; Yamamura, T.; Kuboniwa, M.; Nakayama, K.; Hamada, S.; Amano, A. Porphyromonas gingivalis induces receptor activator of NF- $\mathrm{kB}$ ligand expression in osteoblasts through the activator protein 1 pathway. Infect. Immun. 2004, 72, 1706-1714. [CrossRef] [PubMed]

264. Akiyama, T.; Miyamoto, Y.; Yoshimura, K.; Yamada, A.; Takami, M.; Suzawa, T.; Hoshino, M.; Imamura, T.; Akiyama, C.; Yasuhara R. Porphyromonas gingivalis-derived lysine gingipain enhances osteoclast differentiation induced by tumor necrosis factor- $\alpha$ and interleukin-1 $\beta$ but suppresses that by interleukin-17A: Importance of proteolytic degradation of osteoprotegerin by lysine gingipain. J. Biol. Chem. 2014, 289, 15621-15630. [CrossRef] [PubMed]

265. Tamashunas, A.C.; Katiyar, A.; Zhang, Q.; Purkayastha, P.; Singh, P.K.; Chukkapalli, S.S.; Lele, T.P. Osteoprotegerin is sensitive to actomyosin tension in human periodontal ligament fibroblasts. J. Cell. Physiol. 2021, 236, 5715-5724. [CrossRef]

266. Bergsma, A.; Ganguly, S.S.; Wiegand, M.E.; Dick, D.; Williams, B.O.; Miranti, C.K. Regulation of cytoskeleton and adhesion signaling in osteoclasts by tetraspanin CD82. Bone Rep. 2019, 10, 100196. [CrossRef]

267. Hočevar, K.; Vizovišek, M.; Wong, A.; Kozieł, J.; Fonović, M.; Potempa, B.; Lamont, R.J.; Potempa, J.; Turk, B. Proteolysis of Gingival Keratinocyte Cell Surface Proteins by Gingipains Secreted from Porphyromonas gingivalis-Proteomic Insights Into Mechanisms Behind Tissue Damage in the Diseased Gingiva. Front. Microbiol. 2020, 11, 722. [CrossRef]

268. Ruggiero, S.; Cosgarea, R.; Potempa, J.; Potempa, B.; Eick, S.; Chiquet, M. Cleavage of extracellular matrix in periodontitis: Gingipains differentially affect cell adhesion activities of fibronectin and tenascin-C. Biochim. Biophys. Acta BBA Mol. Basis Dis. 2013, 1832, 517-526. [CrossRef]

269. Qiu, Q.; Zhang, F.; Wu, J.; Xu, N.; Liang, M. Gingipains disrupt F-actin and cause osteoblast apoptosis via integrin $\beta 1$. J. Periodontal Res. 2018, 53, 762-776. [CrossRef]

270. Aliko, A.; Kamińska, M.; Bergum, B.; Gawron, K.; Benedyk, M.; Lamont, R.J.; Malicki, S.; Delaleu, N.; Potempa, J.; Mydel, P. Impact of Porphyromonas gingivalis peptidylarginine deiminase on bacterial biofilm formation, epithelial cell invasion, and epithelial cell transcriptional landscape. Sci. Rep. 2018, 8, 14144. [CrossRef]

271. Kinane, J.A.; Benakanakere, M.R.; Zhao, J.; Hosur, K.B.; Kinane, D.F. Porphyromonas gingivalis influences actin degradation within epithelial cells during invasion and apoptosis. Cell. Microbiol. 2012, 14, 1085-1096. [CrossRef]

272. Sheets, S.M.; Potempa, J.; Travis, J.; Fletcher, H.M.; Casiano, C.A. Gingipains from Porphyromonas gingivalis W83 synergistically disrupt endothelial cell adhesion and can induce caspase-independent apoptosis. Infect. Immun. 2006, 74, 5667-5678. [CrossRef]

273. Bugueno, I.M.; Batool, F.; Keller, L.; Kuchler-Bopp, S.; Benkirane-Jessel, N.; Huck, O. Porphyromonas gingivalis bypasses epithelial barrier and modulates fibroblastic inflammatory response in an in vitro 3D spheroid model. Sci. Rep. 2018, 8, 14914. [CrossRef]

274. Takeuchi, H.; Sasaki, N.; Yamaga, S.; Kuboniwa, M.; Matsusaki, M.; Amano, A. Porphyromonas gingivalis induces penetration of lipopolysaccharide and peptidoglycan through the gingival epithelium via degradation of junctional adhesion molecule 1. PLoS Pathog. 2019, 15, e1008124. [CrossRef]

275. Eick, S.; Gadzo, N.; Tacchi, M.; Sculean, A.; Potempa, J.; Stavropoulos, A. Gingipains impair attachment of epithelial cell to dental titanium abutment surfaces. J. Biomed. Mater. Res. Part. B Appl. Biomater. 2019, 107, 2549-2556. [CrossRef] 
276. Verrelli, D.I.; Albijanic, B. A comparison of methods for measuring the induction time for bubble-particle attachment. Miner. Eng. 2015, 80, 8-13. [CrossRef]

277. Inaba, H.; Sugita, H.; Kuboniwa, M.; Iwai, S.; Hamada, M.; Noda, T.; Morisaki, I.; Lamont, R.J.; Amano, A. Porphyromonas gingivalis promotes invasion of oral squamous cell carcinoma through induction of pro MMP 9 and its activation. Cell. Microbiol. 2014, 16, 131-145. [CrossRef]

278. Abdulkareem, A.; Shelton, R.; Landini, G.; Cooper, P.; Milward, M. Potential role of periodontal pathogens in compromising epithelial barrier function by inducing epithelial-mesenchymal transition. J. Periodontal Res. 2018, 53, 565-574. [CrossRef] [PubMed]

279. Huck, O.; Mulhall, H.; Rubin, G.; Kizelnik, Z.; Iyer, R.; Perpich, J.D.; Haque, N.; Cani, P.D.; de Vos, W.M.; Amar, S. Akkermansia muciniphila reduces Porphyromonas gingivalis-induced inflammation and periodontal bone destruction. J. Clin. Periodontol. 2020, 47, 202-212. [CrossRef]

280. Bhalla, U.S.; Iyengar, R. Emergent properties of networks of biological signaling pathways. Science 1999, 283, 381-387. [CrossRef]

281. Antmen, E.; Demirci, U.; Hasirci, V. Micropatterned Surfaces Expose the Coupling between Actin Cytoskeleton-Lamin/Nesprin and Nuclear Deformability of Breast Cancer Cells with Different Malignancies. Adv. Biol. 2021, 5, 2000048. [CrossRef]

282. Jung, Y.; Lee, S.-H.; Kim, S.-H.; Lim, J.C.; Kim, S.H. Synthesis and characterization of the biodegradable and elastic terpolymer poly (glycolide-co-L-lactide-co- $\epsilon$-caprolactone) for mechano-active tissue engineering. J. Biomater. Sci. Polym. Ed. 2013, 24, 386-397. [CrossRef] [PubMed]

283. Hörner, M.; Raute, K.; Hummel, B.; Madl, J.; Creusen, G.; Thomas, O.S.; Christen, E.H.; Hotz, N.; Gübeli, R.J.; Engesser, R. Phytochrome-based extracellular matrix with reversibly tunable mechanical properties. Adv. Mater. 2019, 31, 1806727. [CrossRef] [PubMed]

284. Kortsmit, J.; Davies, N.H.; Miller, R.; Macadangdang, J.R.; Zilla, P.; Franz, T. The effect of hydrogel injection on cardiac function and myocardial mechanics in a computational post-infarction model. Comput. Methods Biomech. Biomed. Eng. 2013, 16, 1185-1195. [CrossRef]

285. Wu, B.; Fu, Y.; Shi, H.; Yan, B.; Lu, R.; Ma, S.; Markert, B. Tensile testing of the mechanical behavior of the human periodontal ligament. Biomed. Eng. Online 2018, 17, 172. [CrossRef]

286. Uhlir, R.; Mayo, V.; Lin, P.H.; Chen, S.; Lee, Y.-T.; Hershey, G.; Lin, F.-C.; Ko, C.-C. Biomechanical characterization of the periodontal ligament: Orthodontic tooth movement. Angle Orthod. 2017, 87, 183-192. [CrossRef]

287. Pfisterer, K.; Lumicisi, B.; Parsons, M. Imaging of Human Cancer Cells in 3D Collagen Matrices. Bio Protoc. 2021, 11, e3889. [CrossRef]

288. Maeda, E.; Tsutsumi, T.; Kitamura, N.; Kurokawa, T.; Gong, J.P.; Yasuda, K.; Ohashi, T. Significant increase in Young's modulus of ATDC5 cells during chondrogenic differentiation induced by PAMPS/PDMAAm double-network gel: Comparison with induction by insulin. J. Biomech. 2014, 47, 3408-3414. [CrossRef]

289. Ettelt, V.; Belitsky, A.; Lehnert, M.; Loidl-Stahlhofen, A.; Epple, M.; Veith, M. Enhanced selective cellular proliferation by multi-biofunctionalization of medical implant surfaces with heterodimeric BMP-2/6, fibronectin, and FGF-2. J. Biomed. Mater. Res. Part. A 2018, 106, 2910-2922. [CrossRef]

290. Doyle, A.D.; Carvajal, N.; Jin, A.; Matsumoto, K.; Yamada, K.M. Local 3D matrix microenvironment regulates cell migration through spatiotemporal dynamics of contractility-dependent adhesions. Nat. Commun. 2015, 6, 8720. [CrossRef]

291. Qi, L.; Shi, C.; Li, J.; Xu, S.; Han, Y.; Li, J.; Zhang, L. Yes-associated protein promotes cell migration via activating Wiskott-Aldrich syndrome protein family member 1 in oral squamous cell carcinoma. J. Oral Pathol. Med. 2019, 48, 290-298. [CrossRef]

292. Wolf, K.; Te Lindert, M.; Krause, M.; Alexander, S.; Te Riet, J.; Willis, A.L.; Hoffman, R.M.; Figdor, C.G.; Weiss, S.J.; Friedl, P. Physical limits of cell migration: Control by ECM space and nuclear deformation and tuning by proteolysis and traction force. J. Cell Biol. 2013, 201, 1069-1084. [CrossRef] [PubMed]

293. Srinivasan, S.; Babensee, J.E. Controlled Delivery of Immunomodulators from a Biomaterial Scaffold Niche to Induce a Tolerogenic Phenotype in Human Dendritic Cells. ACS Biomater. Sci. Eng. 2020, 6, 4062-4076. [CrossRef] [PubMed]

294. Kara, A.; Koçtürk, S.; Bilici, G.; Havitcioglu, H. Development of biological meniscus scaffold: Decellularization method and recellularization with meniscal cell population derived from mesenchymal stem cells. J. Biomater. Appl. 2021, 0885328220981189. [CrossRef]

295. Amler, A.-K.; Thomas, A.; Tüzüner, S.; Lam, T.; Geiger, M.-A.; Kreuder, A.-E.; Palmer, C.; Nahles, S.; Lauster, R.; Kloke, L. 3D bioprinting of tissue-specific osteoblasts and endothelial cells to model the human jawbone. Sci. Rep. 2021, 11, 4876. [CrossRef]

296. Zeng, W.-Y.; Ning, Y.; Huang, X. Advanced technologies in periodontal tissue regeneration based on stem cells: Current status and future perspectives. J. Dent. Sci. 2020, 16, 501-507. [CrossRef]

297. Lepsky, V.R.; Natan, S.; Tchaicheeyan, O.; Kolel, A.; Zussman, M.; Zilberman, M.; Lesman, A. FITC-Dextran Release from Cell-Embedded Fibrin Hydrogels. Biomolecules 2021, 11, 337. [CrossRef]

298. Selig, M.; Lauer, J.C.; Hart, M.L.; Rolauffs, B. Mechanotransduction and Stiffness-Sensing: Mechanisms and Opportunities to Control Multiple Molecular Aspects of Cell Phenotype as a Design Cornerstone of Cell-Instructive Biomaterials for Articular Cartilage Repair. Int. J. Mol. Sci. 2020, 21, 5399. [CrossRef]

299. Ayuningtyas, F.D.; Kim, M.-H.; Kino-Oka, M. Muscle lineage switching by migratory behaviour-driven epigenetic modifications of human mesenchymal stem cells on a dendrimer-immobilized surface. Acta Biomater. 2020, 106, 170-180. [CrossRef]

300. Merrett, K.; Wan, F.; Lee, C.-J.; Harden, J.L. Enhanced Collagen-like Protein for Facile Biomaterial Fabrication. ACS Biomater. Sci. Eng. 2021. [CrossRef] 
301. Guo, J.; Kim, Y.; Xie, V.; Smith, B.; Watson, E.; Lam, J.; Pearce, H.; Engel, P.; Mikos, A. Modular, tissue-specific, and biodegradable hydrogel cross-linkers for tissue engineering. Sci. Adv. 2019, 5, eaaw7396. [CrossRef]

302. Guo, J.L.; Li, A.; Kim, Y.S.; Xie, V.Y.; Smith, B.T.; Watson, E.; Bao, G.; Mikos, A.G. Click functionalized, tissue-specific hydrogels for osteochondral tissue engineering. J. Biomed. Mater. Res. Part. A 2020, 108, 684-693. [CrossRef]

303. Yuan, Y.; Loh, Y.-h.E.; Han, X.; Feng, J.; Ho, T.-V.; He, J.; Jing, J.; Groff, K.; Wu, A.; Chai, Y. Spatiotemporal cellular movement and fate decisions during first pharyngeal arch morphogenesis. Sci. Adv. 2020, 6, eabb0119. [CrossRef]

304. Stewart, S.A.; Domínguez-Robles, J.; Donnelly, R.F.; Larrañeta, E. Implantable polymeric drug delivery devices: Classification, manufacture, materials, and clinical applications. Polymers 2018, 10, 1379. [CrossRef]

305. Hernández Martinez, V.M.; Garcia Benavides, L.; Totsuka Sutto, S.E.; Cardona Muñoz, E.G.; Campos Bayardo, T.I.; Pascoe Gonzalez, S. Effectiveness of degradable and non-degradable implants to close large septal perforations in an experimental model. J. Plast. Surg. Hand Surg. 2016, 50, 222-226. [CrossRef]

306. Colaris, M.J.; de Boer, M.; van der Hulst, R.R.; Tervaert, J.W.C. Two hundreds cases of ASIA syndrome following silicone implants: A comparative study of 30 years and a review of current literature. Immunol. Res. 2017, 65, 120-128. [CrossRef]

307. Kim, H.; Hong, J.Y.; Jeon, W.-J.; Lee, J.; Ha, I.-H. Evaluation of the effects of differences in silicone hardness on rat model of lumbar spinal stenosis. PLoS ONE 2021, 16, e0251464. [CrossRef]

308. Sharma, S.; Mandhani, A.; Bose, S.; Basu, B. Dynamically crosslinked polydimethylsiloxane-based polyurethanes with contactkilling antimicrobial properties as implantable alloplasts for urological reconstruction. Acta Biomater. 2021. [CrossRef]

309. Valipour, F.; Valipour, F.; Rahbarghazi, R.; Navali, A.M.; Rashidi, M.R.; Davaran, S. Novel hybrid polyester-polyacrylate hydrogels enriched with platelet-derived growth factor for chondrogenic differentiation of adipose-derived mesenchymal stem cells in vitro. J. Biol. Eng. 2021, 15, 6. [CrossRef]

310. Khandaker, M.; Kotturi, H.; Progri, H.; Tummala, S.; Nikfarjam, S.; Rao, P.; Hosna, A.U.; Arasu, D.T.; Williams, W.; Haleem, A In vitro and in vivo effect of polycaprolactone nanofiber coating on polyethylene glycol diacrylate scaffolds for intervertebral disc repair. Biomed. Mater. 2021. [CrossRef]

311. Milojević, M.; Harih, G.; Vihar, B.; Vajda, J.; Gradišnik, L.; Zidarič, T.; Stana Kleinschek, K.; Maver, U.; Maver, T. Hybrid 3D Printing of Advanced Hydrogel-Based Wound Dressings with Tailorable Properties. Pharmaceutics 2021, 13, 564. [CrossRef]

312. Ferrández-Montero, A.; Eguiluz, A.; Vazquez, E.; Guerrero, J.D.; Gonzalez, Z.; Sanchez-Herencia, A.J.; Ferrari, B. Controlled SrR Delivery by the Incorporation of Mg Particles on Biodegradable PLA-Based Composites. Polymers 2021, 13, 1061. [CrossRef]

313. Lu, Y.; Wang, Y.; Zhang, H.; Tang, Z.; Cui, X.; Li, X.; Liang, J.; Wang, Q.; Fan, Y.; Zhang, X. Solubilized Cartilage ECM Facilitates the Recruitment and Chondrogenesis of Endogenous BMSCs in Collagen Scaffolds for Enhancing Microfracture Treatment. ACS Appl. Mater. Interfaces 2021. [CrossRef]

314. Rahoui, N.; Jiang, B.; Taloub, N.; Huang, Y.D. Spatio-temporal control strategy of drug delivery systems based nano structures. J. Control. Release 2017, 255, 176-201. [CrossRef]

315. Arpornmaeklong, P.; Sareethammanuwat, M.; Apinyauppatham, K.; Boonyuen, S. Characteristics and biologic effects of thermosensitive quercetin-chitosan/collagen hydrogel on human periodontal ligament stem cells. J. Biomed. Mater. Res. Part. B Appl. Biomater. 2021. [CrossRef]

316. Johnson, A.; Kong, F.; Miao, S.; Lin, H.-T.V.; Thomas, S.; Huang, Y.-C.; Kong, Z.-L. Therapeutic effects of antibiotics loaded cellulose nanofiber and $\kappa$-carrageenan oligosaccharide composite hydrogels for periodontitis treatment. Sci. Rep. 2020, 10, 18037.

317. Asparuhova, M.B.; Stähli, A.; Guldener, K.; Sculean, A. A Novel Volume-Stable Collagen Matrix Induces Changes in the Behavior of Primary Human Oral Fibroblasts, Periodontal Ligament, and Endothelial Cells. Int. J. Mol. Sci. 2021, 22, 4051. [CrossRef]

318. Chen, H.; Dai, Y.; Cui, J.; Yin, X.; Feng, W. Carbon Monoxide Releasing Molecule-3 Enhances Osteogenic Differentiation of Human Periodontal Ligament Stem Cells by Carbon Monoxide Release. Drug Des. Dev. Ther. 2021, 15, 1691. [CrossRef]

319. Peng, W.; Ren, S.; Zhang, Y.; Fan, R.; Zhou, Y.; Li, L.; Xu, X.; Xu, Y. MgO Nanoparticles-Incorporated PCL/Gelatin-Derived Coaxial Electrospinning Nanocellulose Membranes for Periodontal Tissue Regeneration. Front. Bioeng. Biotechnol. 2021, 9, 216. [CrossRef]

320. Synytsya, A.; Poučková, P.; Zadinová, M.; Troshchynska, Y.; Štětina, J.; Synytsya, A.; Saloň, I.; Král, V. Hydrogels based on low-methoxyl amidated citrus pectin and flaxseed gum formulated with tripeptide glycyl-l-histidyl-l-lysine improve the healing of experimental cutting wounds in rats. Int. J. Biol. Macromol. 2020, 165, 3156-3168. [CrossRef]

321. Zhao, B.; Chen, J.; Zhao, L.; Deng, J.; Li, Q. A simvastatin-releasing scaffold with periodontal ligament stem cell sheets for periodontal regeneration. J. Appl. Biomater. Funct. Mater. 2020, 18, 2280800019900094. [CrossRef]

322. Panzeri, S.; Arosio, D.; Gazzola, S.; Belvisi, L.; Civera, M.; Potenza, D.; Vasile, F.; Kemker, I.; Ertl, T.; Sewald, N. Cyclic RGD and isoDGR Integrin Ligands Containing cis-2-amino-1-cyclopentanecarboxylic (cis- $\beta$-ACPC) Scaffolds. Molecules 2020, $25,5966$. [CrossRef] [PubMed]

323. Almonte-Becerril, M.; Gimeno-LLuch, I.; Villarroya, O.; Benito-Jardón, M.; Kouri, J.B.; Costell, M. Genetic abrogation of the fibronectin- $\alpha 5 \beta 1$ integrin interaction in articular cartilage aggravates osteoarthritis in mice. PLoS ONE 2018, 13, e0198559. [CrossRef] [PubMed]

324. Massam-Wu, T.; Chiu, M.; Choudhury, R.; Chaudhry, S.S.; Baldwin, A.K.; McGovern, A.; Baldock, C.; Shuttleworth, C.A.; Kielty, C.M. Assembly of fibrillin microfibrils governs extracellular deposition of latent TGF $\beta$. J. Cell Sci. 2010, 123, 3006-3018. [CrossRef] [PubMed] 
325. Khorolsuren, Z.; Lang, O.; Pallinger, E.; Foldes, A.; Szabolcs, G.G.; Varga, G.; Mezo, G.; Vag, J.; Kohidai, L. Functional and cell surface characteristics of periodontal ligament cells (PDLCs) on RGD-synthetic polypeptide conjugate coatings. J. Periodontal Res. 2020, 55, 713-723. [CrossRef]

326. Matsugami, D.; Murakami, T.; Yoshida, W.; Imamura, K.; Bizenjima, T.; Seshima, F.; Saito, A. Treatment with functionalized designer self-assembling peptide hydrogels promotes healing of experimental periodontal defects. J. Periodontal Res. 2021, 56, 162-172. [CrossRef]

327. Etemadi Sh, M.; Hsieh, N.-C.; Movahed Mohammadi, S.S.; Momeni, S.; Razavi, S.M.; Alizargar, J. Histological and Radiological Evaluation of Low-Intensity Pulsed Ultrasound Versus Whole Body Vibration on Healing of Mandibular Bone Defects in Rats. Medicina 2020, 56, 457. [CrossRef]

328. Li, H.; Deng, Y.; Tan, M.; Feng, G.; Kuang, Y.; Li, J.; Song, J. Low-intensity pulsed ultrasound upregulates osteogenesis under inflammatory conditions in periodontal ligament stem cells through unfolded protein response. Stem Cell Res. Ther. 2020, 11, 215.

329. Shobara, K.; Ogawa, T.; Shibamoto, A.; Miyashita, M.; Ito, A.; Sitalaksmi, R.M. Osteogenic effect of low-intensity pulsed ultrasound and whole-body vibration on peri-implant bone. An experimental in vivo study. Clin. Oral Implant. Res. 2021, 32, 641-650. [CrossRef]

330. Liu, X.; Hu, Y.; Wu, L.; Li, S. Effects of collimated and focused low-intensity pulsed ultrasound stimulation on the mandible repair in rabbits. Ann. Transl. Med. 2020, 8, 98. [CrossRef]

331. Shimizu, T.; Fujita, N.; Tsuji-Tamura, K.; Kitagawa, Y.; Fujisawa, T.; Tamura, M.; Sato, M. Osteocytes as main responders to low-intensity pulsed ultrasound treatment during fracture healing. Sci. Rep. 2021, 11, 10298. [CrossRef]

332. Wang, Y.; Qiu, Y.; Li, J.; Zhao, C.; Song, J. Low-intensity pulsed ultrasound promotes alveolar bone regeneration in a periodontal injury model. Ultrasonics 2018, 90, 166-172. [CrossRef]

333. Li, H.; Zhou, J.; Zhu, M.; Ying, S.; Li, L.; Chen, D.; Li, J.; Song, J. Low-intensity pulsed ultrasound promotes the formation of periodontal ligament stem cell sheets and ectopic periodontal tissue regeneration. J. Biomed. Mater. Res. Part. A 2021, 109, 1101-1112. [CrossRef]

334. Li, Y.; Sun, C.; Feng, G.; He, Y.; Li, J.; Song, J. Low-intensity pulsed ultrasound activates autophagy in periodontal ligament cells in the presence or absence of lipopolysaccharide. Arch. Oral Biol. 2020, 117, 104769. [CrossRef]

335. Ying, S.; Tan, M.; Feng, G.; Kuang, Y.; Chen, D.; Li, J.; Song, J. Low-intensity Pulsed Ultrasound regulates alveolar bone homeostasis in experimental Periodontitis by diminishing Oxidative Stress. Theranostics 2020, 10, 9789. [CrossRef]

336. Liu, S.; Zhou, M.; Li, J.; Hu, B.; Jiang, D.; Huang, H.; Song, J. LIPUS inhibited the expression of inflammatory factors and promoted the osteogenic differentiation capacity of hPDLCs by inhibiting the NF- $\mathrm{KB}$ signaling pathway. J. Periodontal Res. 2020, 55, 125-140. [CrossRef]

337. Alshihah, N.; Alhadlaq, A.; El-Bialy, T.; Aldahmash, A.; Bello, I. The effect of low intensity pulsed ultrasound on dentoalveolar structures during orthodontic force application in diabetic ex-vivo model. Arch. Oral Biol. 2020, 119, 104883. [CrossRef]

338. Jiang, Y.; Yuan, Y.; Xiong, Y.; Wang, B.; Guo, Y.; Gong, P.; Zhang, L. Low-intensity pulsed ultrasound improves osseointegration of dental implant in mice by inducing local neuronal production of $\alpha$ CGRP. Arch. Oral Biol. 2020, 115, 104736. [CrossRef]

339. Callhoff, J.; Dietrich, T.; Chubrieva, M.; Klotsche, J.; Zink, A. A patient-reported questionnaire developed in a German early arthritis cohort to assess periodontitis in patients with rheumatoid arthritis. Arthritis Res. Ther. 2019, 21, 197. [CrossRef]

340. Strassburg, S.; Caduc, M.; Stark, G.B.; Jedrusik, N.; Tomakidi, P.; Steinberg, T.; Simunovic, F.; Finkenzeller, G. In vivo evaluation of an electrospun gelatin nonwoven mat for regeneration of epithelial tissues. J. Biomed. Mater. Res. Part A 2019, 107, 1605-1614. [CrossRef]

341. Schulz, S.; Angarano, M.; Fabritius, M.; Mülhaupt, R.; Dard, M.; Obrecht, M.; Tomakidi, P.; Steinberg, T. Nonwoven-based gelatin/polycaprolactone membrane proves suitability in a preclinical assessment for treatment of soft tissue defects. Tissue Eng. Part. A 2014, 20, 1935-1947. [CrossRef]

342. Jedrusik, N.; Steinberg, T.; Husari, A.; Volk, L.; Wang, X.; Finkenzeller, G.; Strassburg, S.; Tomakidi, P. Gelatin nonwovens-based epithelial morphogenesis involves a signaling axis comprising EGF-receptor, MAP kinases ERK 1/2, and $\beta 1$ integrin. J. Biomed. Mater. Res. Part. A 2019, 107, 663-677. [CrossRef]

343. Jedrusik, N.; Meyen, C.; Finkenzeller, G.; Stark, G.B.; Meskath, S.; Schulz, S.D.; Steinberg, T.; Eberwein, P.; Strassburg, S.; Tomakidi, P. Nanofibered gelatin-based nonwoven elasticity promotes epithelial Histogenesis. Adv. Healthc. Mater. 2018, 7, 1700895. [CrossRef]

344. Dunnwald, M.; Tomanek-Chalkley, A.; Alexandrunas, D.; Fishbaugh, J.; Bickenbach, J. Isolating a pure population of epidermal stem cells for use in tissue engineering. Exp. Dermatol. 2001, 10, 45-54. [CrossRef]

345. Franzè, E.; Monteleone, I.; Laudisi, F.; Rizzo, A.; Dinallo, V.; Di Fusco, D.; Colantoni, A.; Ortenzi, A.; Giuffrida, P.; Di Carlo, S. Cadherin-11 is a Regulator of intestinal fibrosis. J. Crohn's Colitis 2020, 14, 406-417. [CrossRef]

346. Niu, C.; Yang, P.; Yao, B. Engineering Protease-Resistant and Highly Active Phytases. In Inositol Phosphates; Springer: New York, NY, USA, 2020; pp. 155-162.

347. Frank, C.F.; Hostetter, M.K. Cleavage of E-cadherin: A mechanism for disruption of the intestinal epithelial barrier by Candida albicans. Transl. Res. 2007, 149, 211-222. [CrossRef]

348. Oh, C.; Kim, H.J.; Kim, H.-M. Vitamin D maintains E-cadherin intercellular junctions by downregulating MMP-9 production in human gingival keratinocytes treated by TNF- $\alpha$. J. Periodontal Implant. Sci. 2019, 49, 270. [CrossRef] 
349. Jin, C.; Lee, G.; Oh, C.; Kim, H.J.; Kim, H.-M. Substrate roughness induces the development of defective E-cadherin junctions in human gingival keratinocytes. J. Periodontal Implant. Sci. 2017, 47, 116. [CrossRef]

350. Bischoff, M.C.; Lieb, S.; Renkawitz-Pohl, R.; Bogdan, S. Filopodia-based contact stimulation of cell migration drives tissue morphogenesis. Nat. Commun. 2021, 12, 791. [CrossRef] [PubMed]

351. Dyberg, C.; Fransson, S.; Andonova, T.; Sveinbjörnsson, B.; Lännerholm-Palm, J.; Olsen, T.K.; Forsberg, D.; Herlenius, E.; Martinsson, T.; Brodin, B. Rho-associated kinase is a therapeutic target in neuroblastoma. Proc. Natl. Acad. Sci. USA 2017, 114, E6603-E6612. [CrossRef]

352. Macks, C.; Jeong, D.; Lee, J.S. Local delivery of RhoA siRNA by PgP nanocarrier reduces inflammatory response and improves neuronal cell survival in a rat TBI model. Nanomed. Nanotechnol. Biol. Med. 2021, 32, 102343. [CrossRef]

353. Fogli, S.; Stefanelli, F.; Battolla, B.; Bianchi, F.; Breschi, M.C.; Mattii, L. Salbutamol inhibits RhoA activation in normal but not in desensitized bronchial smooth muscle cells. J. Pharm. Pharmacol. 2015, 67, 1416-1420. [CrossRef] [PubMed]

354. Fujimoto, T.; Sato-Ohira, S.; Tanihara, H.; Inoue, T. RhoA activation decreases phagocytosis of trabecular meshwork cells. Curr. Eye Res. 2020, 496-503. [CrossRef] [PubMed]

355. Goto, R.; Nishida, E.; Kobayashi, S.; Aino, M.; Ohno, T.; Iwamura, Y.; Kikuchi, T.; Hayashi, J.-i.; Yamamoto, G.; Asakura, M. Gelatin Methacryloyl-Riboflavin (GelMA-RF) Hydrogels for Bone Regeneration. Int. J. Mol. Sci. 2021, 22, 1635. [CrossRef] [PubMed]

356. Kim, S.; Kang, J.Y.; Ballance, W.C.; Sutton, B.P.; Shin, D.H.; Jang, K.H.; Shin, M.; Kong, H.; Kim, J.W. Fabrication of cell penetrating peptide-conjugated bacterial cellulose nanofibrils with remarkable skin adhesion and water retention performance. Int. J. Pharm. 2021, 600, 120476. [CrossRef] [PubMed]

357. Tone, Y.; Mamchaoui, K.; Tsoumpra, M.K.; Hashimoto, Y.; Terada, R.; Maruyama, R.; Gait, M.J.; Arzumanov, A.A.; McClorey, G.; Imamura, M. Immortalized Canine Dystrophic Myoblast Cell Lines for Development of Peptide-Conjugated Splice-Switching Oligonucleotides. Nucleic Acid Ther. 2021, 31, 172-181. [CrossRef]

358. Unkart, J.T.; Chen, S.L.; Wapnir, I.L.; González, J.E.; Harootunian, A.; Wallace, A.M. Intraoperative tumor detection using a ratiometric activatable fluorescent peptide: A first-in-human phase 1 study. Ann. Surg. Oncol. 2017, 24, 3167-3173. [CrossRef]

359. Lulla, R.R.; Goldman, S.; Yamada, T.; Beattie, C.W.; Bressler, L.; Pacini, M.; Pollack, I.F.; Fisher, P.G.; Packer, R.J.; Dunkel, I.J. Phase I trial of p28 (NSC745104), a non-HDM2-mediated peptide inhibitor of p53 ubiquitination in pediatric patients with recurrent or progressive central nervous system tumors: A Pediatric Brain Tumor Consortium Study. Neuro Oncol. 2016, 18, 1319-1325. [CrossRef]

360. Zhang, G.; Dai, S.; Chen, Y.; Wang, H.; Chen, T.; Shu, Q.; Chen, S.; Shou, L.; Cai, X. Aqueous extract of Taxus chinensis var. mairei regulates the Hippo-YAP pathway and promotes apoptosis of non-small cell lung cancer via ATF3 in vivo and in vitro. Biomed. Pharmacother. 2021, 138, 111506. [CrossRef] [PubMed]

361. Wang, Y.; Zhang, Y.; Feng, X.; Tian, H.; Fu, X.; Gu, W.; Wen, Y. Metformin inhibits mTOR and c-Myc by decreasing YAP protein expression in OSCC cells. Oncol. Rep. 2021, 45, 1249-1260. [CrossRef] [PubMed]

362. Lim, T.H.; Lai, T.Y.; Takahashi, K.; Wong, T.Y.; Chen, L.-J.; Ruamviboonsuk, P.; Tan, C.S.; Lee, W.K.; Cheung, C.M.G.; Ngah, N.F Comparison of ranibizumab with or without Verteporfin photodynamic therapy for polypoidal choroidal vasculopathy: The EVEREST II Randomized Clinical Trial. JAMA Ophthalmol. 2020, 138, 935-942. [CrossRef]

363. Wang, C.; Zhu, X.; Feng, W.; Yu, Y.; Jeong, K.; Guo, W.; Lu, Y.; Mills, G.B. Verteporfin inhibits YAP function through up-regulating 14-3-3 $\sigma$ sequestering YAP in the cytoplasm. Am. J. Cancer Res. 2016, 6, 27-37. [PubMed]

364. Zhou, L.; Wang, Q.; Zhang, H.; Li, Y.; Xie, S.; Xu, M. YAP Inhibition by Nuciferine via AMPK-Mediated Downregulation of HMGCR Sensitizes Pancreatic Cancer Cells to Gemcitabine. Biomolecules 2019, 9, 620. [CrossRef] [PubMed]

365. Cassino, T.R.; Drowley, L.; Okada, M.; Beckman, S.A.; Keller, B.; Tobita, K.; LeDuc, P.R.; Huard, J. Mechanical loading of stem cells for improvement of transplantation outcome in a model of acute myocardial infarction: The role of loading history. Tissue Eng. Part A 2012, 18, 1101-1108. [CrossRef] [PubMed]

366. Götschi, T.; Schulz, N.; Snedeker, J.G.; Hanimann, J.; Franchi, M.V.; Spörri, J. Three-Dimensional Mapping of Shear Wave Velocity in Human Tendon: A Proof of Concept Study. Sensors 2021, 21, 1655. [CrossRef]

367. Wang, Z.; Weng, Y.; Ishihara, Y.; Odagaki, N.; Hlaing, E.E.H.; Izawa, T.; Okamura, H.; Kamioka, H. Loading history changes the morphology and compressive force-induced expression of receptor activator of nuclear factor kappa B ligand/osteoprotegerin in MLO-Y4 osteocytes. PeerJ 2020, 8, e10244. [CrossRef]

368. Bidan, C.M.; Fratzl, M.; Coullomb, A.; Moreau, P.; Lombard, A.H.; Wang, I.; Balland, M.; Boudou, T.; Dempsey, N.M.; Devillers, T. Magneto-active substrates for local mechanical stimulation of living cells. Sci. Rep. 2018, 8, 1464. [CrossRef]

369. Kojima, T.; Husari, A.; Dieterle, M.P.; Fontaine, S.; Prucker, O.; Tomakidi, P.; Rühe, J. PnBA/PDMAA-Based Iron-Loaded Micropillars Allow for Discrete Cell Adhesion and Analysis of Actuation-Related Molecular Responses. Adv. Mater. Interfaces 2020, 7, 1901806. [CrossRef]

370. Chatelet, M.; Afota, F.; Savoldelli, C. Review of bone graft and implant survival rate: A comparison between autogenous bone block versus guided bone regeneration. J. Stomatol. Oral Maxillofac. Surg. 2021. [CrossRef]

371. Yu, D.; Huang, C.; Jiang, C.; Zhu, H. Features of a simvastatin-loaded multi-layered co-electrospun barrier membrane for guided bone regeneration. Exp. Ther. Med. 2021, 22, 713. [CrossRef]

372. Porrelli, D.; Mardirossian, M.; Musciacchio, L.; Pacor, M.; Berton, F.; Crosera, M.; Turco, G. Antibacterial Electrospun Polycaprolactone Membranes Coated with Polysaccharides and Silver Nanoparticles for Guided Bone and Tissue Regeneration. ACS Appl. Mater. Interfaces 2021, 13, 17255-17267. [CrossRef] 
373. De Souza Balbinot, G.; da Cunha Bahlis, E.A.; Visioli, F.; Leitune, V.C.B.; Soares, R.M.D.; Collares, F.M. Polybutylene-adipateterephthalate and niobium-containing bioactive glasses composites: Development of barrier membranes with adjusted properties for guided bone regeneration. Mater. Sci. Eng. C 2021, 125, 112115. [CrossRef]

374. Küçüktürkmen, B.; Öz, U.C.; Toptaş, M.; Devrim, B.; Saka, O.M.; Bilgili, H.; Deveci, M.S.; Ünsal, E.; Bozkır, A. Development of Zoledronic Acid Containing Biomaterials for Enhanced Guided Bone Regeneration. J. Pharm. Sci. 2021. [CrossRef]

375. Toledano-Osorio, M.; Manzano-Moreno, F.J.; Toledano, M.; Osorio, R.; Medina-Castillo, A.L.; Costela-Ruiz, V.J.; Ruiz, C. Doxycycline-doped membranes induced osteogenic gene expression on osteoblastic cells. J. Dent. 2021, 109, 103676. [CrossRef]

376. Toledano-Osorio, M.; Manzano-Moreno, F.J.; Toledano, M.; Medina-Castillo, A.L.; Costela-Ruiz, V.J.; Ruiz, C.; Osorio, R. Doxycycline-Doped Polymeric Membranes Induced Growth, Differentiation and Expression of Antigenic Phenotype Markers of Osteoblasts. Polymers 2021, 13, 1063. [CrossRef]

377. Naenni, N.; Stucki, L.; Huesler, J.; Schneider, D.; Hämmerle, C.H.; Jung, R.E.; Thoma, D.S. Implants sites with concomitant bone regeneration using a resorbable or non-resorbable membrane result in stable marginal bone levels and similar profilometric outcomes over 5 years. Clin. Oral Implant. Res. 2021. [CrossRef]

378. Li, J.; Yan, J.-F.; Wan, Q.-Q.; Shen, M.-J.; Ma, Y.-X.; Gu, J.-T.; Gao, P.; Tang, X.-Y.; Yu, F.; Chen, J.-H. Matrix stiffening by self-mineralizable guided bone regeneration. Acta Biomater. 2021, 125, 112-125. [CrossRef]

379. Barajaa, M.A.; Nair, L.S.; Laurencin, C.T. Bioinspired scaffold designs for regenerating musculoskeletal tissue interfaces. Regen. Eng. Transl. Med. 2020, 6, 451-483. [CrossRef]

380. Li, J.; Liu, Y.; Zhang, Y.; Yao, B.; Li, Z.; Song, W.; Wang, Y.; Duan, X.; Yuan, X.; Fu, X. Biophysical and Biochemical Cues of Biomaterials Guide Mesenchymal Stem Cell Behaviors. Front. Cell Dev. Biol. 2021, 9, 397.

381. De Medeiros, G.; Kromm, D.; Balazs, B.; Norlin, N.; Günther, S.; Izquierdo, E.; Ronchi, P.; Komoto, S.; Krzic, U.; Schwab, Y. Cell and tissue manipulation with ultrashort infrared laser pulses in light-sheet microscopy. Sci. Rep. 2020, 10, 1942.

382. Ma, Y.; Lin, M.; Huang, G.; Li, Y.; Wang, S.; Bai, G.; Lu, T.J.; Xu, F. 3D spatiotemporal mechanical microenvironment: A hydrogel-based platform for guiding stem cell fate. Adv. Mater. 2018, 30, 1705911. [CrossRef]

383. Richter, B.; Hahn, V.; Bertels, S.; Claus, T.K.; Wegener, M.; Delaittre, G.; Barner-Kowollik, C.; Bastmeyer, M. Guiding cell attachment in 3D microscaffolds selectively functionalized with two distinct adhesion proteins. Adv. Mater. 2017, 29, 1604342. [CrossRef]

384. Li, Y.; Xiao, Y.; Liu, C. The horizon of materiobiology: A perspective on material-guided cell behaviors and tissue engineering. Chem. Rev. 2017, 117, 4376-4421. [CrossRef]

385. Kang, E.-S.; Kim, D.-S.; Suhito, I.R.; Lee, W.; Song, I.; Kim, T.-H. Two-dimensional material-based bionano platforms to control mesenchymal stem cell differentiation. Biomater. Res. 2018, 22, 10. [CrossRef]

386. Suhito, I.R.; Han, Y.; Kim, D.-S.; Son, H.; Kim, T.-H. Effects of two-dimensional materials on human mesenchymal stem cell behaviors. Biochem. Biophys. Res. Commun. 2017, 493, 578-584. [CrossRef]

387. Song, J.; Michas, C.; Chen, C.S.; White, A.E.; Grinstaff, M.W. Controlled Cell Alignment Using Two-Photon Direct Laser Writing-Patterned Hydrogels in 2D and 3D. Macromol. Biosci. 2021, 21, 2100051. [CrossRef]

388. Cheng, D.; Jayne, R.K.; Tamborini, A.; Eyckmans, J.; White, A.E.; Chen, C.S. Studies of 3D directed cell migration enabled by direct laser writing of curved wave topography. Biofabrication 2019, 11, 021001. [CrossRef]

389. Dietrich, M.; Le Roy, H.; Brückner, D.B.; Engelke, H.; Zantl, R.; Rädler, J.O.; Broedersz, C.P. Guiding 3D cell migration in deformed synthetic hydrogel microstructures. Soft Matter 2018, 14, 2816-2826. [CrossRef]

390. Odde, D.J.; Renn, M.J. Laser-guided direct writing of living cells. Biotechnol. Bioeng. 2000, 67, 312-318. [CrossRef]

391. Kehrlbar, D.; Özgen, M.; YolbaŞ, S.; Yildirim, A.; Önalan, E.; ÇİftÇİ, O.; Özercan, İ.; Koca, S. The inhibition of Src kinase suppresses the production of matrix metalloproteinases in from synovial fibroblasts and inhibits MAPK and STATs pathways. Turk. J. Med. Sci. 2021. [CrossRef]

392. Darwish, I.A.; Khalil, N.Y.; Alsaif, N.A.; Herqash, R.N.; Sayed, A.Y.; Abdel-Rahman, H.M. Charge-Transfer Complex of Linifanib with 2, 3-dichloro-3, 5-dicyano-1, 4-benzoquinone: Synthesis, Spectroscopic Characterization, Computational Molecular Modelling and Application in the Development of Novel 96-microwell Spectrophotometric Assay. Drug Des. Dev. Ther. 2021, 15, 1167. [CrossRef]

393. Roskoski, R., Jr. Properties of FDA-approved small molecule protein kinase inhibitors. Pharmacol. Res. 2019, 144, 19-50. [CrossRef] [PubMed] 